ESCOLA POLITÉCNICA DA UNIVERSIDADE DE SÃO PAULO

DEPARTAMENTO DE ENGENHARIA NAVAL E OCEÂNICA

\author{
LUIZ MÜLLER
}

Proposição de metodologia baseada em confiabilidade para gerenciamento da integridade de poços em produção

São Paulo

2021 


\section{LUIZ MÜLLER}

\section{Proposição de metodologia baseada em confiabilidade para gerenciamento da integridade de poços em produção}

Versão Corrigida

Dissertação apresentada à Escola Politécnica da Universidade de São Paulo para obtenção do título de Mestre em Ciências

Área de Concentração: Engenharia Naval e Oceânica

Orientador: Prof. Dr. Marcelo Ramos Martins

São Paulo

2021 
Autorizo a reprodução e divulgação total ou parcial deste trabalho, por qualquer meio convencional ou eletrônico, para fins de estudo e pesquisa, desde que citada a fonte.

Este exemplar foi revisado e corrigido em relação à versão original, sob responsabilidade única do autor e com a anuência de seu orientador. São Paulo, 30 de novembro de 2021

Assinatura do autor:

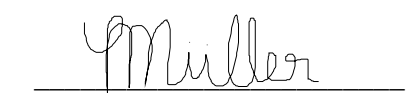

Assinatura do orientador:

\section{Catalogação-na-publicação}

Müller, Luiz

Proposição de metodologia baseada em confiabilidade para gerenciamento da integridade de poços em produção / L. Müller -- versão corr. -São Paulo, 2021.

$94 \mathrm{p}$.

Dissertação (Mestrado) - Escola Politécnica da Universidade de São Paulo. Departamento de Engenharia Naval e Oceânica.

1.Integridade de Poço 2.Engenharia de Confiabilidade 3.Gerenciamento de Risco 4.Elementos de Barreira de Poços 5.Poços Submarinos I.Universidade de São Paulo. Escola Politécnica. Departamento de Engenharia Naval e Oceânica II.t. 
Nome: MÜLLER, Luiz

Título: Proposição de metodologia baseada em confiabilidade para gerenciamento da integridade de poços em produção

Dissertação apresentada à Escola Politécnica da Universidade de São Paulo para obtenção do título de Mestre em Ciências

Aprovado em:

Banca Examinadora

Prof. Dr.

Instituição:

Julgamento:

Prof. Dr.

Instituição:

Julgamento:

Prof. Dr.

Instituição:

Julgamento: 


\section{AGRADECIMENTOS}

Agradeço primeiramente a minha esposa e eterna companheira Laís Guizelini da Paz, minha incentivadora e inspiração. Também agradeço a minha filha canina Zhara, que por diversas vezes esteve ao meu lado nas horas de estudo.

Agradeço aos meus pais Lígia Sarto Müller e Luiz Carlos de Andrade Müller que são a base de tudo, além de meu irmão Rafael Sarto Müller que é um exemplo de busca pelo conhecimento.

Com satisfação lembro dos meus colegas do LabRisco/USP, que foram grandes parceiros de estudo e de troca de conhecimento, principalmente Carlos Henrique Bittencourt de Morais, Danilo Taverna Martins Pereira de Abreu, Everton Nogueira Lima, Marco Aurélio Pestana e Ruben Dario Benites Perez.

Meu especial agradecimento ao Prof. Dr. Joaquim Rocha dos Santos e ao meu orientador Prof. Dr. Marcelo Ramos Martins que acreditou em mim e com dedicação ensinou, apoiou e direcionou o caminhar desta dissertação.

Agradeço também aos colegas da Petrobras que possibilitaram que este trabalho de pesquisa fosse desenvolvido.

À Petrobras pelo suporte financeiro e disponibilidade de tempo para execução do mestrado.

Finalmente, agradeço a Deus. 
"Where is the wisdom we have lost in knowledge? Where is the knowledge we have lost in information?"

(Eliot, 1934) 


\section{RESUMO}

\section{MÜLLER, Luiz. Proposição de metodologia baseada em confiabilidade para} gerenciamento da integridade de poços em produção. 2021. 94 f. Dissertação (Mestrado em Engenharia Naval e Oceânica) - Escola Politécnica da Universidade de São Paulo, São Paulo, 2021.

Integridade de Poço pode ser definida como a capacidade do poço em conter fluidos, evitando vazamentos indesejados para o meio ambiente. Para um adequado gerenciamento da integridade de poços na etapa de produção é necessário definir técnicas e periodicidade de testes, inspeções e monitoramento. Entretanto, durante o processo de gerenciamento da integridade de poços planos de teste, inspeção e monitoramento podem não ser cumpridos adequadamente e falhas ou degradações em barreiras de segurança do poço podem ser identificadas, fazendo com que o risco previamente assumido pelo projeto do poço se eleve. Dessa forma, pode-se fazer uso de análises de confiabilidade e risco para auxiliar nas tomadas de decisão quanto à continuidade operacional. Mas quanto de redução na confiabilidade do poço ou de elevação de risco é aceitável? Por quanto tempo? Qual é a eficácia de cada possível ação para aumentar a confiabilidade do sistema? Este trabalho ataca estes questionamentos fazendo uso de técnicas de análise de confiabilidade e desenvolve uma metodologia para gerenciamento de integridade de poços baseada na comparação entre a confiabilidade prevista na fase do projeto do poço e a confiabilidade dos elementos de barreira do poço durante a etapa de produção levando em consideração evidências de sucesso e falha obtidas com inspeções e testes realizados. Como caso de referência, é utilizado um poço de petróleo submarino típico do pré-sal brasileiro. A relação funcional entre os elementos de barreira do poço é modelada e os dados de confiabilidade utilizados são provenientes de bancos de dados internacionais reconhecidos. Na metodologia proposta é possível usar taxas de falha constantes ou variáveis ao longo do tempo e a confiabilidade relativa do sistema de poço é calculada a cada momento, considerando o conhecimento adquirido ao testar e inspecionar os componentes durante a etapa de produção. Essa metodologia auxilia na determinação do nível de risco atual do poço em produção e na avaliação da necessidade ou não de uma intervenção com sonda, propondo um prazo máximo para sua realização baseado em confiabilidade. Os resultados são fundamentais como embasamento técnico para suporte 
ao gerenciamento do risco e tomada de decisão quanto à integridade de poços em produção.

Palavras-chave: Integridade de Poço. Engenharia de Confiabilidade. Gerenciamento de Risco. Elementos de Barreira de Poços. Poços Submarinos. 


\begin{abstract}
MÜLLER, Luiz. Proposition of reliability-based methodology for well integrity management during operational phase. 2021. 94 f. Dissertação (Mestrado em Engenharia Naval e Oceânica) - Escola Politécnica da Universidade de São Paulo, São Paulo, 2021.
\end{abstract}

Well integrity can be defined as the well's ability to contain fluids, preventing unwanted leakage into the environment. For a proper management of well integrity during the operational phase it is necessary to define techniques and periodicity of testing, inspections, and monitoring. However, during the well integrity management process testing, inspection or monitoring plans may not be adequately adhered to and failures or degradations in well safety barriers may be identified, increasing the risk previously assumed by the well project. Thus, reliability and risk analysis can be used to assist in decision making regarding operational continuity. But how much reduction in well reliability is acceptable? For how long? How effective is each possible action in increasing system reliability? This work addresses the questions raised through the development of a methodology for well integrity management based on the comparison between well design reliability and the reliability of well barrier elements during operational phase considering evidence of success and failure obtained from inspection and testing. As a reference case, a typical subsea oil well from the Brazilian pre-salt is used and the functional relationship between the barrier elements is modeled. The reliability data used comes from recognized international databases. In such methodology is possible to use constant or variable failure rates over time and the relative reliability of the well system is calculated at each moment, considering the knowledge acquired in tests and inspections of components during the operational phase. Such methodology assists in determining the current risk level of the well in production, the need or not for a workover and proposes a maximum reliability-based timeframe for maintenance intervention. Results are critical as a technical foundation for risk management support and decision-making regarding well integrity during operational phase.

Keywords: Well Integrity. Reliability Engineering. Risk Management. Well Barrier Elements. Subsea Wells. 


\section{LISTA DE ILUSTRAÇÕES}

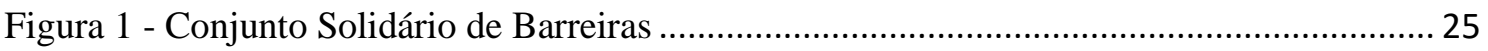

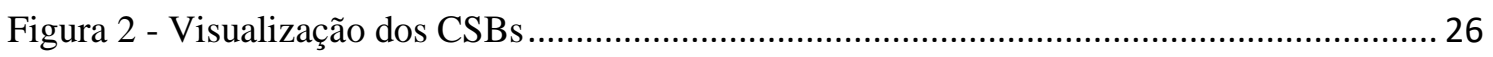

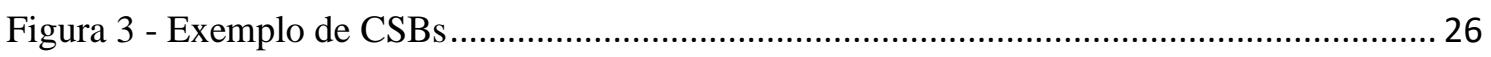

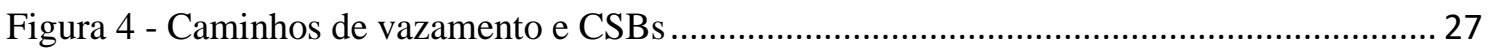

Figura 5 - Comportamento da taxa de falha ao longo do ciclo de vida do componente - curva da

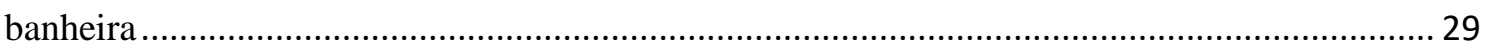

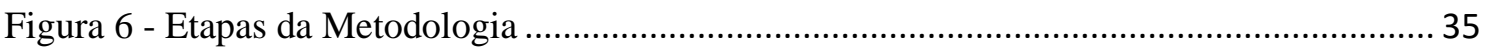

Figura 7 - Quatro principais caminhos de vazamento entre reservatório e meio ambiente.......... 36

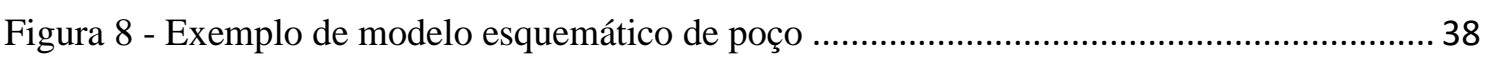

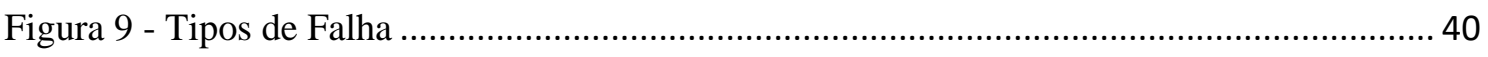

Figura 10 - Exemplo de Modos de Falha típicos em um poço de petróleo ................................... 41

Figura 11 - Exemplo de diagrama de barreiras .................................................................... 43

Figura 12 - Visão geral de abordagens de modelagem e cálculo de confiabilidade..................... 44

Figura 13 - Exemplo de blowout de poço em produção modelado por árvore de falha............... 45

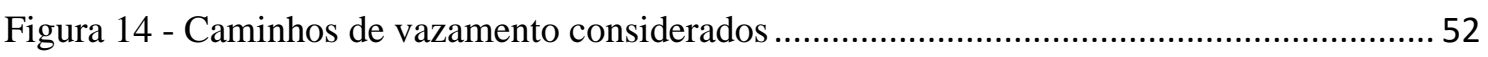

Figura 15 - Modelo Esquemático do Poço Exemplo..................................................................... 53

Figura 16 - Diagrama de Barreiras do Poço Exemplo.................................................................... 57

Figura 17 - Diagrama de Blocos de Confiabilidade do Poço Exemplo....................................... 60

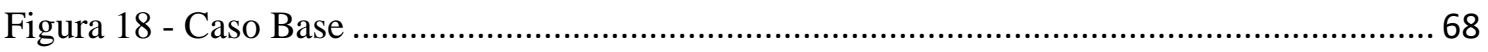

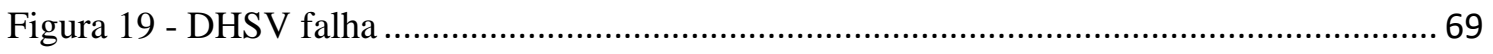

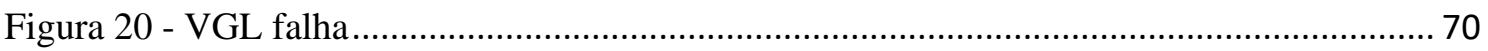

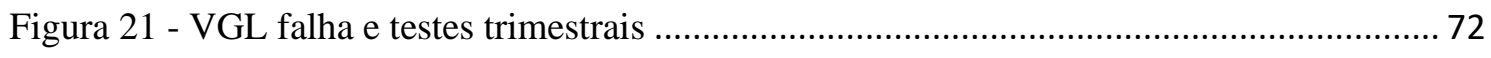

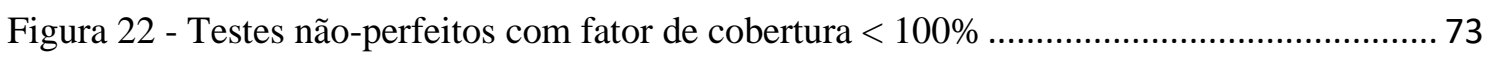

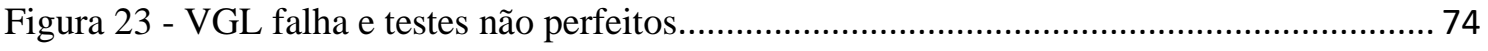

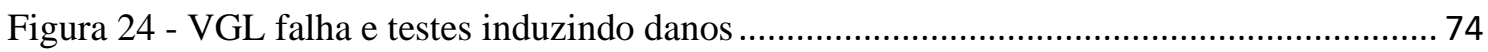

\section{LISTA DE TABELAS}

Tabela 1 - Incidentes recentes relacionados com perda de integridade de poços no Brasil ......... 16

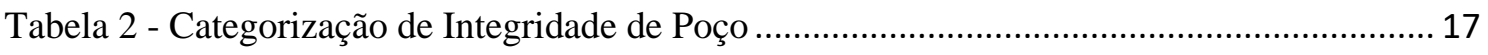

Tabela 3 - Elementos de barreira e respectivos modos de falha.................................................. 55

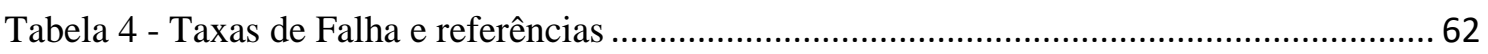

Tabela 5 - Periodicidade de Testes para o Poço Exemplo ............................................................. 66 


\section{LISTA DE ABREVIATURAS E SIGLAS}

$\mathrm{AI}$ - Annulus Intervention Valve

ALARP - As Low As Reasonably Practicable

AMV - Annulus Master Valve

ANM - Árvore de Natal Molhada

ANP - Agência Nacional do Petróleo, Gás Natural e Biocombustíveis.

BAP - Base Adaptadora de Produção

BDD - Binary Decision Diagram

BOP - Blowout Preventer

BSEE - Bureau of Safety and Environmental Enforcement

CCF - Common Cause Failure

COP - Coluna de Produção

CSB - Conjunto Solidário de Barreiras

CVU - Conjunto de Vedação Universal

DHSV - Down Hole Safety Valve

DSSS - Dispositivo de Segurança de Sub-Superfície

EL - External Leakage

FNF - Falha no Fechamento

FTA - Fault Tree Analysis

FTC - Fail to Close

FTO - Fail to Open

GLV - Gas Lift Valve

HSE - Health and Safety Executive

IBP - Instituto Brasileiro de Petróleo, Gás e Biocombustíveis

IEC - International Electrotechnical Commission

IL - Internal leak

IOGP - International Association of Oil \& Gas Producers

ISO - International Organization for Standardization

LAP - Leakage Across Packer

LCP - Leakage in Closed Position

M1 - Master 1 Valve

M2 - Master 2 Valve

MGL - Mandril de Gás Lift 
NASA - National Aeronautics and Space Administration

NOG - Norwegian Oil and Gas

NORSOK - Norsk Sokkels Konkurranseposisjon

NRC - Nuclear Regulatory Commission

OREDA - Offshore \& Onshore Reliability Data

PFD - Probabilidade de Falha na Demanda

PKR - Packer

PLU - Plugged

PMV - Production Master Valve

RBD - Reliability Block Diagram

RMS - Reliability Management System

ROV - Remotely Operated Underwater Vehicle

RTSGSO - Regulamento Técnico do Sistema de Gerenciamento da Segurança

Operacional

S1 - Swab 1 Valve

S2 - Swab 2 Valve

SCSSV - Surface-controlled subsurface safety valve

SSSV - SubSurface Safety Valve

SGIP - Sistema de Gerenciamento da Integridade de Poços

SPO - Spurious operation

TAC - Tubing-Annulus Leak

TC - Test Coverage

TH - Tubing Hanger

USP - Universidade de São Paulo

VCA - Vazamento da Coluna para o Anular

VE - Vazamento Externo

VGL - Válvula de Gás Lift

VI - Vazamento Interno

VPF - Vazamento na Posição Fechada

$\mathrm{W} 1$ - Wing 1 Valve

W2 - Wing 2 Valve

WH - Wellhead

XMT - Christmas tree

XO - Válvula CrossOver 


\section{SUMÁRIO}

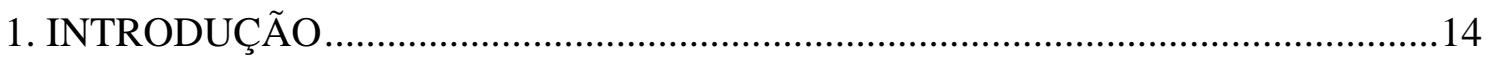

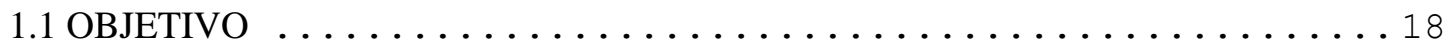

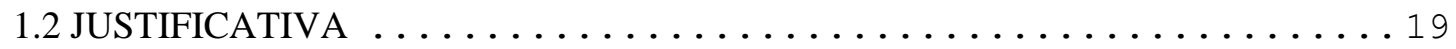

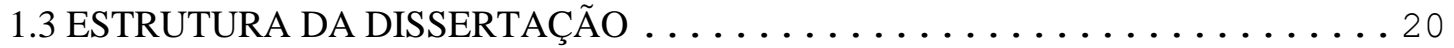

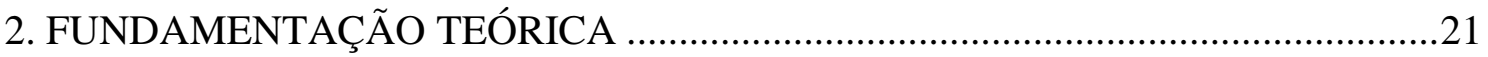

2.1 INTEGRIDADE DE POÇO . . . . . . . . . . . . . . . . . 21

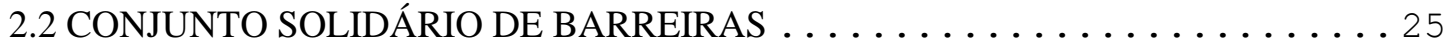

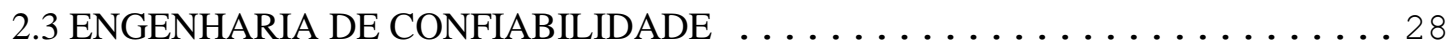

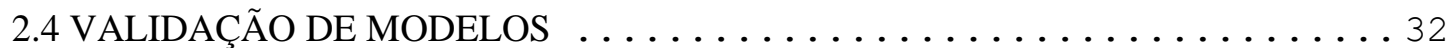

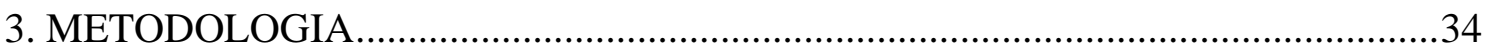

3.1 ETAPA 1: IDENTIFICAÇÃO DOS CAMINHOS DE VAZAMENTO . . . . . . 36

3.2 ETAPA 2: REPRESENTAÇÃO DO POÇO EM MODELO ESQUEMÁTICO . . . . 37

3.3 ETAPA 3: DEFINIÇÃO DOS MODOS DE FALHA . . . . . . . . . 39

3.4 ETAPA 4: CONSTRUÇÃO DO DIAGRAMA DE BARREIRAS $\ldots \ldots \ldots \ldots \ldots 42$

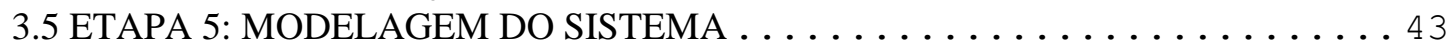

3.6 ETAPA 6: DADOS DE CONFIABILIDADE DOS COMPONENTES . . . . . . 45

3.7 ETAPA 7: CÁLCULO DA CONFIABILIDADE DO SISTEMA $\ldots \ldots \ldots \ldots \ldots 46$

3.8 ETAPA 8: ATUALIZAÇÃO DA CONFIABILIDADE COM EVIDÊNCIAS

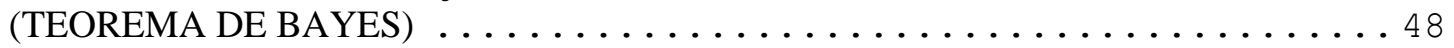

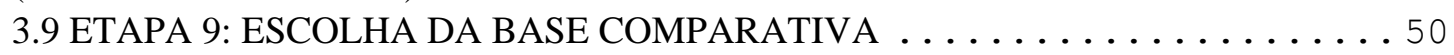

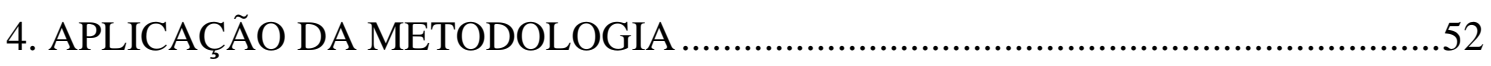

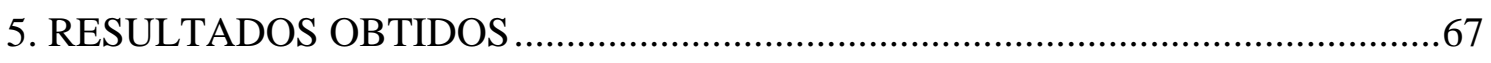

5.1. IDENTIFICAÇÃO DE FALHA NA DHSV . . . . . . . . . . . . . 69

5.2. IDENTIFICAÇÃO DE COMUNICAÇÃO COLUNA-ANULAR POR FALHA NA VGL

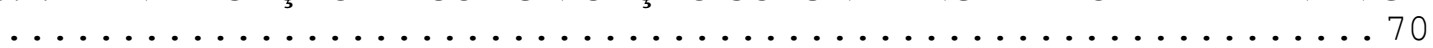

5.3. FLEXIBILIZAÇÃO DE PREMISSAS SOBRE OS TESTES . . . . . . . . . . . 72

6. CONCLUSÕES E RECOMENDAÇÕES PARA TRABALHOS FUTUROS ............75

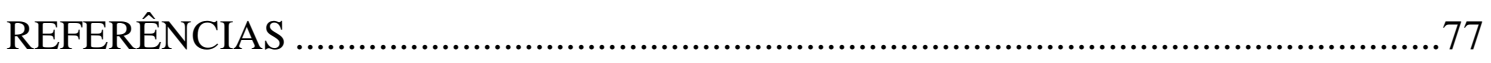

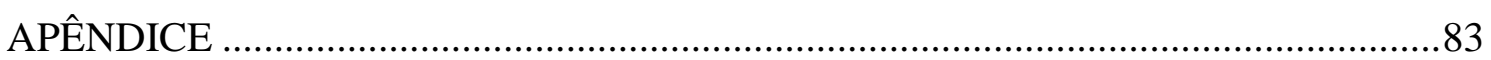




\section{INTRODUÇÃO}

No dia 03 de novembro de 2016 foi publicada no diário oficial da união a resolução número 46 da ANP (ANP, 2016), cujo objetivo foi aprovar o Regime de Segurança Operacional para Integridade de Poços de Petróleo e Gás Natural, que instituiu o Regulamento Técnico do Sistema de Gerenciamento da Integridade de Poços (SGIP).

Com a implantação de regulação nacional específica para Integridade de Poços, as empresas detentoras dos direitos de exploração e produção de petróleo e gás natural no território brasileiro estão confrontando seus procedimentos técnicos e processos de gestão de integridade de poço com as melhores práticas da indústria do petróleo.

Para entender a conjuntura atual da exigência regulatória em relação a gerenciamento de integridade de poços baseado em segurança operacional é importante analisar o contexto histórico.

Historicamente a Segurança de Processo e os estudos de Risco e Confiabilidade tiveram desenvolvimento mais vertiginoso após grandes acidentes que contribuíram para a criação e aprimoramento de legislação, regulação, fiscalização e normas técnicas.

Como marco regulatório na exigência de análise quantitativa de confiabilidade e dos riscos de segurança tem-se, segundo (Martins, 2013):

- Na indústria nuclear: A NRC (Nuclear Regulatory Commission) passa a exigir análise probabilística de segurança após o acidente na Three Mile Island na Pensilvânia em 1979.

- Na indústria aeroespacial: A NASA (National Aeronautics and Space Administration) passa a obrigar a análise probabilística de segurança após o acidente com a Challenger em 1986 (Stamatelatos \& Dezfuli, 2011).

Já na indústria de Óleo e Gás offshore foi a partir do acidente de Piper Alpha no Mar do Norte em 1988 que deixou 167 mortes que a HSE (Health and Safety Executive) e demais reguladoras passaram a exigir programas de segurança para instalações offshore incluindo análise probabilística de segurança (UK Statutory Instruments, 1992).

No Brasil a regulação para a Indústria de Óleo e Gás veio anos depois. A Agência Nacional do Petróleo, Gás Natural e Biocombustíveis (ANP) foi criada em 1997 pela Lei Ordinária nº 9.478/1997 (Lei do Petróleo) e implantada pelo Decreto nº 2.455/1998. 
O desenvolvimento de Regulamentação Nacional do Sistema de Gestão de Segurança Operacional de Plataformas foi motivado pelo afundamento da plataforma P-36 em 2001 e adernamento da P-34 em 2002, conforme (Chambriard, 2014), sendo efetivamente implantado em 2007 com a resolução ANP nº 43/2007 (ANP, 2007).

Em relação especificamente a Integridade de Poços a ANP identificou a necessidade de criação de um regulamento específico para tratar as disciplinas relacionadas a poços após os acidentes de Cancã em 2009, Macondo em 2010 e os underground blowout ocorridos no campo de Frade em 2011 e 2012 (ANP, 2016a). Como consequência no dia 03 de novembro de 2016 foi publicada no diário oficial da união a resolução número 46 da ANP, cujo objetivo foi aprovar o Regime de Segurança Operacional para Integridade de Poços de Petróleo e Gás Natural, que instituiu o Regulamento Técnico do Sistema de Gerenciamento da Integridade de Poços (SGIP).

Além de influenciar a regulamentação brasileira de integridade de poço, o acidente de Macondo no Golfo de México em abril de 2010 e o acidente de Montara em agosto de 2009 influenciaram mudanças em toda a indústria internacional de óleo e gás, como por exemplo, na criação da nova norma internacional ISO 16530 (Petroleum and natural gas industries - Well integrity) (ISO, 2011) e do Bureau of Safety and Environmental Enforcement (BSEE) (Morais, et al., 2019).

A título de ilustração, segue Tabela 1 relacionando os incidentes mais recentes relacionados à integridade de poços ocorridos no Brasil, que foram determinantes para embasamento do SGIP e demonstram a importância da necessidade de criar uma metodologia que analise o desempenho e a confiabilidade dos elementos de barreira relacionados com poços de petróleo, visando um gerenciamento mais eficaz da integridade e segurança de poços. 
Tabela 1 - Incidentes recentes relacionados com perda de integridade de poços no Brasil

\begin{tabular}{|c|c|c|c|}
\hline Área/Ano & Incidente & Caracterizaçđ̆o & Principais Causas Identificadas \\
\hline $\begin{array}{l}\text { Dom João Mar, } \\
2015\end{array}$ & $\begin{array}{l}\text { Kick no poço 7- } \\
\text { DJM-885H-BAS } \\
\text { Etapa do Ciclo de } \\
\text { Vida: abandono após } \\
\text { evento de kick/prisđ̃o } \\
\text { de coluna }\end{array}$ & $\begin{array}{l}\text { - Pressão na cabeça de poço. } \\
\text { - Falha na integridade de } \\
\text { CSB permanente (tampão } \\
\text { de abandono). }\end{array}$ & $\begin{array}{l}\text { - Reservatório influenciado por } \\
\text { injetor } \\
\text { - Prisäo de coluna por diferencial de } \\
\text { pressåo resultante de sobrepressão } \\
\text { do injetor } \\
\text { - Falha na cimentação para abandono } \\
\text { de poço. } \\
\text { - Isolamento de zonas com potenciais } \\
\text { de fluxo diferentes. } \\
\text { Anular da Coluna de perfuração } \\
\text { com o poço cimentado com } \\
\text { passagem de pressấo }\end{array}$ \\
\hline Sapinhoá, 2013 & $\begin{array}{l}\text { Klck/ Underground } \\
\text { blowout de água no } \\
\text { Poço 8-SPH-11-SPS } \\
\text { Etapa do Ciclo de } \\
\text { Vida: construção } \\
\text { (perfuração) }\end{array}$ & - Perda do Poço & $\begin{array}{l}\text { Năo realizada abrangência de } \\
\text { incidentes ocorridos em poços } \\
\text { similares construídos pelo mesmo } \\
\text { Operador do Contrato. } \\
\text { Gestão de mudança não contemplou } \\
\text { todos os cenários de ríscos. }\end{array}$ \\
\hline $\begin{array}{l}\text { Campo de } \\
\text { Marlim, } 2013\end{array}$ & $\begin{array}{l}\text { Poço 7-MRL- } \\
\text { 13iHP-RJS } \\
\text { Etapa do Ciclo de } \\
\text { Vida: abandono } \\
\text { temporário (sem } \\
\text { monitoramento) }\end{array}$ & $\begin{array}{l}\text { - Vazamento de } 111 \text { litros } \\
\text { de petróleo pela árvore de } \\
\text { natal de poço } \\
\text { desconectado da } \\
\text { plataforma. }\end{array}$ & $\begin{array}{l}\text { - Abertura inadvertida das válvulas da } \\
\text { árvore de natal. } \\
\text { - Falha do CSB. }\end{array}$ \\
\hline $\begin{array}{l}\text { Campo de } \\
\text { Frade, Área 2, } \\
2012 \text {. }\end{array}$ & $\begin{array}{l}\text { Underground } \\
\text { blowout do Poço 8- } \\
\text { FR-28D-RJS } \\
\text { Etapa do Ciclo de } \\
\text { Vida: produção }\end{array}$ & $\begin{array}{l}\text { - Vazamento de } 55 \text { litros de } \\
\text { petróleo. } \\
\text { - Fratura do reservatório até } \\
\text { o leito marinho. }\end{array}$ & $\begin{array}{l}\text { - Pressão de injeção maior que a } \\
\text { resistência da rocha. } \\
\text { - Gestão de mudança inadequada. } \\
\text { - Não atendimento às boas melhores } \\
\text { práticas. }\end{array}$ \\
\hline $\begin{array}{l}\text { Campo de } \\
\text { Frade, } \\
\text { Área } 1,2011 .\end{array}$ & $\begin{array}{l}\text { Kick/ Underground } \\
\text { blowout do Poço 9- } \\
\text { FR-50DP-RJS. } \\
\text { Etapa do Ciclo de } \\
\text { Vida: projeto/ } \\
\text { construçấo }\end{array}$ & $\begin{array}{l}\text { Vazamento de } 3.700 \text { barris } \\
\text { de petróleo. } \\
\text { - Underground blowout. }\end{array}$ & $\begin{array}{l}\text { - Falha de projeto na estimativa da } \\
\text { pressão de poros. } \\
\text { - Paredes do poço submetidas a } \\
\text { pressōes superiores ao seu limite de } \\
\text { resistência. } \\
\text { - Premíssas de projeto inadequadas } \\
\text { para a incerteza da pressão de poros. }\end{array}$ \\
\hline Cancã, 2009 & $\begin{array}{l}\text { Campo de Cancă } \\
\text { Poço 7-CNC-3-ES } \\
\text { Etapa do Ciclo de } \\
\text { Vida: construçäo }\end{array}$ & $\begin{array}{l}\text { - } \quad \text { Blowrout } \\
\text { - } \quad \text { Perda da sonda. }\end{array}$ & $\begin{array}{l}\text { - Cimentaçāo de zona portadora de } \\
\text { gás. } \\
\text { - Falha na cimentação. } \\
\text { - } \quad \text { Balha na deteç̧ão do kick. } \\
\text { em DMT). } \\
\text { - Torque insuficiente nos parafusos } \\
\text { das portas do BOP. } \\
\text { - Falha do material do selo. } \\
\text { - Teste inadequado do BOP. }\end{array}$ \\
\hline $\begin{array}{l}\text { Campo de } \\
\text { Marlim Sul, } \\
2004\end{array}$ & $\begin{array}{l}\text { Poço 8-MLS-61HPA } \\
\text { Etapa do Ciclo de } \\
\text { Vida: produçắo }\end{array}$ & $\begin{array}{l}\text { - Fratura do reservatório até } \\
\text { o leito marinho. }\end{array}$ & $\begin{array}{l}\text { Pressão de injeç̆to maior que a } \\
\text { resistência da rocha (reservatório } \\
\text { compartimentado). }\end{array}$ \\
\hline Taquipe, 2000 & $\begin{array}{l}\text { Poço TQ-82 } \\
\text { Etapa do Ciclo de } \\
\text { Vida: produção }\end{array}$ & $\begin{array}{l}\text { - Vazamento de água de } \\
\text { injeçăo para o entorno do } \\
\text { poço. }\end{array}$ & $\begin{array}{l}\text { Falha dos elementos de barreira } \\
\text { (coluna de injeção e revestimento de } \\
\text { produçãa). } \\
\text { Falta de gestão da pressão dos } \\
\text { anulares. }\end{array}$ \\
\hline $\begin{array}{l}\text { Plataforma de } \\
\text { Enchova, } 1984 \\
\text { e } 1988\end{array}$ & $\begin{array}{l}\text { Campo de Enchova } \\
\text { Etapa do Ciclo de } \\
\text { Vida: intervençăo }\end{array}$ & $\begin{array}{l}\text { Morte de } 42 \text { trabalhadores } \\
\text { em 1984. } \\
\text { (Nota: Relacionadas à } \\
\text { queda da balecira durante } \\
\text { evacuação - Enchova } \\
\text { 1984) } \\
\text { Destruição da Plataforma } \\
\text { em 1988. }\end{array}$ & $\begin{array}{l}\text { Blowout Preventer (BOP) não } \\
\text { estava em condiçōes de operação } \\
\text { durante conversão de poço de óleo } \\
\text { para gás. } \\
\text { Vazamento em um dos poços } \\
\text { conectados à plataforma. }\end{array}$ \\
\hline
\end{tabular}

Fonte: (ANP, 2016a) 
Com a implantação do Regulamento Técnico do Sistema de Gerenciamento da Integridade de Poços (SGIP), a ANP normatiza a adoção das melhores práticas da indústria, torna-as juridicamente exigíveis e fomenta a melhoria contínua da gestão de integridade de poços no Brasil (ANP, 2016a).

Um ponto significativo, em relação à integridade de poço, é a integridade do Conjunto Solidário de Barreiras (CSB), conforme descrito no item 11.3.1. do SGIP: "Garantir, durante todo o Ciclo de Vida do Poço, no mínimo 02 (dois) CSB independentes (Primário e Secundário).”. A (NORSOK D-010, 2021) também requer que poços surgentes (cujo fluido é capaz de fluir naturalmente do reservatório para o meio ambiente ou outra formação) em produção tenham dois conjuntos solidários de barreiras mecânicas independentes.

Entretanto, durante a etapa de produção de um poço os elementos de barreira podem sofrer falhas ou degradações ao longo do tempo, que elevam o risco previamente assumido pelo projeto do poço.

Mas quanto de redução na confiabilidade do poço ou de elevação de risco é aceitável? Por quanto tempo? Qual é a eficácia de cada possível ação para aumentar a confiabilidade do sistema?

Usualmente, a indústria do petróleo conta com análises qualitativas de riscos ou com procedimentos de gerenciamento de falhas para responder a essas perguntas, como por exemplo o descrito em (NOG 117, 2017) que a depender das falhas presentes no poço são atribuídas categorias de cores para a integridade do poço.

Tabela 2 - Categorização de Integridade de Poço

\begin{tabular}{|c|l|}
\hline Category & Principle \\
\hline Red & $\begin{array}{l}\text { One barrier failure and the other is } \\
\text { degraded/not verified, or leak to surface }\end{array}$ \\
\hline Orange & $\begin{array}{l}\text { One barrier failure and the other is intact, or a } \\
\text { single failure may lead to leak to surface }\end{array}$ \\
\hline \hline Yellow & One barrier degraded, the other is intact \\
\hline Green & Healthy well - no or minor issue \\
\hline
\end{tabular}

Fonte: (NOG 117, 2017) 
Esta dissertação aborda as questões levantadas através do desenvolvimento de uma metodologia para gerenciamento de integridade de poço de forma quantitativa baseada na engenharia de confiabilidade, para melhor compreender a probabilidade real de um vazamento de poço no período de operação definido. Essa abordagem é capaz de apoiar a tomada de decisão em relação à continuidade operacional de uma forma bem fundamentada.

\subsection{OBJETIVO}

O objetivo geral desta dissertação é estabelecer uma metodologia que permita estimar confiabilidade atual e esperada para o tempo de operação previsto para um poço de petróleo na etapa de produção e abandono temporário.

Ao estimar a confiabilidade pretende-se avaliar os impactos que evidências de sucesso ou falhas em barreiras de segurança do poço trazem para a confiabilidade previamente assumida pelo projeto do poço.

Com a metodologia proposta será possível auxiliar nas tomadas de decisão quanto à continuidade operacional de poços em estado degradado, a necessidade ou não de uma intervenção com sonda e o prazo para a manutenção.

Esta dissertação busca responder as seguintes perguntas específicas:

1) Qual a confiabilidade esperada para a etapa de produção de um poço de petróleo ao ser construído?

2) O que muda na confiabilidade do poço em produção ao identificar uma falha em algum componente de barreira. E ao identificar mais falhas?

3) Qual o impacto na confiabilidade do poço em produção quando ocorre algum atraso em teste de componente de barreira?

4) Como definir qual o prazo máximo aceitável para uma intervenção no poço que reestabeleça a condição de integridade?

5) Qual a eficácia de possível medida de redução de risco (ex.: redução de prazo de testes de componentes) em relação à confiabilidade do sistema? 


\subsection{JUSTIFICATIVA}

O regulamento técnico SGIP da ANP é majoritariamente baseado em desempenho (nãoprescritivo) apesar de possuir elementos prescritivos (ANP, 2016a). Essa visão tem sido a tendência mais recente da legislação internacional da indústria de óleo e gás (Morais, et al., 2019).

No item 9.2.2.2. do SGIP está descrito que:
Após a detecção de falha de um dos elementos do CSB, deverá ser executado, imediatamente, um procedimento de gerenciamento de falhas ou gestão de mudança para definir o momento mais oportuno, em relação à segurança, para o restabelecimento do CSB que perdeu sua integridade.

Dessa forma, é de responsabilidade do operador a identificação de quais ações são necessárias para redução dos riscos do poço a um nível ALARP ("As Low As Reasonably Practicable”). O regulamento do SGIP tem ênfase em risco, omitindo questões específicas de confiabilidade. Sendo assim, este trabalho traz uma visão adicional à legislação brasileira, na medida em que busca detalhar como uma visão de confiabilidade pode auxiliar na determinação das ações necessárias a serem tomadas em caso de falha de elemento de barreira de poço.

Por exemplo, em caso de falha de elemento de barreira de poço, este trabalho irá propor como reduzir a periodicidade de verificação de demais elementos dos CSB de forma a contribuir para aumentar a confiabilidade instantânea do poço.

Explorar questões de confiabilidade contribui com as avaliações de risco, na medida em que pode fornecer uma estimativa mais robusta da probabilidade de perda de integridade em um período definido.

No cenário moldado na última década, pós acidente de Macondo, com desenvolvimento de novas normas, recomendações práticas para a indústria, regulamentos e de exigências regulatórias o desenvolvimento de uma metodologia para auxiliar a determinação do nível de confiabilidade atual do poço, a necessidade ou não de uma intervenção com sonda e uma estimativa de prazo para intervenção baseada em confiabilidade e risco certamente trará ganho financeiro e diferencial competitivo no mercado. 
Segundo (Corneliussen, 2017, pp. 2, tradução nossa):

Uma organização madura em integridade de poço deve lidar com os desafios quando uma falha no envelope de barreira for detectada e tomar ações que garantam a segurança e, ao mesmo tempo, contribuam para alta disponibilidade e operações otimizadas. Uma integridade de poço eficiente consiste em equilibrar a segurança versus o custo.

\subsection{ESTRUTURA DA DISSERTAÇÃO}

Essa dissertação será dividida em seis capítulos.

O primeiro capítulo apresentou a introdução do trabalho, o objetivo, a justificativa e a estrutura da dissertação.

O segundo capítulo apresentará a fundamentação teórica necessária para o desenvolvimento do trabalho. Serão abordados conceitos relacionados à Integridade de Poço, Conjunto Solidário de Barreiras, Engenharia de Confiabilidade e Validação de Modelos.

O terceiro capítulo apresentará a metodologia proposta para a modelagem da integridade de poço e avaliação da variação da confiabilidade do sistema em caso de evidência de falha ou sucesso de alguma barreira de segurança do poço.

O quarto capítulo mostrará um exemplo de aplicação da metodologia em um poço de petróleo submarino típico do pré-sal brasileiro.

No quinto capítulo será explorado como os resultados obtidos podem auxiliar na tomada de decisão quanto à continuidade operacional de poços em estado degradado.

Por fim, o sexto capítulo apresenta as conclusões e recomendações para trabalhos futuros. 


\section{FUNDAMENTAÇÃO TEÓRICA}

Neste capítulo serão apresentados fundamentos teóricos necessário para o bom entendimento do trabalho. Os conceitos discutidos foram separados em quatro partes.

Nas duas primeiras subseções são apresentados os temas integridade de poço e conjunto solidário de barreiras respectivamente, essenciais para entendimento da modelagem de um poço de petróleo. As principais referências e trabalho afins sobre os temas também são apresentados e discutidos.

Em seguida são apresentados conceitos de engenharia de confiabilidade, destacando algumas técnicas de modelagem de confiabilidade de sistemas e o teorema de Bayes.

Para finalizar esse capítulo, é discorrido sobre o tema de validação de modelos.

\subsection{INTEGRIDADE DE POÇO}

A definição mais conhecida de integridade de poço é dada pela (NORSOK D-010, 2021, pp. 10, tradução nossa) como “aplicação de soluções técnicas, operacionais e organizacionais para reduzir o risco de liberação descontrolada de fluidos de formação ao longo do ciclo de vida de um poço".

Além da (NORSOK D-010, 2021) pode-se citar outras referências normativas sobre integridade de poço, como por exemplo:

- a primeira edição da ISO 16530-1 (Petroleum and natural gas industries - Well integrity - Life Cycle Governance), lançada em março de 2017 pela International Organization for Standardization (ISO), contemplando requisitos de integridade de poço para todo o ciclo de vida de um poço de petróleo ou gás natural;

- e a sexta revisão da Norwegian Oil and Gas Association No.: 117 (Recommended Guidelines Well Integrity), de novembro de 2017 que descreve uma sistemática de categorização de integridade de poço e estabelece uma tabela comparativa de descrição e categorização de poços.

Em consonância com a regulação sobre integridade de poço instituída pela ANP e de acordo com as normas técnicas internacionais sobre o tema, o Instituto Brasileiro de 
Petróleo, Gás e Biocombustíveis (IBP) desenvolveu em julho de 2017 um guia com diretrizes para abandono de poços, contendo diversos aspectos de integridade de poço (IBP, 2017).

Avaliações de risco e integridade de poços em produção e aplicação de metodologias que permitam estimar atributos de confiabilidade de barreiras de segurança de poços vêm sendo estudado por diversos autores, conforme discutido a seguir.

A execução de análises qualitativas de risco com equipe multidisciplinar é muito comum na indústria para auxiliar o gerenciamento de integridade de poço. Neste sentido, (Dethlefs \& Chastain, 2012) apresentam as vantagens e a forma de realizar uma análise qualitativa de risco com foco em integridade de poço, discutindo objetivos, metodologia, seleção de equipe, preparação de dados, modos de falha e o próprio processo de avaliação de risco incluindo a matriz de tolerabilidade, forma de registro, resultados e recomendações. (Abreu, Morais, Santos, Colombo, \& Martins, 2019) também discutem a elaboração de análises preliminares de risco para as diferentes fases do ciclo de vida de um poço.

A utilização de fundamentos da Teoria de Confiabilidade em análise de integridade de poço tem como uma das primeiras referências o trabalho de (Takashina, 1989) que buscou ações preventivas relativas à garantia de qualidade e procurou quantificar a segurança de projetos de poços.

Uma metodologia para a análise de risco quantitativa de poços na fase de produção foi desenvolvida por (Corneliussen, 2006), focando principalmente em dois aspectos de segurança de poço: (i) prevenir fluxo descontrolado de fluido do poço para o meio ambiente (função de segurança contínua) e (ii) parar o influxo de fluido em caso de um dano a jusante do poço (função de segurança sob demanda).

Contudo, segundo (da Fonseca, 2012) a metodologia proposta por (Corneliussen, 2006) é complexa na medida em que requer a identificação de todos os possíveis caminhos e atalhos por onde podem ocorrer vazamentos para o meio ambiente. Assim, a metodologia para análise de integridade de poços durante a fase de produção apresentada em (da Fonseca, 2012) fundamenta-se em técnicas de Engenharia de Confiabilidade e no conceito de Conjuntos Solidários de Barreiras (CSB), o qual será definido e explicado no próximo item. As falhas de cada equipamento de barreira foram representadas pelo modelo exponencial e os resultados obtidos foram conservadores uma vez que 
desconsideram barreiras alternativas (back-ups) aos CSBs, sendo sugerido um refinamento da modelagem de confiabilidade dos equipamentos.

(Holand \& Andersen, 2012) analisaram o risco de operar um poço submarino isolado completado com ou sem DHSV (Down Hole Safety Valve). Para tanto foram utilizados bancos de dados reconhecidos pela indústria e obtidos resultados importantes como: comparação da probabilidade de blowouts em poços isolados, com e sem DHSV durante a fase de produção; avaliação do risco de não realizar uma intervenção para restabelecimento de DHSV falha e; o efeito da frequência de teste na probabilidade de blowout de poços isolados durante a fase de produção.

(Kostøl, 2014) observa que para avaliar o risco geral de um poço deve-se considerar tanto o estado de integridade da barreira física dos poços como as possíveis consequências do vazamento. Em seu trabalho, o autor propõe um sistema de categorização de criticidade de segurança de poço pelo risco global associado, que leva em consideração as consequências potenciais como uma segunda dimensão, além do status de integridade da barreira. Assim, os recursos disponíveis devem ser priorizados para os poços com maior criticidade.

(de Oliveira, 2016) realiza um estudo de confiabilidade de sistemas de Controle de Dispositivos de Segurança de Sub-Superfície em Poços utilizando o modelo de análise de confiabilidade markoviano. Nesse trabalho são realizadas comparações entre os diferentes tipos e configurações do sistema com uma visão mais focada na perda de produção do que na segurança, tendo de forma geral as configurações do sistema multiplexadas com acionamento hidráulico apresentado maior confiabilidade durante a vida produtiva do poço.

(Bouças, 2017) apresenta uma metodologia para verificar confiabilidade de um sistema de barreiras de poços de petróleo utilizando o Método de Monte Carlo. Através de simulações, essa metodologia permitiu calcular a confiabilidade do sistema poço de petróleo como um todo, em função da sua configuração e da confiabilidade de elementos de barreira individuais.

(Haaland, 2017) apresenta um modelo probabilístico estruturado de simulação para calcular a confiabilidade do revestimento de um poço em função do tempo. Neste trabalho, os dados de falha de revestimento foram gerados por simulações de Monte Carlo e tratados como "dados experimentais" para, a partir de análises, encontrar os atributos 
de confiabilidade. O modelo pode ser estendido para incluir outros elementos de barreira de poço.

Uma metodologia para avaliar a probabilidade de perda de contenção de poços submarinos durante a fase de produção considerando taxas de falha variáveis no tempo foi desenvolvida por (Alves \& Netto, 2013). (Mendes, Fonseca, \& Miura, 2016) também abordam o tema integridade de poço durante a fase de produção e, através de cálculo de parâmetros de confiabilidade, estima quando o poço está em estado degradado de integridade e quando é esperado perda de contenção. A abordagem é conservadora, não considerando elementos de barreira alternativos, mas apenas os elementos mínimos dos conjuntos solidários de barreira primário e secundário. (Colombo, 2018) apresenta "uma abordagem que considera o comportamento da confiabilidade das barreiras de segurança ao longo da vida produtiva do poço e que mostra a evolução dos possíveis estados de integridade em que o poço possa se encontrar.”. Para tanto, a disponibilidade do poço é modelada por um processo markoviano.

Apesar de trabalhos anteriores já terem abordado a utilização da confiabilidade e disponibilidade para avaliar a probabilidade de perda de contenção de poços submarinos em produção, esse trabalho tem como contribuição a exposição de uma metodologia sistêmica com enfoque em utilização prática por operadoras no processo de avalição do risco e tomada de decisão quanto à continuidade operacional de poços em estado degradado.

Durante a etapa de produção de um poço, é possível identificar falhas de componentes que alteram a confiabilidade instantânea do sistema. Esta dissertação discute e propõe uma metodologia para modelar a integridade do poço e a variação da confiabilidade do sistema em caso de evidência de falha ou sucesso de um elemento de barreira e compara os resultados com a confiabilidade do poço anteriormente assumida e aceita pelo projeto. Por conseguinte, pretende-se aplicar a metodologia para definir um prazo máximo em que um reparo no poço precisa ser feito. 


\subsection{CONJUNTO SOLIDÁRIO DE BARREIRAS}

Quando se fala em Integridade de Poço, o princípio mais aceito mundialmente é uma filosofia de barreiras baseada no Conjunto Solidário de Barreiras (CSB), um detalhamento desta filosofia é descrito em (Miura, 2004) e (Miura, Morooka, Mendes, \& Guilherme, 2006). O Conjunto Solidário de Barreiras é uma junção de elementos de barreira que juntos previnem a passagem do fluido do reservatório para o meio ambiente pelos diversos caminhos possíveis em um poço de petróleo.

(Miura, 2004) reforça que é importante ter em mente que as barreiras de um CSB devem ser solidárias, ou seja, precisam impedir inclusive a comunicação entre caminhos independentes desde a zona com hidrocarboneto até o meio ambiente, conforme exposto na Figura 1.

Figura 1 - Conjunto Solidário de Barreiras

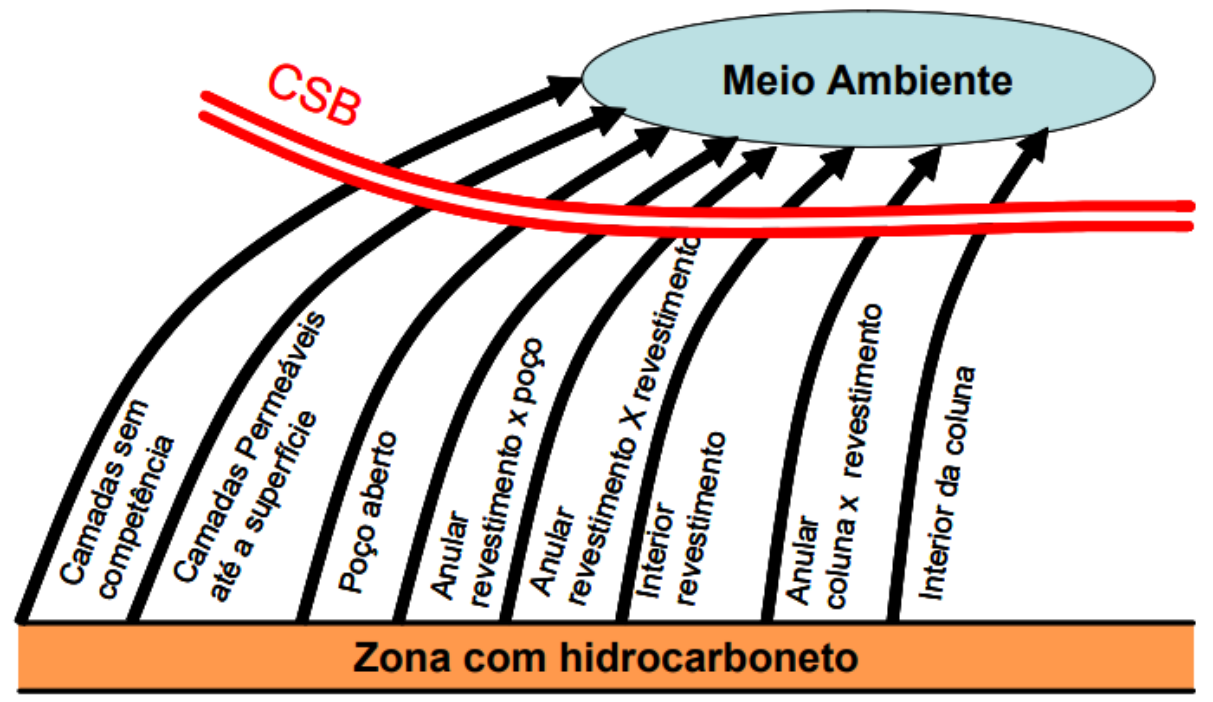

Fonte: (Miura, 2004)

Na Figura 2 é possível ter uma visualização da ideia de envelopar o perigo (“hazard”) através de dois conjuntos solidários de barreiras. Usualmente é chamado de primário - e representado em azul - o CSB mais próximo da fonte de perigo que, no caso de um poço de petróleo, é o hidrocarboneto presente no reservatório. 
Figura 2 - Visualização dos CSBs

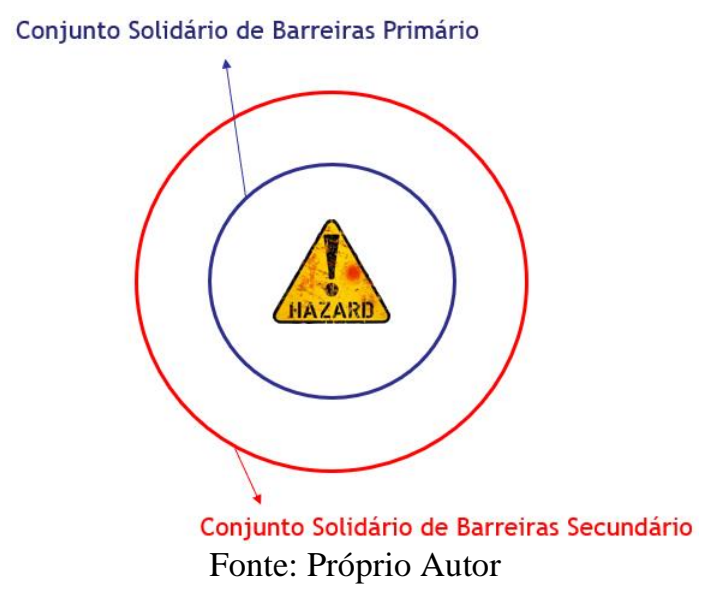

Um exemplo típico dos dois Conjuntos Solidário de Barreiras de um poço de petróleo na fase operacional é mostrado na Figura 3 juntamente com a listagem dos elementos de barreira pertencentes ao envelope primário (em azul) e secundário (em vermelho).

Figura 3 - Exemplo de CSBs

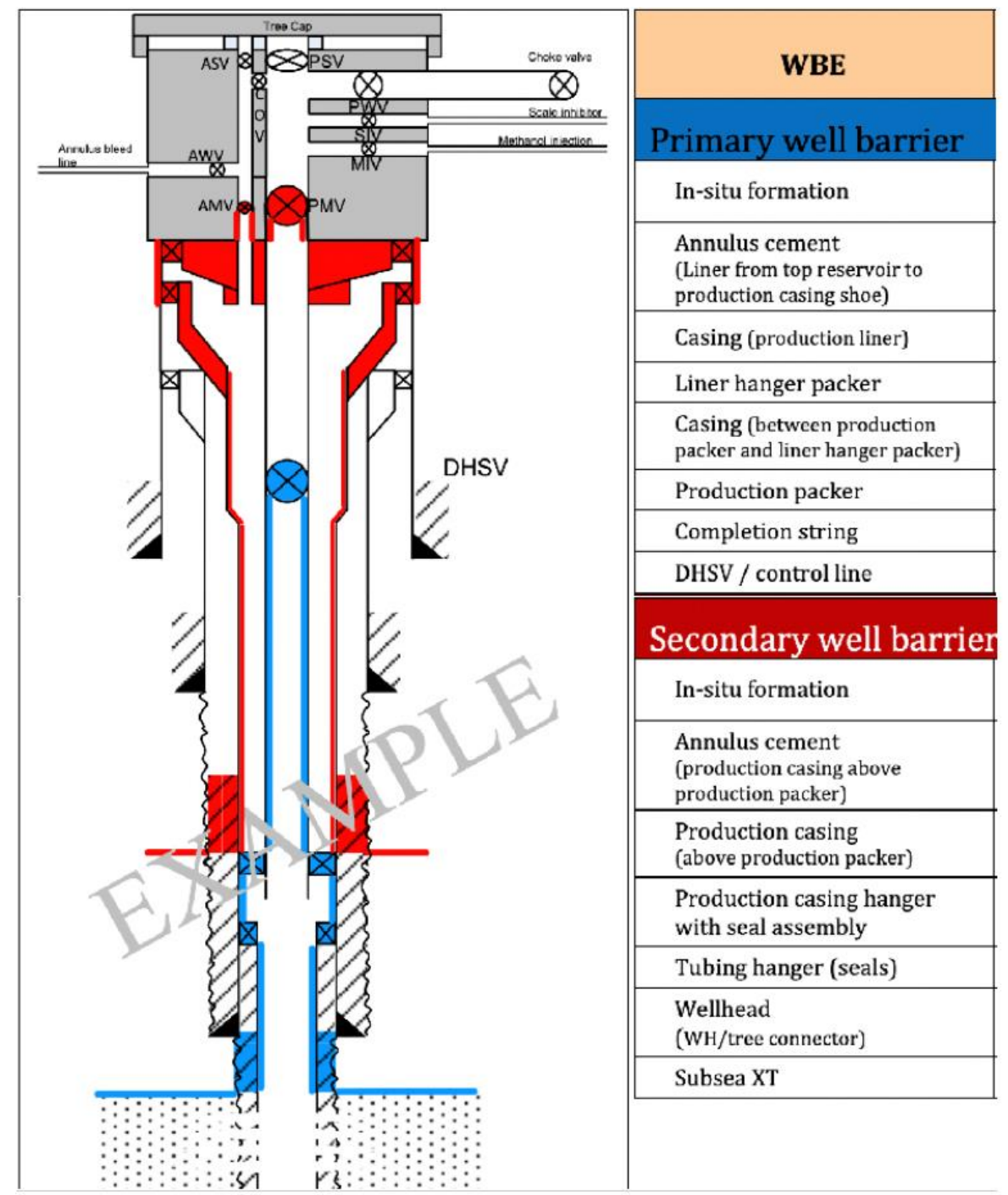

Fonte: (NORSOK D-010, 2021) 
As barreiras de um poço de petróleo podem ser separadas em barreiras passivas, que não necessitam de nenhuma ação para executar sua função de segurança, e em barreiras ativas, as quais precisam se mover de um estado para o outro para desempenhar sua função de segurança (Corneliussen, 2006). O packer de produção, a coluna e o revestimento são exemplos de barreiras passivas, enquanto a DHSV e as válvulas da Árvore de Natal são barreiras ativas.

É importante ter em mente que um poço de petróleo pode apresentar mais barreiras além dos elementos dos dois CSBs. No exemplo da Figura 3 pode-se observar que apenas duas das válvulas da Árvore de Natal (AMV e PMV) fazem parte do CSB secundário, sendo as demais válvulas redundâncias.

Durante a etapa de produção (da Fonseca, 2012) adota quatro principais possíveis caminhos entre o reservatório e o meio ambiente para avaliar a integridade de um poço, são eles: coluna, poço, anular externo e rocha. Na Figura 4 é possível visualizar que as interligações que fazem interface entre dois caminhos adjacentes também devem fazer parte dos elementos que compõe o conjunto solidário de barreiras.

Figura 4 - Caminhos de vazamento e CSBs

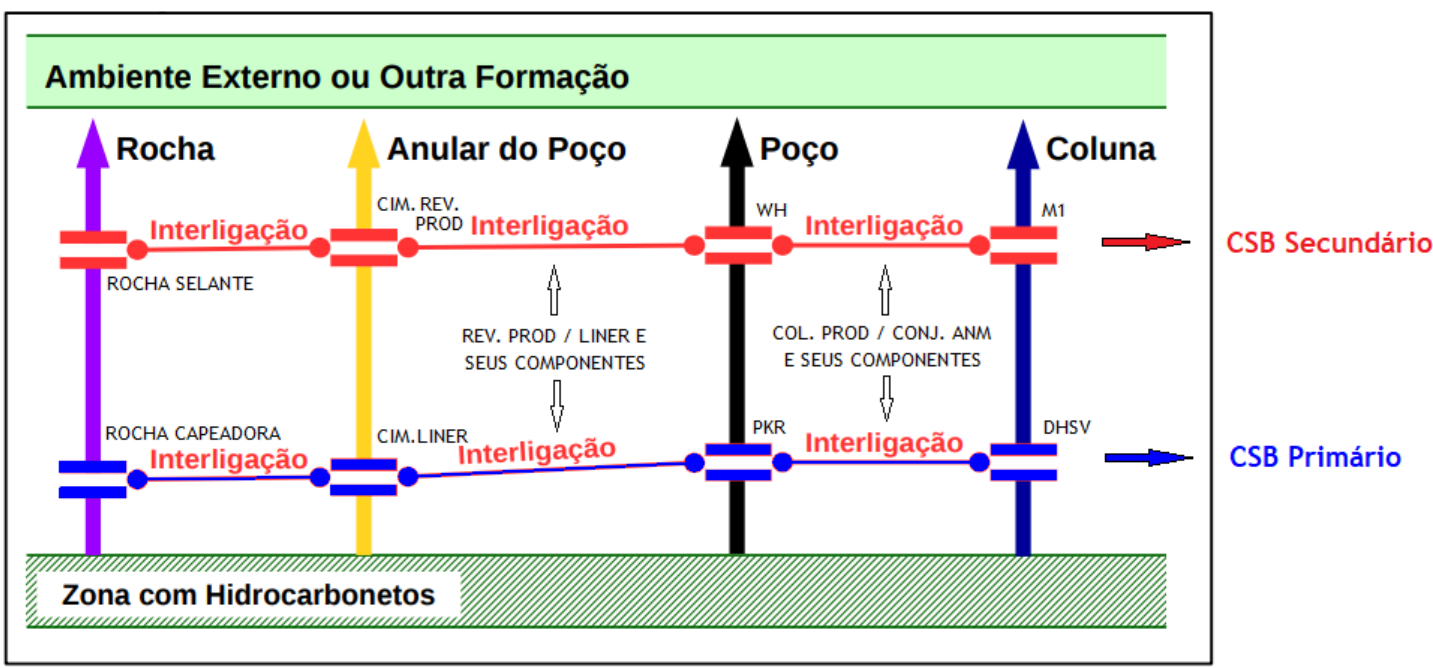

Fonte: adaptado de (Mendes, Fonseca, \& Miura, 2016)

Os CSBs do poço são o ponto de partida para avaliação de integridade e usualmente é requerida a presença de dois conjuntos solidários de barreiras independentes ao longo de toda a vida produtiva de poços surgentes (NORSOK D-010, 2021) e (ANP, 2016).

No processo de gerenciamento da integridade de poço cada elemento de barreira deve passar por testes, inspeções ou monitoramento para confirmação da integridade da barreira perante os requisitos de performance (critérios de aceitação). Orientações 
relacionadas às barreiras de segurança em poços de petróleo estão presentes nas diversas referências normativas sobre integridade de poço (NORSOK D-010, 2021), (ISO 165301, 2017) e (NOG 117, 2017).

\subsection{ENGENHARIA DE CONFIABILIDADE}

Confiabilidade pode ser definida como a probabilidade de um componente ou sistema executar a função para a qual foi projetado, durante um período de tempo pré-definido, sob determinadas condições ambientais e operacionais dado que estava funcionando, ou em condições de operar, no instante inicial (Martins, 2013). Segundo (Modarres, Kaminskiy, \& Krivtsov, 2017, pp. 11, tradução nossa) “A definição de confiabilidade mais amplamente aceita é a capacidade de um item (um produto ou um sistema) operar sob condições operacionais específicas por um designado período de tempo ou número de ciclos".

Diversas distribuições de probabilidade paramétricas podem ser utilizadas para representar o tempo até a falha de um componente, possibilitando a avaliação da confiabilidade, a depender das características intrínsecas dos modos de falha do componente e do comportamento da taxa de falha. As mais usuais são:

- Taxa de falha constante: distribuição exponencial;

$$
R(t)=e^{-\lambda t}
$$

onde $\mathrm{R}=$ função confiabilidade, $\mathrm{t}=$ tempo, $\chi=$ taxa de falha.

- Taxa de falha variável com o tempo: distribuição Weibull, Normal, Lognormal, Beta, Gamma, etc.

Segue a equação da função confiabilidade obtida quando o tempo a até a falha é representado por uma distribuição de Weibull:

$$
R(t)=e^{-\left(\frac{t}{\alpha}\right)^{\beta}}
$$

onde $\mathrm{R}=$ função confiabilidade, $\mathrm{t}=$ tempo, $\beta$ = fator de forma, $\alpha=$ fator de escala.

Usualmente representa-se a taxa de falha de um componente ao longo do tempo por uma curva conhecida na literatura como Curva da Banheira (Bathtub curve), representada na 
Figura 5, pois ela é bastante representativa dos possíveis comportamentos da taxa de falha, embora alguns sistemas não sigam necessariamente esse formato. No trecho inicial, uma taxa de falha decrescente (Mortalidade Infantil) usualmente representando falhas advindas de defeitos de fabricação, construção ou projeto. Na sequência, uma região de taxa de falha constante (Vida Operacional) que representa falhas aleatórias. E, por fim, uma taxa de falha crescente (Obsolescência) que representa o final da vida útil (Martins, 2013).

Figura 5 - Comportamento da taxa de falha ao longo do ciclo de vida do componente curva da banheira

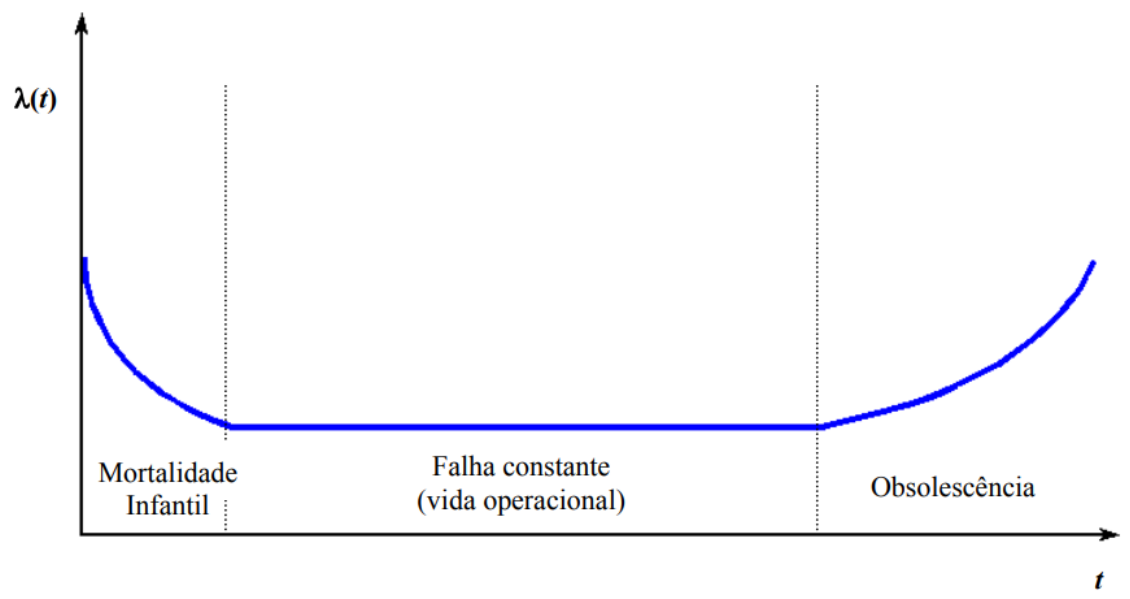

Fonte: (Martins, 2013)

A distribuição de Weibull é bastante utilizada em análises de confiabilidade pois é capaz de representar as 3 regiões da curva da banheira. Para $\beta=1$ a taxa de falha $\chi(t)$ é constante e igual a $1 / \alpha$; para $0<\beta<1$ a taxa de falha $\chi(\mathrm{t})$ decresce com o tempo e para $\beta>1$ a taxa de falha $\chi(t)$ cresce com o tempo.

As curvas de distribuição de probabilidade do tempo até a falha de componentes são usualmente obtidas a partir de ensaios sejam eles censurados ou completos. Existem métodos para estimar a curva de probabilidade de falha acumulada a partir dos dados de ensaios como, por exemplo, método dos momentos, método da máxima verossimilhança ou método gráfico.

Com as curvas de probabilidade de falha acumulada de componentes de um sistema é possível calcular a confiabilidade do sistema através de técnicas que auxiliam na modelagem de sistema complexos, como: Diagrama de Blocos, Árvore de Falhas, Redes Bayesianas, Cadeias de Markov, Redes de Petri, entre outras. 
O Diagrama de Blocos é uma técnica que considera os componentes estatisticamente independentes e demonstra graficamente através de um conjunto de blocos como a confiabilidade dos componentes contribui para o sucesso de um sistema. Por ser uma das técnicas mais utilizadas em análise de confiabilidade de sistemas é um método apresentado e detalhado nos mais diversos livros sobre o tema. Uma importante referência normativa da indústria sobre o tema é a IEC 61078 (Reliability Block Diagrams).

A Árvore de Falhas é uma técnica dedutiva e estruturada para identificar os possíveis caminhos que levam ao evento indesejado (evento topo). Os eventos são considerados independentes, discretos e binários sendo associados através de portões lógicos. Este método teve sua origem em programas aeroespaciais na década de 1960 (Stamatelatos, et al., 2002). Duas importantes referências da indústria sobre o tema são a NUREG-0492 (Fault Tree Handbook) e a IEC 61025 (Fault Tree Analysis (FTA)).

As Redes Bayesianas são grafos acíclicos direcionados que representam as relações de probabilidade condicional entre as variáveis. Este método trata-se de um processo probabilístico que permite considerar as dependências entre os eventos e uso de variáveis multiestado. As Redes Bayesianas foram introduzidas por Judea Pearl na década de 1980 (Cai, et al., 2019), e mais informações sobre a técnica podem ser encontradas em (Pearl, 1988) e no capítulo 5 de (Martins, 2013).

As Cadeias de Markov são processos estocásticos em que a distribuição de probabilidade do próximo estado depende apenas do estado atual. As Redes de Petri são gráficos que consistem em posições, transições e arcos direcionados utilizados para modelagem de sistemas. Ambos os métodos têm bastante aplicação em estudos de confiabilidade pois são capazes de lidar com dependência e multiestado. Importantes referências normativas da indústria sobre essas técnicas são a IEC 61165 (Application of Markov Techniques) e a IEC 62551 (Petri Net Techniques).

Tendo modelado o sistema e a influência de cada componente na confiabilidade do sistema é possível atualizar a informação de confiabilidade instantânea do sistema a partir de novas informações (evidências) de sucesso ou falha de seus componentes. Para tanto basta fazer o cálculo da confiabilidade condicionada utilizando o teorema de Bayes.

Antes da apresentação matemática do teorema de Bayes é importante conhecer as duas principais interpretações da probabilidade: 
- Interpretação frequentista de probabilidade: A probabilidade de um evento é o limite da frequência relativa deste evento quando o número de experimentos independentes e sob as mesmas condições cresce indefinidamente.

- Interpretação subjetiva (bayesiana) de probabilidade: A probabilidade de um evento é o grau de crença (ou confiança) que temos sobre a sua ocorrência. Sendo assim, é dependente do indivíduo, suas informações e crenças.

Na interpretação subjetiva de probabilidade o teorema de Bayes é fundamental na medida em que liga o grau de crença na ocorrência de um evento antes (a priori) e depois ( $a$ posteriori) de se considerar evidências (novas informações).

Segundo o teorema de Bayes, sendo A e E dois eventos têm-se:

$$
P(A \mid E)=\frac{P(E \mid A) P(A)}{P(E)}
$$

sendo,

$\mathrm{P}(\mathrm{A})$ e $\mathrm{P}(\mathrm{E})$ as probabilidades a priori de A e E;

$\mathrm{P}(\mathrm{A} \mid \mathrm{E})$ a probabilidade a posteriori (probabilidade condicionada) de A condicional a $\mathrm{E}$; $\mathrm{P}(\mathrm{E} \mid \mathrm{A})$ a probabilidade a posteriori (probabilidade condicionada) de E condicional a A. Em relação a confiabilidade, pode-se utilizar o teorema de Bayes para cálculo da confiabilidade condicionada dadas evidências de tempo de operação sem falha. Por exemplo, sendo obtida evidência de sucesso em $T_{0}$, pode-se escrever que a confiabilidade em $\mathrm{t}+T_{0}$ é igual a:

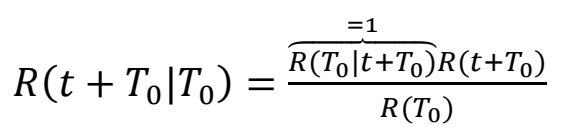

Em resumo, durante a etapa operacional de um sistema, sendo obtida uma nova evidência a respeito do estado de algum dos seus componentes é possível utilizar o teorema de Bayes para obter uma probabilidade a posteriori (atualização do grau de crença na ocorrência do evento) considerando a informação da evidência obtida. 


\subsection{VALIDAÇÃO DE MODELOS}

Em diversas situações da engenharia o uso de modelos é crucial para a realização de avaliações, inferências e entendimento acerca da realidade. Nesse trabalho são utilizados modelos para a aplicação da metodologia, como por exemplo: representação do poço na forma de um modelo esquemático, representação dos modos de falha de componentes e suas relações funcionais, modelagem do sistema por diagrama de blocos, utilização do modelo de taxa de falha constante para o cálculo da confiabilidade e de premissas sobre independência, cobertura de testes, modos de falha comuns, degradação, etc.

Um modelo é uma representação simplificada da percepção da realidade com um propósito específico. Pode-se dizer que todos os seres humanos usam modelos para tratar seus problemas e que as decisões tomadas são baseadas em modelos mentais da realidade (Santos, 2012).

Agora, como pode-se validar um modelo? Segundo (Sterman, 2000), nenhum modelo pode ser plenamente verificado ou validado, pois todos os modelos são errados uma vez que são representações limitadas e simplificadas do mundo real. Em seu livro sobre modelos no processo de política (Greenberger, Crenson, \& Crissey, 1976, pp. 70-71, tradução nossa) concluem que:

\footnotetext{
Nenhum modelo foi ou será totalmente validado. Visto que, por projeto, todos os modelos são simplificações do sistema de referência, eles nunca são inteiramente válidos no sentido de serem totalmente suportados pela verdade objetiva. "Útil", “esclarecedor", "convincente" ou "inspira confiança" são descritores mais adequados para se aplicar aos modelos do que "válido".
}

Segundo (Churchman, 1973) um ponto de vista, ou um modelo, é realista na medida em que pode ser adequadamente interpretado, compreendido e aceito por outros pontos de vista. E, em vez de apenas apresentar evidências de casos em que o modelo é válido, o que pode levar ao viés de confirmação, bons modeladores focam nas limitações do modelo para que ele possa ser melhorado e para que não haja uso indevido dele. De uma forma ou de outra, decisões serão tomadas com base em algum modelo (mental ou formal), basta escolher qual (Sterman, 2000). 
Sendo assim, é importante ressaltar que os modelos utilizados nessa dissertação são baseados em teorias consolidadas da engenharia de confiabilidade e que as limitações e premissas utilizadas são apresentadas e discutidas.

No capítulo 4 desta dissertação será feito um exemplo de aplicação da metodologia, sendo os resultados encontrados expressos em probabilidades. Segundo (Aven, 2013) para produzir probabilidades é preciso basear a avaliação em conhecimento (premissas), como por exemplo a consideração de que os dados históricos utilizados são representativos para o futuro.

De acordo com (Aven, 2020) sempre haverá uma dúvida sobre a qualidade e o desempenho de um modelo, dessa forma somos levados a fazer considerações sobre a razoabilidade das suposições feitas. As premissas e considerações utilizadas para a aplicação da modelagem podem ser entendidas como a explicitação das crenças justificadas para a avaliação realizada, portanto a questão crítica é a força dessas crenças, a qual deve ser informada para os tomadores de decisão e outras partes interessadas que utilizarão os resultados obtidos (Aven \& Zio, 2011).

Mesmo que os valores de probabilidade obtidos sejam representados por intervalos de incerteza é importante uma discussão a respeito da força do conhecimento que os suporta.

Segundo (Flage \& Aven, 2009), (Aven, 2013) e (Aven, 2017) uma possível abordagem para classificar o grau da força do conhecimento que suporta uma análise probabilística é verificar se as seguintes condições são atendidas:

- As suposições feitas são razoáveis?

- Dados confiáveis estão disponíveis?

- Existe ampla concordância/consenso entre especialistas?

- Os fenômenos envolvidos são bem compreendidos e os modelos utilizados são conhecidos por fornecer previsões com a precisão necessária?

Durante o desenvolvimento desta dissertação os questionamentos acima foram considerados, sendo apresentado nas conclusões do trabalho um julgamento sobre a verificação dessas condições. 


\section{METODOLOGIA}

Tendo em mente o conceito de confiabilidade exposto no item 2.3 é necessário explicitar o escopo do que será analisado:

- Sistema: Poço de Petróleo em Produção (cujos componentes devem ser detalhados);

- Função para a qual o sistema foi projetado: conter fluidos (evitando liberação descontrolada para o meio externo);

- Período de tempo: depende do projeto do poço (ex.: 27 anos);

- Condições Operacionais: operação dentro do envelope operacional como especificado pelo projeto.

Este trabalho é focado em Integridade de Poço, dessa forma, falha é definida como perda de contenção para o meio externo às barreiras do poço. Outros tipos problemas de poço também poderiam ser considerados falhas, como por exemplo os eventos indesejados em poços de petróleo mapeados no trabalho de (Vargas, et al., 2019) que tem relação com perda de produção (e não com perda de contenção), não sendo escopo deste trabalho.

A metodologia elaborada nesta dissertação se baseia na confiabilidade para $o$ gerenciamento da integridade de poços em produção e abandono temporário e apresenta nove etapas, as quais serão sequencialmente detalhadas e discutidas a seguir.

Apesar de existirem diversos outros estudos relacionados a avaliação de confiabilidade de poços de petróleo, a principal contribuição desta dissertação é a apresentação de uma forma estruturada e encadeada das etapas necessárias para desenvolver na prática um gerenciamento da integridade de poços em produção ou em abandono temporário baseado em confiabilidade. Além de sua aplicação prática em um poço exemplo.

Somente após a explanação detalhada sobre cada etapa é que será, no capítulo seguinte, aplicada a metodologia proposta em um poço exemplo (poço de petróleo submarino típico do pré-sal brasileiro) com o esclarecimento das premissas adotadas. Importante ter em mente que se pode aplicar a metodologia desenvolvida em qualquer tipo de poço na etapa de produção ou de abandono temporário, bastando seguir as nove etapas. A sequência das etapas da metodologia está ilustrada na Figura 6 e descrita nas subseções seguintes. 
Figura 6 - Etapas da Metodologia

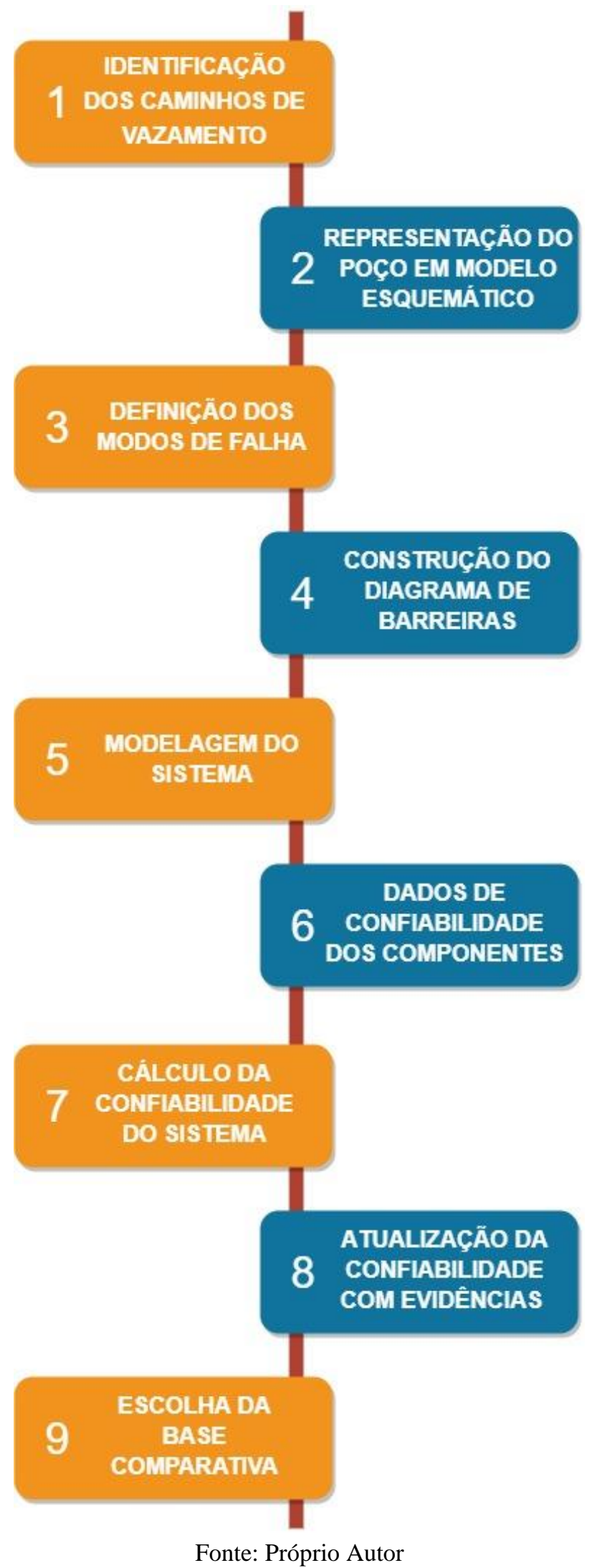




\subsection{ETAPA 1: IDENTIFICAÇÃO DOS CAMINHOS DE VAZAMENTO}

Para que haja perda de contenção para o meio externo o fluxo de óleo precisa partir do reservatório para o meio ambiente passando por algum caminho de vazamento. Em cada possível caminho de vazamento existem diversos elementos de barreira.

(Miura, 2004) representa na Figura 1 oito possíveis caminhos de vazamento entre a zona com hidrocarboneto (reservatório) e o meio ambiente sem detalhar os vazamentos internos de componentes que ficariam contidos em cavidades internas do poço.

Já (da Fonseca, 2012) adota quatro principais possíveis caminhos entre o reservatório e o meio ambiente para avaliar a integridade de um poço, são eles: coluna, poço, anular externo e rocha. A Figura 7 explicita estes quatro caminhos, desde o reservatório (faixa horizontal em amarelo) até o meio ambiente.

Figura 7 - Quatro principais caminhos de vazamento entre reservatório e meio ambiente

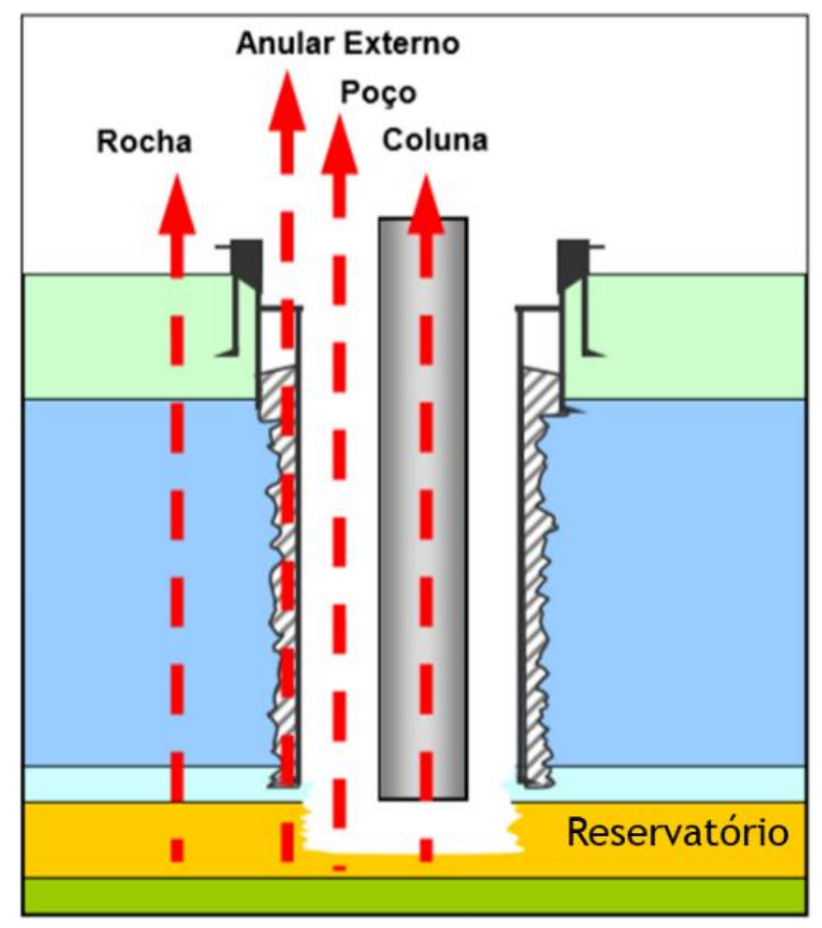

Fonte: (da Fonseca, 2012)

Caso se deseje obter o risco absoluto de perda de contenção do poço para o meio ambiente deve-se levar em consideração todos os possíveis caminhos de vazamento. Também seria importante considerar o ciclo de vida do poço como um todo incluindo uma possível existência de dívida técnica advinda das fases de projeto e construção que possam impactar os riscos durante a operação (Santos, Abreu, Morais, Colombo, \& Martins, 
2019). Nesta dissertação não são discutidos aspectos de projeto e construção, apenas compara-se o entregue pelo projeto do poço, sem discutir o mérito, com o que está sendo realizado durante a operação.

Com essa abordagem não se chega na confiabilidade do poço considerando todos os possíveis caminhos de vazamento e todos os elementos, mas ao considerar os caminhos e elementos que são relevantes para a etapa de produção, chega-se a uma boa aproximação.

É importante que a discussão a respeito de quais caminhos de vazamento são relevantes na etapa de produção de um poço de petróleo seja realizada na primeira etapa da metodologia dado que embasará o conteúdo das demais etapas, sendo crucial para escolha de quais são as barreiras relevantes a serem modeladas e o nível de detalhamento demandado.

\subsection{ETAPA 2: REPRESENTAÇÃO DO POÇO EM MODELO ESQUEMÁTICO}

A representação de um poço de petróleo em modelo esquemático é prática comum para auxiliar o gerenciamento de integridade das barreiras de segurança do mesmo, tanto a (ISO 16530-1, 2017) quanto a (NORSOK D-010, 2021) recomendam manter atualizado o esquemático de barreiras do poço detalhando claramente no mesmo os conjuntos solidários de barreira primário e secundário, bem como informações sobre qualquer problema de integridade de poço identificado.

Considerando os caminhos de vazamento pela coluna e pelo poço (anular-A) com seus respectivos elementos de barreira, é possível desenhar um modelo esquemático do poço com seus principais componentes. Segue Figura 8 com exemplo de modelo esquemático de um poço na fase de produção. 
Figura 8 - Exemplo de modelo esquemático de poço

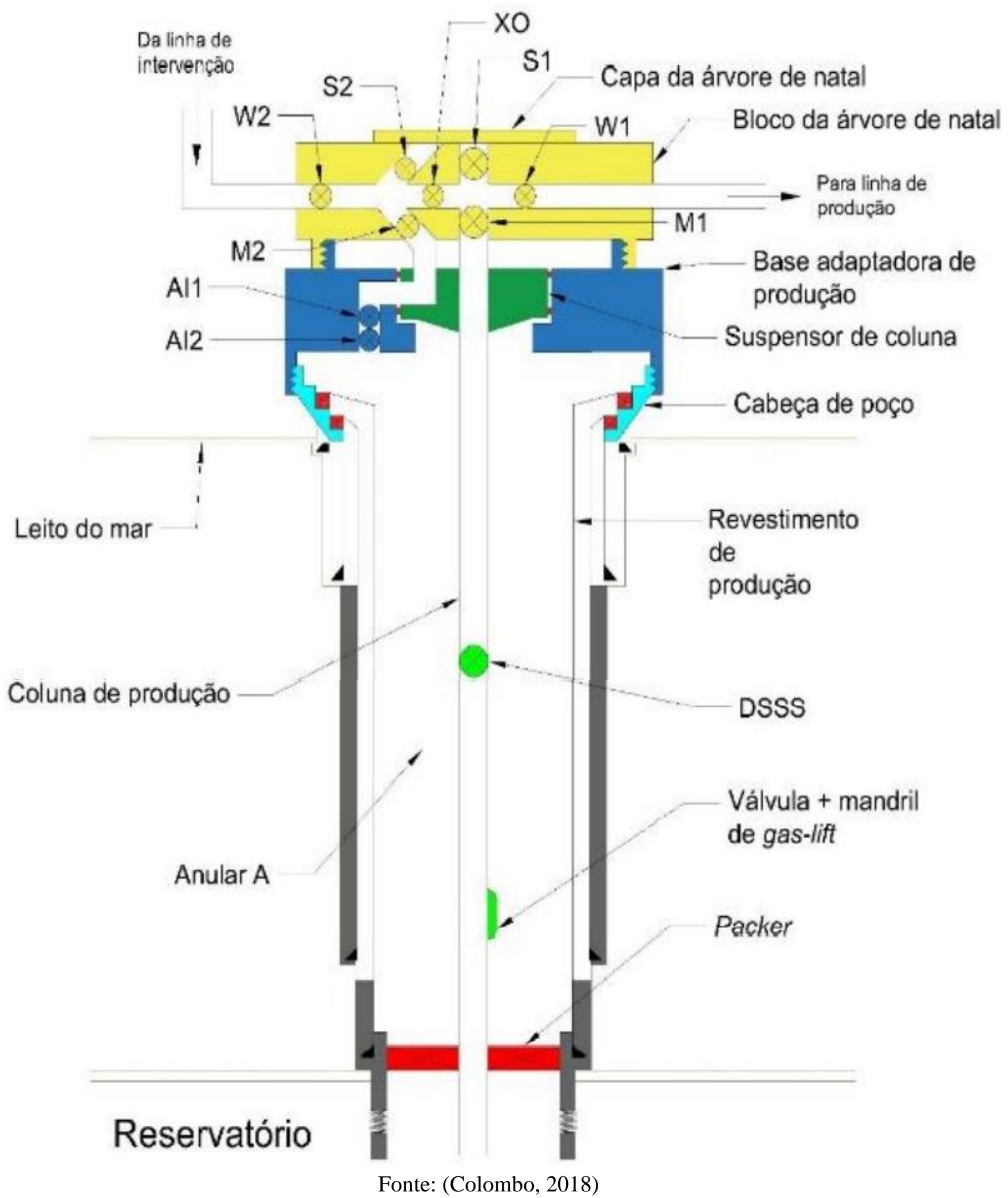

Caso o poço a ser avaliado tenha outros componentes e/ou outras relações funcionais, basta refazer a modelagem.

Um aspecto significativo é que em caso de não ser possível impedir que o fluxo de óleo chegue no meio externo com a atuação dos elementos que compõem as barreiras de 
segurança do poço considerados na modelagem do poço é entendido que ele perdeu a integridade, ainda que o óleo fique contido e não atinja diretamente o mar.

Desta forma, se o modelo não considera a linha de produção a jusante das válvulas da Árvore de Natal, pode-se dizer que se todas as válvulas no caminho da coluna (pela Figura 8: DSSS, M1 e W1) estiverem travadas abertas é considerado que o poço perdeu sua integridade - sua capacidade de conter fluidos - independentemente de ter havido ou não liberação para o meio ambiente. Neste mesmo caso, se a falha for em apenas uma das válvulas não resultará em perda da integridade do poço, porém sua confiabilidade estará impactada.

O modelo esquemático deve representar todas as barreiras que serão utilizadas na modelagem, dessa forma é possível ser mais ou menos conservador, a depender de quantas e quais barreiras são consideradas.

É recomendável considerar minimamente os elementos dos conjuntos solidários de barreiras do poço presentes nos caminhos de vazamento identificados.

\subsection{ETAPA 3: DEFINIÇÃO DOS MODOS DE FALHA}

Cada componente de barreira pode falhar de diversas formas, essas formas de falha são conhecidas como Modos de Falha. Segundo a (ISO 14224, 2016, pp. 7, tradução nossa) modo de falha é a "maneira pela qual a falha ocorre".

Existem falhas de componentes que, do ponto de vista de integridade de poço, levam o poço para uma condição segura e falhas que são perigosas. Falha segura (safe failure) é uma "falha que favorece uma determinada ação de segurança" (IEC 61511-1, 2017, pp. 25 , tradução nossa), enquanto que falha perigosa (dangerous failure) é uma "falha que impede ou desabilita uma determinada função ou ação de segurança" (IEC 61511-1, 2017, pp. 15, tradução nossa).

Neste trabalho são relevantes os modos de falha presentes na fase de operação do poço que o levam para condições de maior risco, ou seja, as falhas perigosas. Tais falhas podem ser detectáveis ou não detectáveis. Falha detectável (detected failure) é uma "falha que é imediatamente evidente para o pessoal de operação ou manutenção assim que ela ocorre" (ISO TR 12489, 2013, pp. 22, tradução nossa), enquanto falha não-detectável (undetected 
failure) é uma "falha que [quando ocorre] não é imediatamente evidente para o pessoal de operação ou manutenção" (ISO TR 12489, 2013, pp. 22, tradução nossa). Os tipos de falha discutidos estão representados na Figura 9.

Figura 9 - Tipos de Falha

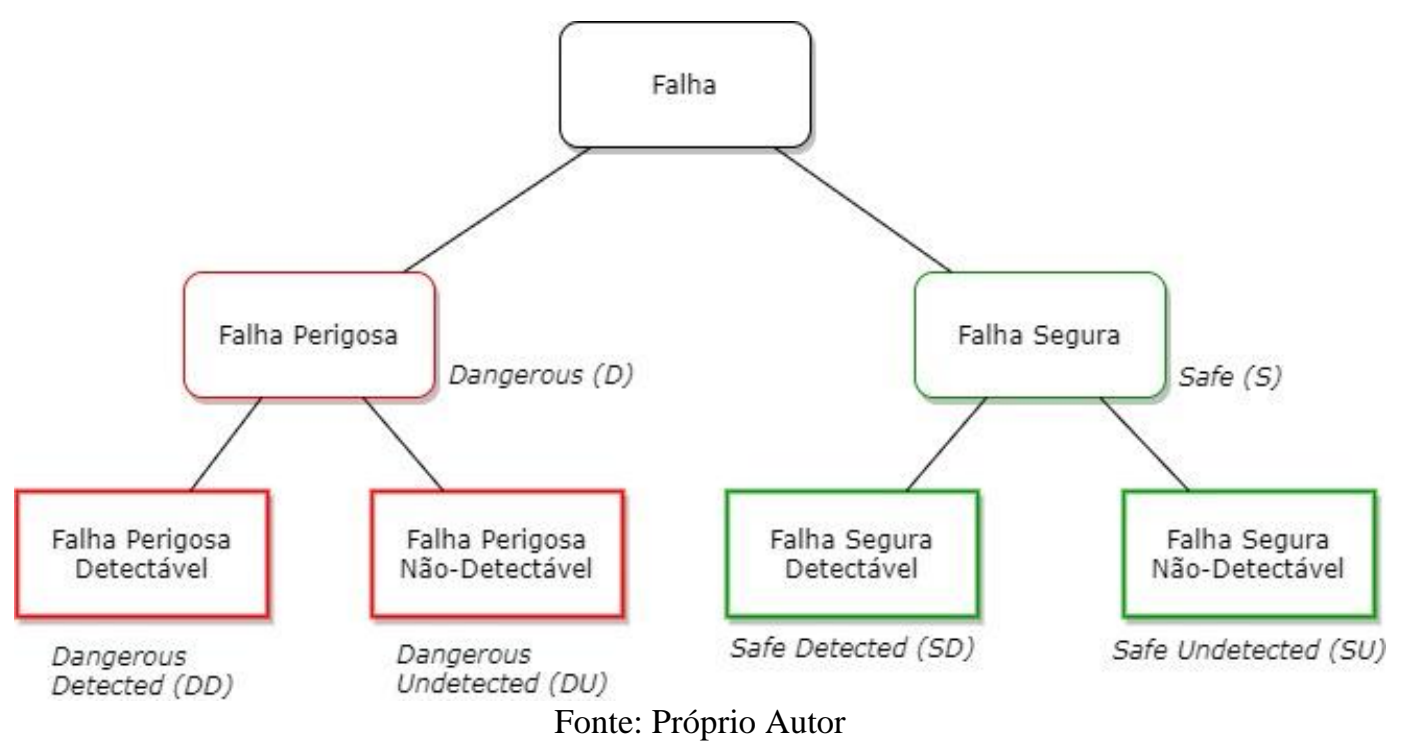

As barreiras presentes em cada caminho de vazamento (tratados na etapa 1) e representadas no modelo esquemático do poço (etapa 2) devem ter seus modos de falha perigosos, detectáveis ou não-detectáveis, definidos nesta etapa 3. Os modos de falha perigosa para uma válvula de segurança do tipo "fail safe closed" podem ser, por exemplo, falhar em fechar ou vazar na posição fechada.

Por fim, é interessante conhecer o anexo Q da norma (ISO 16530-1, 2017) que exemplifica possíveis caminhos de vazamento entre cavidades em um poço de petróleo gerados por modos de falha típicos, conforme Figura 10. 
Figura 10 - Exemplo de Modos de Falha típicos em um poço de petróleo

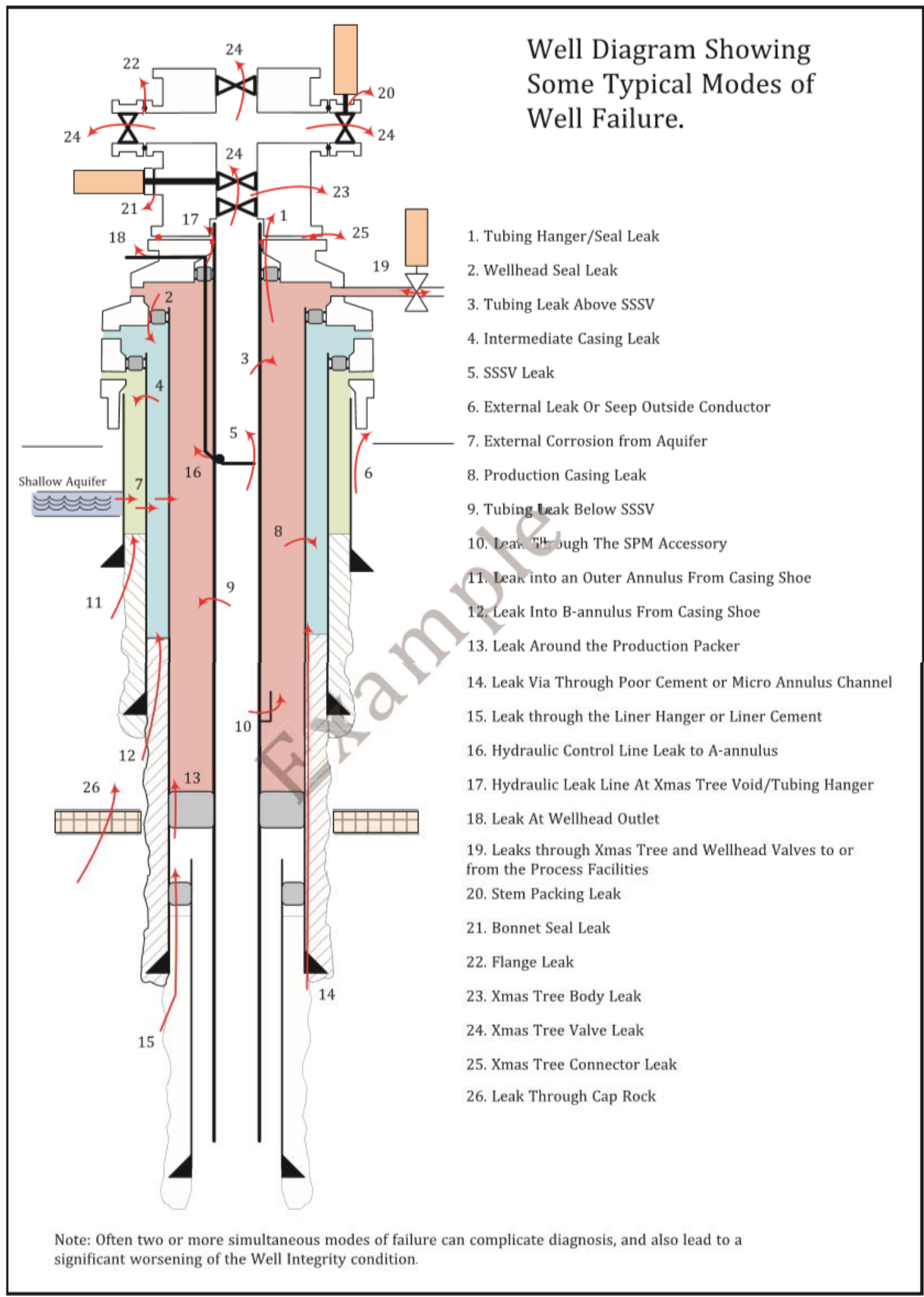

Fonte: (ISO 16530-1, 2017) 


\subsection{ETAPA 4: CONSTRUÇÃO DO DIAGRAMA DE BARREIRAS}

Considerando o modelo esquemático do poço e suas barreiras, é possível construir um diagrama de barreiras detalhando os modos de falha de componentes e vazamentos internos entre cavidades que levam a perda de integridade do sistema poço como um todo pelos caminhos de vazamento.

Segundo (Corneliussen, 2006) os diagramas de barreira vêm sendo utilizados de diversas formas desde a década de 90 para auxiliar análises de risco de poços. Em 2006 (Corneliussen, 2006) propôs um procedimento formal para construção destes diagramas. Tais diagramas permitem uma visualização simplificada de todas as possibilidades de caminho de vazamento entre o reservatório e o meio ambiente (ou meio externo às barreiras do poço). Um exemplo de diagrama de barreiras de um poço na fase de produção considerando os caminhos de vazamento da coluna, do anular-A e interligação entre eles, elaborado por (da Fonseca, 2012), está representado na Figura 11. Para o fluido perigoso sair do reservatório e chegar ao meio ambiente é necessário passar por cavidades do poço, ou seja, espaços em que a pressão pode ser trapeada e sofrer acúmulo no caso de falha (vazamento) de uma ou mais barreiras. Neste exemplo os blocos verdes representam as cavidades do poço e os blocos brancos identificam o conjunto de falhas que levam à comunicação entre as cavidades. As falhas são descritas pelos modos de falha dos componentes, a saber: falha no fechamento (FNF), vazamento na posição fechada (VPF), vazamento externo (VE), vazamento interno (VI) e vazamento da coluna para o anular (VCA). 
Figura 11 - Exemplo de diagrama de barreiras

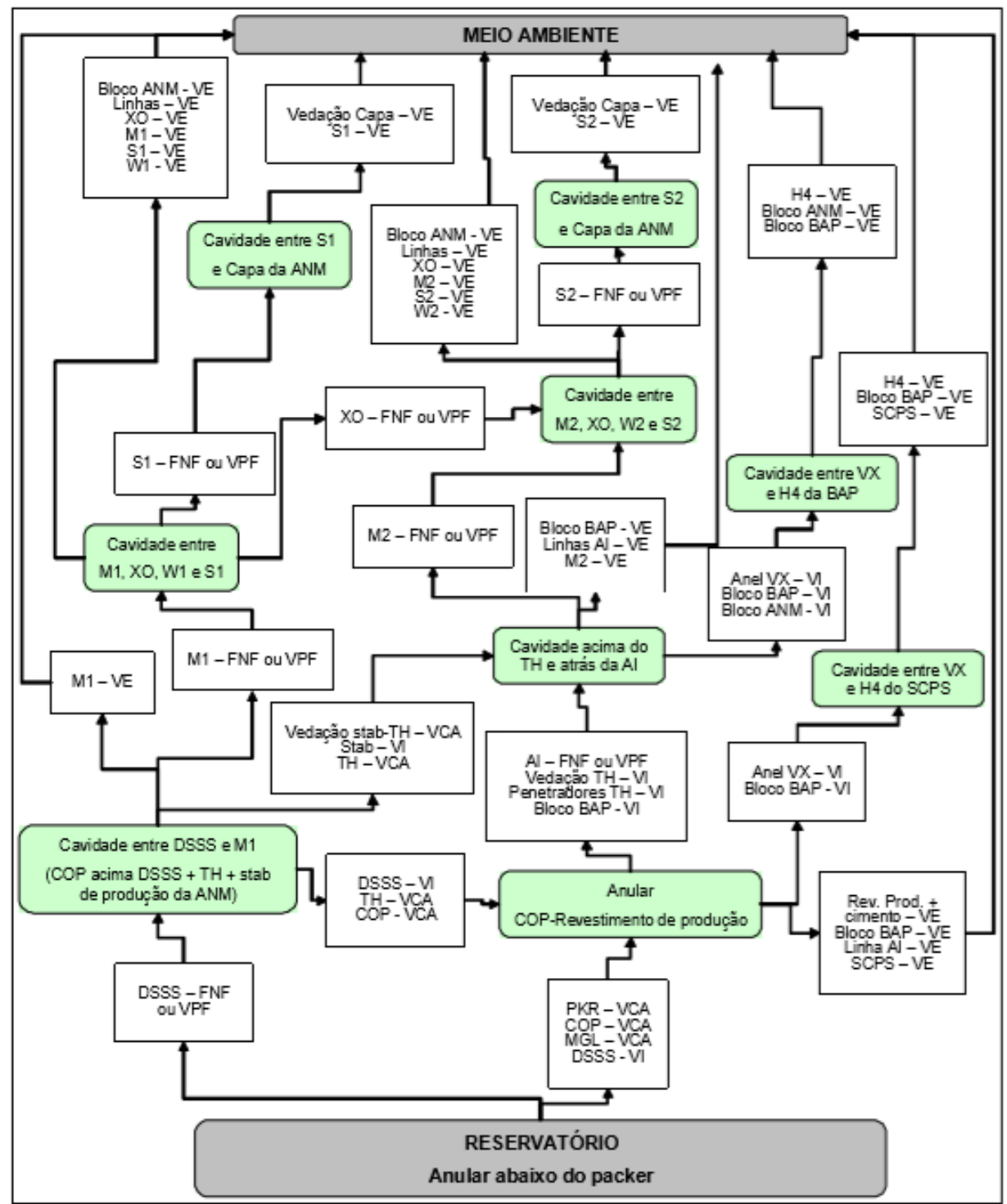

Fonte: (da Fonseca, 2012)

\subsection{ETAPA 5: MODELAGEM DO SISTEMA}

Um poço submarino de petróleo é um sistema complexo que pode ser modelado de diversas formas. Em (Mendes, Fonseca, \& Miura, 2016) a modelagem é feita através de árvore de sucesso, em (Alves, 2012), (Zanetti, 2014) e (Zulqarnain \& Tyagi, 2015) é feita com uma árvore de falhas, em (Colombo, et al., 2020) é feita através das cavidades do poço e utilização de uma cadeia de Markov, já em (Lavasani, Ramzali, Sabzalipour, \& Akyuz, 2015) a modelagem é feita utilizando uma árvore de falhas fuzzy. Via modelagem por Diagrama de Blocos tem-se, por exemplo, o trabalho de (Júnior, Lima, Colombo, 
Abreu, \& Salvalagio, 2020), que trata da seleção de configurações de poços de petróleo durante a fase de concepção do projeto.

A (ISO TR 12489, 2013) propõe um fluxo para auxiliar na escolha da técnica de modelagem para cálculo da confiabilidade do sistema a depender da complexidade do sistema, exposto na Figura 12.

Figura 12 - Visão geral de abordagens de modelagem e cálculo de confiabilidade

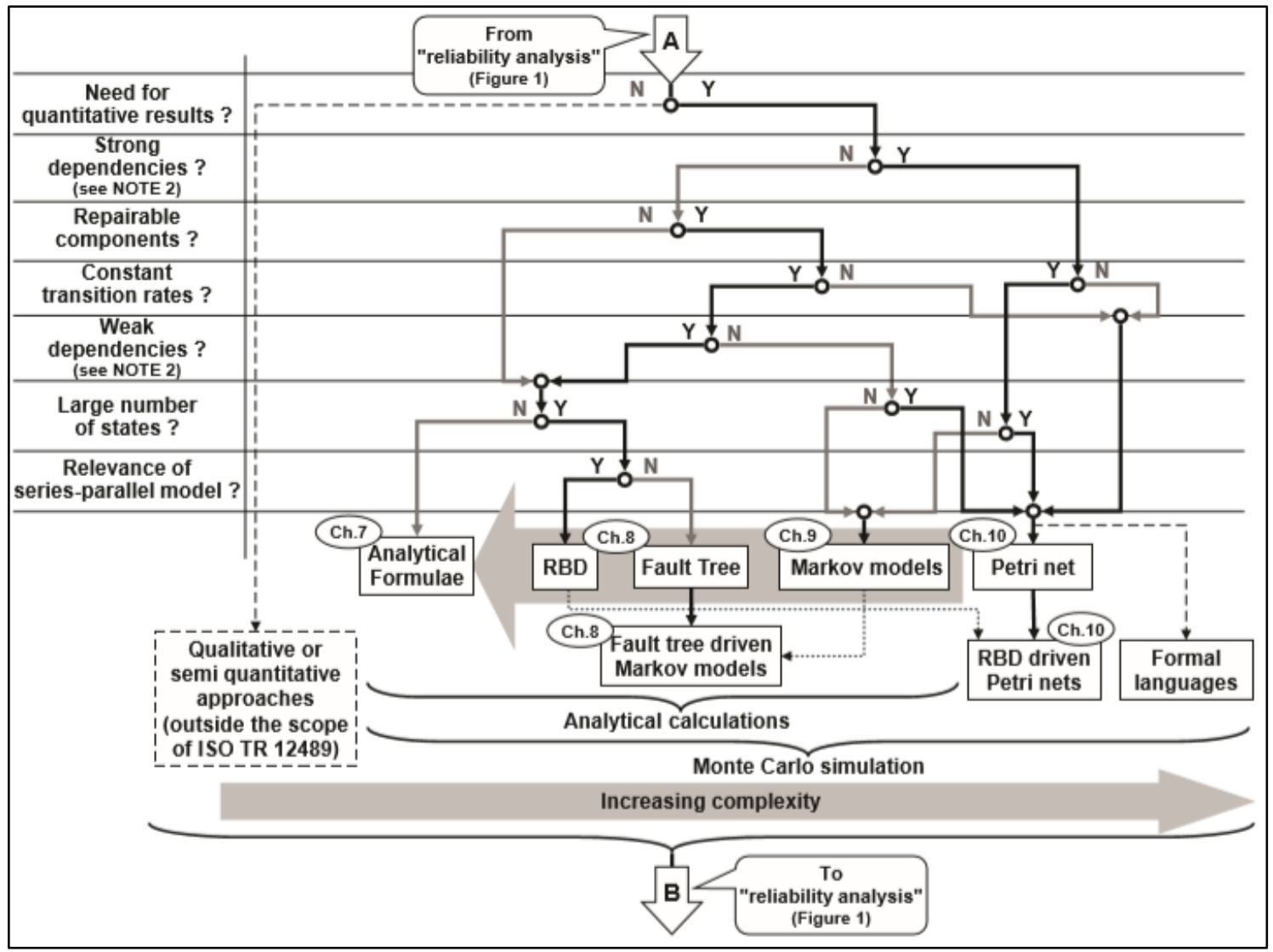

Fonte: (ISO TR 12489, 2013)

No capítulo seguinte, em que as etapas da metodologia serão aplicadas para um poço exemplo, será discutido qual a técnica de modelagem de sistema mais se adequa ao caso específico com base no fluxo da Figura 12.

Dentre as diversas formas de modelagem de um poço submarino de petróleo em produção, que podem ser consultadas nas referências citadas, segue como exemplo a modelagem de blowout (perda de contenção descontrolada) de poço em produção via árvore de falha na Figura 13. 
Figura 13 - Exemplo de blowout de poço em produção modelado por árvore de falha

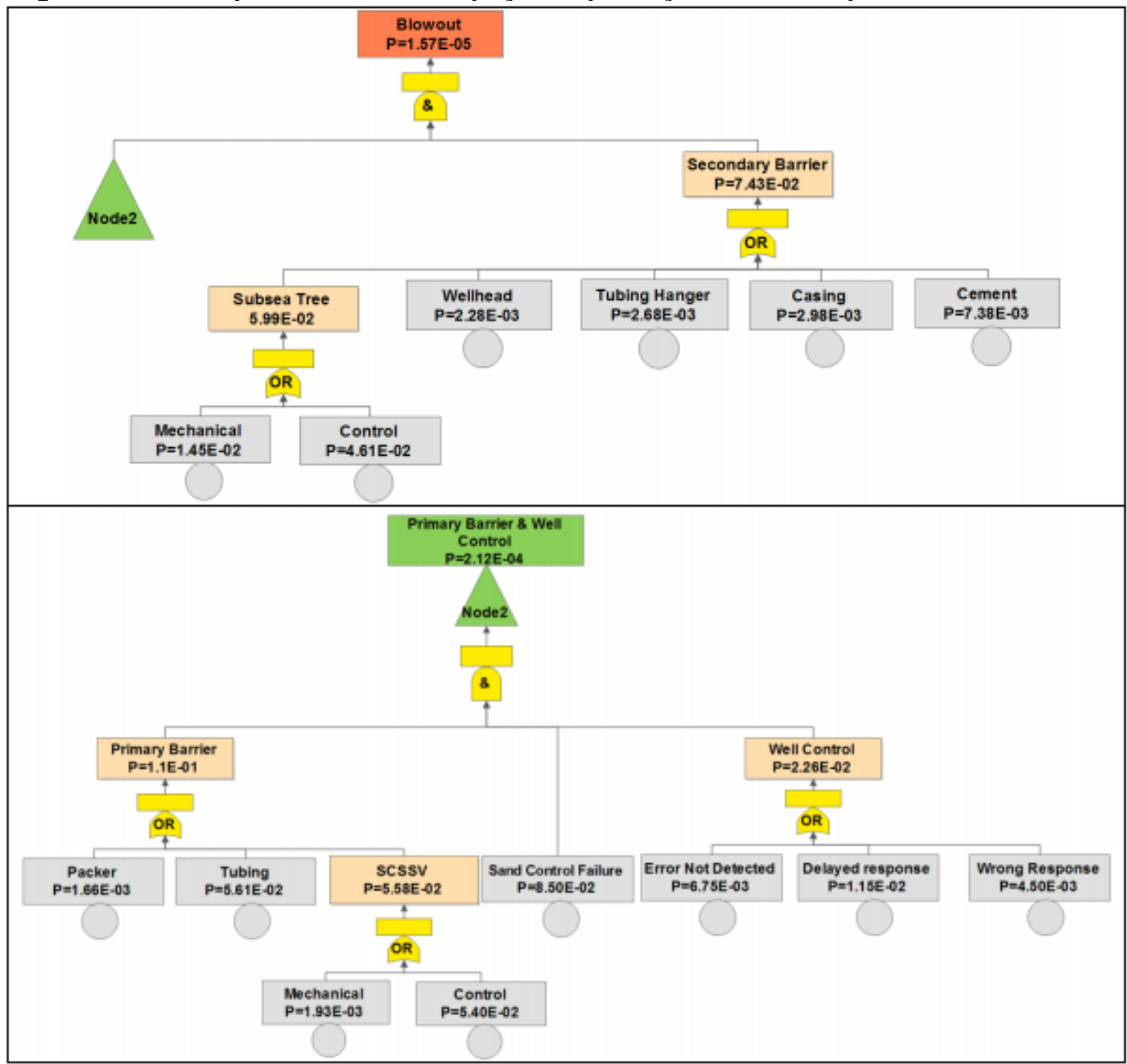

Fonte: (Zulqarnain \& Tyagi, 2015)

\subsection{ETAPA 6: DADOS DE CONFIABILIDADE DOS COMPONENTES}

Com o sistema modelado é necessário obter a taxa de falha de cada um dos modos de falha mapeados para chegar à função de confiabilidade do sistema.

A função de confiabilidade $R(t)$ pode ser obtida a partir da taxa de falha $\chi(t)$ pela seguinte equação:

$$
R(t)=e^{-\int_{0}^{t} \lambda(t) d t}
$$


É importante ter em mente que a função confiabilidade é dependente do tempo, portanto para avaliar a confiabilidade de um componente a partir de sua taxa de falha é necessário a definição do tempo de missão.

Dados de confiabilidade, incluindo taxas de falha, podem ser obtidos de diversas formas (ISO TR 12489, 2013), como por exemplo:

- Dados próprios: obtidos de campo ou testes de confiabilidade

- Dados genéricos: obtidos de bancos de dados

- Elicitação de Especialistas: obtidos através do julgamento de especialistas

Muitas vezes, devido à baixa quantidade de dados observados na instalação é necessário buscar a opinião de especialistas ou utilizar dados de falha de bancos de dados genéricos.

Como fonte de dados genéricos para equipamentos submarinos e poços a (IOGP 434-20, 2019) recomenda utilizar o OREDA (SINTEF, 2015) e o WellMaster RMS Project.

As incertezas na estimativa dos parâmetros da distribuição de confiabilidade podem ser quantificadas através de um tratamento estatístico e obtenção de intervalos de confiança. Outra abordagem é tratar os parâmetros como variáveis aleatórias, então a partir de uma distribuição a priori dos parâmetros da função confiabilidade, tendo novas informações, testes ou observações é possível, por meio de inferência bayesiana, atualizar a distribuição a priori obtendo-se uma distribuição a posteriori que melhor representa os parâmetros de interesse (Modarres, Kaminskiy, \& Krivtsov, 2017).

\subsection{ETAPA 7: CÁLCULO DA CONFIABILIDADE DO SISTEMA}

Tendo modelado o sistema e todos os dados de taxa de falha (seja ela constante ou variável) dos elementos básicos é possível calcular a curva de confiabilidade do sistema. Uma forma muito comum de cálculo de confiabilidade em sistemas complexos é através da determinação de seus cut-sets ou path-sets mínimos.

Um cut-set é um conjunto de eventos que, caso ocorram simultaneamente, levam a falha do sistema; enquanto um path-set é um conjunto de eventos que, caso ocorram simultaneamente, levam ao sucesso do sistema. Já um cut-set mínimo é um conjunto formado pela menor quantidade possível de eventos de falha que, caso ocorram 
simultaneamente, levam a falha do sistema. Ou seja, um cut-set mínimo não contém nenhum outro cut-set dentro de si.

Após se determinar o conjunto dos cut-sets (ou path-sets) mínimos, o sistema equivalente é dado pelos cut-sets em série (ou path-sets em paralelo) e o cálculo da confiabilidade do sistema é dado por:

$$
\begin{gathered}
R_{S}(t)=1-\operatorname{Pr}\left(C_{1} \cup C_{2} \cup \ldots \cup C_{k}\right) \\
\text { ou } \\
R_{S}(t)=\operatorname{Pr}\left(P_{1} \cup P_{2} \cup \ldots \cup P_{m}\right)
\end{gathered}
$$

onde $R_{s}=$ função confiabilidade do sistema, $\mathrm{t}=$ tempo, $C_{i}=$ cut-set mínimo i, $P_{i}=$ pathset mínimo $\mathrm{i}, \mathrm{k}=$ número de cut-sets mínimos e $\mathrm{m}=$ número de path-sets mínimos

Um cálculo aproximado da confiabilidade do sistema pode ser feito considerando que os sets são conjuntos disjuntos. Entretanto, como usualmente os cut-sets mínimos (ou pathsets mínimos) obtidos não são conjuntos disjuntos, a avaliação por cut-set fornece um limite inferior para a confiabilidade, enquanto a avaliação por path-sets fornece um limite superior para a confiabilidade. Dessa forma tem-se que:

$$
\begin{aligned}
& R_{S}(t) \geq 1-\left[\operatorname{Pr}\left(C_{1}\right)+\operatorname{Pr}\left(C_{2}\right)+\cdots+\operatorname{Pr}\left(C_{k}\right)\right] \\
& R_{S}(t) \leq \operatorname{Pr}\left(P_{1}\right)+\operatorname{Pr}\left(P_{2}\right)+\cdots+\operatorname{Pr}\left(P_{m}\right)
\end{aligned}
$$

Quando a ocorrência dos cut-sets são eventos raros a avaliação pelos cut-sets mínimos, mesmo não sendo disjuntos, fornece uma boa aproximação para a confiabilidade do sistema.

Para o cálculo exato da confiabilidade pode-se usar o método combinatório, que levaria a $2^{\text {número de elementos }}$ combinações, ou a equação exata por cut-sets mínimos (ou pathsets mínimos) que existindo k cut-set (ou path-sets) o cálculo levará a uma equação de $2^{k-1}$ termos. Em ambos os casos o custo computacional pode ficar inviável dependendo do número de elementos do sistema.

Segundo (Abreu \& Martins, 2017):

O cálculo da probabilidade de ocorrência exata do evento topo, entretanto, representa um obstáculo do ponto de vista computacional. O número de termos na expressão tende a aumentar exponencialmente com a quantidade de cut-sets mínimos e, naturalmente, torna impraticável o cálculo na forma convencional para a avaliação de sistemas de grande complexidade. 
Uma possível solução para reduzir o tempo computacional é transformar o conjunto de cut-sets mínimos (ou path-sets mínimos) em um conjunto disjunto. Um algoritmo para executar essa transformação foi proposto por (Abraham, 1979).

No caso de avaliações quantitativas de árvores de falha existem alguns procedimentos comumente utilizados: método das Substituições Sucessivas (traduzindo a árvore lógica para sua correspondente expressão booleana), o método da Tabela Verdade (técnica combinatória) e o uso de Diagramas Binários de Decisão (Binary Decision Diagram BDD) (Martins, 2013).

Também é possível fazer quantificação da confiabilidade através de simulações com a utilização do método de Monte Carlo, que pode ser usado para estimar um valor (por exemplo, uma probabilidade desconhecida) ou simular (reproduzir) o processo estocástico descrevendo o comportamento de um sistema complexo (Birolini, 2017).

Outro ponto importante no cálculo da confiabilidade do sistema é definir se serão consideradas ou não as possíveis causas comuns de falha (Common Cause Failures $C C F$ ). Os modelos mais utilizados para considerar as causas comuns de falha são: modelo fator $\beta$, modelo das letras gregas e modelo fator $\alpha$ (Martins, 2013).

\subsection{ETAPA 8: ATUALIZAÇÃO DA CONFIABILIDADE COM EVIDÊNCIAS (TEOREMA DE BAYES)}

Com a modelagem do poço elaborada e o cálculo da confiabilidade realizado é possível atualizar a informação de confiabilidade instantânea do sistema a partir de novas informações (evidências) de sucesso ou falha (ou ainda degradação) de seus componentes.

Durante a etapa operacional de um poço de petróleo, sendo obtida uma nova evidência do estado de integridade de algum elemento de barreira do poço, pode-se utilizar o teorema de Bayes para obter a confiabilidade a posteriori (atualização do grau de crença na ocorrência do evento) do sistema considerando a evidência obtida.

Um ponto fundamental para atualização da confiabilidade a partir de evidências é a definição dos critérios de aceitação das barreiras do poço. Uma vez que se deve considerar 
que o teste trouxe uma evidência de sucesso, apenas se o elemento barreira atingiu os critérios de aceitação definidos para aprovação do teste.

Exemplos de critérios de aceitação de elementos de barreira de poços podem ser obtidos em relatórios de consolidação de boas práticas da indústria, como por exemplo em (NORSOK D-010, 2021) e (ISO 16530-1, 2017).

Como as evidências obtidas durante a etapa de produção de um poço de petróleo advém de testes, monitoramento ou inspeções, estas podem não ser completas, ou seja, não ser $100 \%$ conclusivas sobre o modo de falha testado, uma vez que pode haver mecanismos de falha que ativam determinado modo de falha que não são passíveis de verificação durante o teste.

Testes não perfeitos podem ser modelados introduzindo um fator de cobertura do teste, para representar a fração de falhas que podem ser detectadas durante um teste, ou uma probabilidade de falha independente do teste, para representar um valor de probabilidade de falha na demanda devido a uma falha não detectável em teste, mas revelada sob demanda real (NOG 070, 2018).

Outro fato relevante é que um teste pode induzir degradação no componente, nesse aspecto (Hafver, Oliveria, \& Pedersen, 2019) discutem intervalos ótimos de teste considerando possíveis modelos para representar o aumento da taxa de falha devido ao dano, como por exemplo o modelo de dano linear em que a taxa de falha é aumentada por um valor fixo a cada teste e o modelo de dano composto em que a taxa de falha é multiplicada por um fator a cada teste. (Colombo, Abreu, \& Duim, 2019) realizaram uma comparação entre a evolução da probabilidade de falha média na demanda de um Blowout Preventer (BOP) em função do tempo, para uma política de testes sem considerar e considerando o efeito de degradação induzida pelo teste. 


\subsection{ETAPA 9: ESCOLHA DA BASE COMPARATIVA}

Por fim, os resultados podem ser comparados com algum valor prescritivo, como por exemplo, a probabilidade máxima de perda de contenção aceitável ou com alguma base comparativa.

A definição de uma probabilidade máxima de perda de contenção aceitável é bastante complexa e depende de diversos fatores, tratando-se mais de uma análise de teoria da decisão do que de risco. Deve-se levar em conta não apenas a probabilidade de falha como também a consequência da falha (e sua severidade) para uma avaliação completa do risco, bem como o grau de tolerabilidade ao risco da empresa, as relações de custo-benefício e o contexto em que o cenário de risco está inserido. Tal valor de probabilidade pode ou não ter alguma referência na legislação ou em normas da indústria e varia de acordo com o apetite ao risco e a situação concreta em análise, devendo se levar em conta o conceito de redução de risco para a região ALARP ( "As Low As Reasonably Practicable”). Segundo (Kaplan \& Garrick, 1981) o risco não pode ser dito como aceitável ou não isoladamente, mas apenas em combinação com os custos e benefícios que são associados a esse risco. E conforme (Apostolakis, 2004) o processo de tomada de decisão de questões relacionadas à segurança é informado pelo risco (risk-informed) e não baseado no risco (risk-based).

Em todo caso, para auxiliar a decisão sobre a aceitabilidade ou não do risco é importante haver alguma referência para comparação e, na ausência de valores prescritivos que possam ser utilizados como probabilidade máxima de perda de contenção, uma proposta é que os resultados obtidos nas Etapas 7 e 8 (descritas anteriormente) sejam comparados com o previsto na fase de projeto do poço ou com o constatado e aceito após sua construção e início da operação de produção.

A análise comparativa utilizando o mesmo modelo proposto como referência tem algumas vantagens, como por exemplo: mesmo que dados de entrada tenham viés ou não sejam tão representativos é esperada uma menor sensibilidade no resultado final, pois caso haja uma superestimação (ou subestimação) de dados de entrada essa variação também afetará a curva comparativa. Outra vantagem é que se pode refinar mais ou menos a modelagem do sistema que a análise comparativa continua válida, bastando utilizar a 
própria modelagem do sistema para obter os resultados do caso real e do caso base, a fim de compará-los de forma relativa.

Existem várias possibilidades para a definição de uma base comparativa (ou caso base): uma proposta é a utilização apenas dos elementos que constituem os dois conjuntos solidários de barreira do poço (CSBs); outra é considerar também demais barreiras redundantes existentes além dos dois CSBs. Além disso, deve-se previamente definir quais são os testes, monitoramentos e inspeções que constituirão o caso de referência (caso base). (Colombo, 2018), por exemplo, usa como referência a curva gerada caso todos os testes previstos na política gerenciamento de barreiras aprovada e aceita pela empresa sejam sempre positivos durante a vida útil do poço, ou seja, sempre que a barreira é testada conclui-se que ela está intacta. Segundo (Colombo, 2018):

A razão da escolha deste caso como referência se dá pelo fato de que se todos os testes periódicos fossem bem-sucedidos a operadora não iria questionar-se sobre a integridade do poço e manteria o mesmo em produção. Logo, entendese que a curva de probabilidade gerada desta forma seria uma curva de probabilidade de vazamento amplamente aceitável. 


\section{APLICAÇÃO DA METOdOLOGIA}

Neste capítulo será realizado um estudo de caso com aplicação das nove etapas da metodologia em um poço de petróleo submarino típico do pré-sal brasileiro, sendo detalhadas as premissas e considerações feitas neste trabalho. No capítulo seguinte serão explorados os resultados obtidos desta aplicação e como eles podem auxiliar na tomada de decisão quanto à continuidade operacional de poços em estado degradado.

\section{- Etapa 1: Identificação dos Caminhos de Vazamento}

Como o foco desta dissertação é a confiabilidade relativa entre o projeto e a operação só serão considerados os caminhos de vazamento em que existam elementos de barreira passíveis de monitoramento, inspeção ou teste na etapa de produção do ciclo de vida do poço. Dessa forma, serão avaliados os caminhos de vazamento pela coluna e pelo anularA do poço e as interligações entre eles (Figura 14). Os demais caminhos de vazamento existentes no poço, inclusive rocha e anulares externos são caminhos formados por elementos (ex.: cimento e rocha) em que nenhuma ação de monitoramento, inspeção ou teste é feita durante a fase operacional, de forma que não existirão evidências que possibilitem atualizar a avaliação da probabilidade de falha por esses caminhos durante a fase operacional, mantendo a avaliação de confiabilidade completamente dependente do projeto e construção do poço. Como a metodologia desse trabalho é baseada na confiabilidade relativa entre o previsto em projeto e o executado na operação tais possíveis caminhos de vazamento não tem relevância e não serão discutidos.

Figura 14 - Caminhos de vazamento considerados

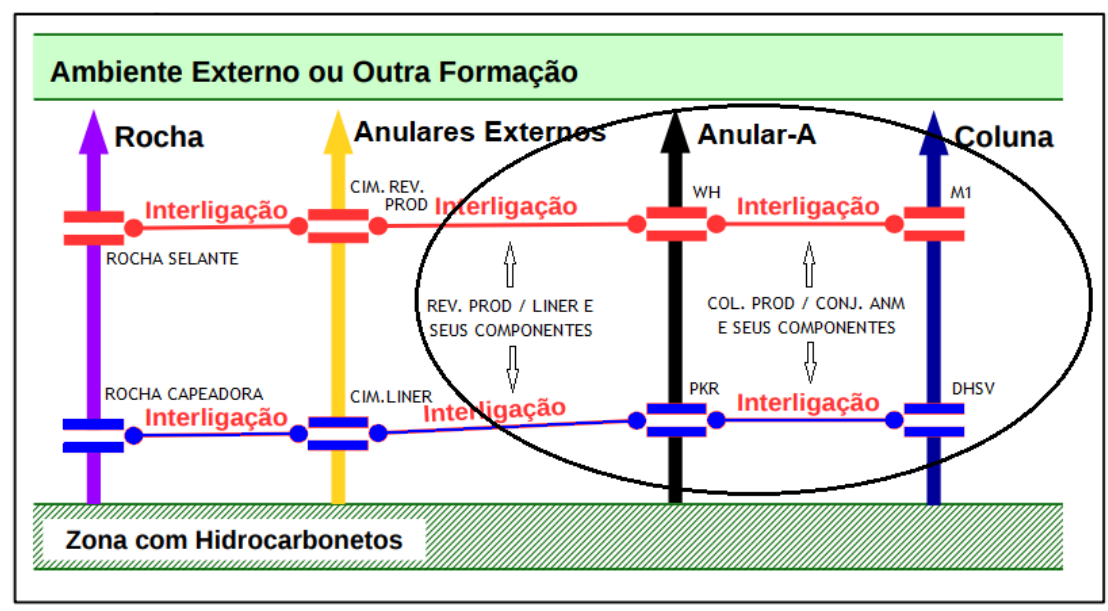

Fonte: adaptado de (Mendes, Fonseca, \& Miura, 2016) 


\section{- Etapa 2: Representação do Poço em Modelo Esquemático}

Foi proposto o seguinte modelo esquemático para o poço exemplo (poço de petróleo submarino típico do pré-sal brasileiro na etapa de produção), conforme Figura 15.

Figura 15 - Modelo Esquemático do Poço Exemplo

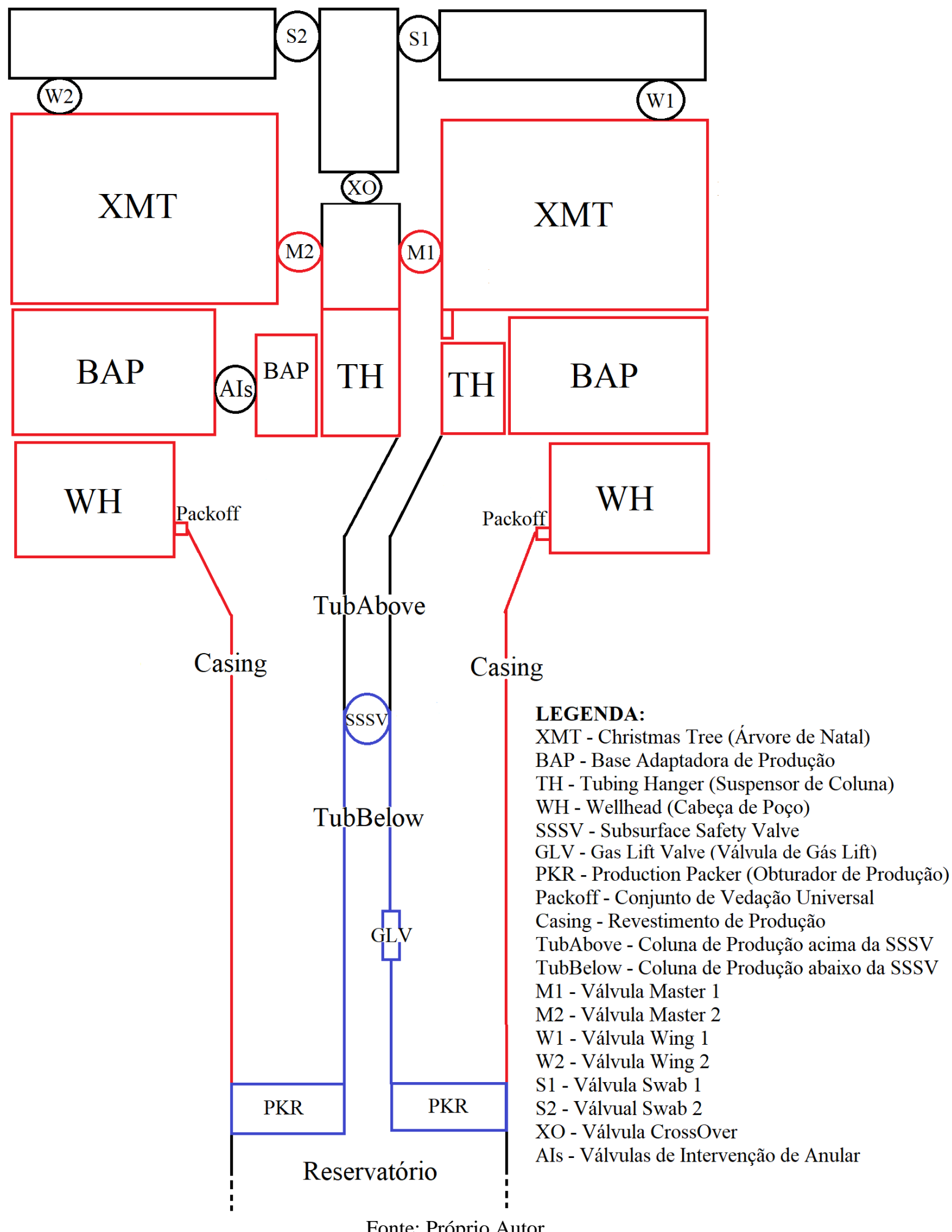

Fonte: Próprio Autor 
Importante notar que no modelo proposto os elementos mais a jusante no caminho da coluna de produção são as válvula Wing 1 (W1) e a Swab 1 (S1), de forma que caso não seja possível impedir que o fluxo de óleo chegue a jusante da válvula Wing 1 ou da Swab 1 é considerado que o poço perdeu a integridade (perda de contenção para o meio externo às barreiras do poço), ainda que o mesmo esteja conectado a um duto submarino e o óleo não atinja diretamente o mar. Foi escolhida esta abordagem pois o duto submarino não faz parte da integridade de poço, mas sim do sistema submarino de interligação com a plataforma de produção. Além disso, o fato de não ser possível impedir que o fluxo de óleo chegue à jusante da válvula Wing 1 (ou da Swab 1) pode dificultar e aumentar significativamente o risco de uma intervenção com sonda para manutenção do poço.

Também foi considerado que caso não seja possível impedir que o fluxo de óleo chegue à parte externa do Casing (Revestimento de Produção) é tido que o poço perdeu sua integridade (perda de contenção para o meio externo às barreiras do poço) ainda que o óleo fique contido nos demais revestimentos ou cimentação. Esta abordagem é conservadora pois nenhuma verificação de integridade dos demais revestimentos ou cimentação é realizada durante a fase de produção (não sendo possível obter evidências que possibilitariam atualizar a avaliação da probabilidade de falha destes componentes). Ademais, uma falha no revestimento de produção pode dificultar e aumentar significativamente o risco de uma intervenção com sonda para manutenção do poço.

\section{- Etapa 3: Definição dos Modos de Falha}

Segue tabela com os elementos de barreira e respectivos modos de falha considerados. 
Tabela 3 - Elementos de barreira e respectivos modos de falha

\begin{tabular}{|c|c|c|}
\hline $\begin{array}{l}\text { Elemento de } \\
\text { Barreira }\end{array}$ & Descrição & Modo de Falha \\
\hline GLV & Válvula de Gás Lift & Vazamento da Posição Fechada (LCP) \\
\hline TubBelow & Coluna de produção/injeção abaixo da SSSV & Comunicação Coluna-Anular (TAC) \\
\hline PKR & Obturador de Produção & $\begin{array}{l}\text { Vazamento através do Obturador de } \\
\text { Produção (LAP) }\end{array}$ \\
\hline \multirow{2}{*}{ SSSV } & \multirow{2}{*}{ Válvula de Segurança de Subsuperfície } & Falha em Fechar (FTC) \\
\hline & & Vazamento na Posição Fechada (LCP) \\
\hline TubAbove & Coluna de produção/injeção acima da SSSV & Comunicação Coluna-Anular (TAC) \\
\hline Casing & Revestimento de Produção & Vazamento Externo (EL) \\
\hline Packoff(CVU) & Conjunto de Vedação Universal & Vazamento Externo (EL) \\
\hline WH & Interface Cabeça de Poço / Base Adaptadora de Produção & Vazamento Externo (EL) \\
\hline XMT & Interface Árvore de Natal / Base Adaptadora de Produção & Vazamento Externo (EL) \\
\hline TH & Interface Suspensor Coluna / Base Adaptadora Produção & Vazamento Interno (IL) \\
\hline TH_Anu & Junta ou vedação do Anular ao Suspensor de Coluna & Vazamento Interno (IL) \\
\hline TH_Tub & Junta ou vedação da Coluna ao Suspensor de Coluna & Vazamento Interno (IL) \\
\hline \multirow{3}{*}{ M1 } & \multirow{3}{*}{ Válvula Master 1} & Vazamento Externo (EL) \\
\hline & & Falha em Fechar (FTC) \\
\hline & & Vazamento na Posição Fechada (LCP) \\
\hline \multirow{3}{*}{ W1 } & \multirow{3}{*}{ Válvula Wing 1} & Vazamento Externo (EL) \\
\hline & & Falha em Fechar (FTC) \\
\hline & & Vazamento na Posição Fechada (LCP) \\
\hline \multirow{3}{*}{ M2 } & \multirow{3}{*}{ Válvula Master 2} & Vazamento Externo (EL) \\
\hline & & Falha em Fechar (FTC) \\
\hline & & Vazamento na Posição Fechada (LCP) \\
\hline \multirow{3}{*}{ AIs } & \multirow{3}{*}{ Válvulas de Intervenção de Anular } & Vazamento Externo (EL) \\
\hline & & Falha em Fechar (FTC) \\
\hline & & Vazamento na Posição Fechada (LCP) \\
\hline \multirow{3}{*}{ W2 } & \multirow{3}{*}{ Válvula Wing 2} & Vazamento Externo (EL) \\
\hline & & Falha em Fechar (FTC) \\
\hline & & Vazamento na Posição Fechada (LCP) \\
\hline \multirow{3}{*}{ XO } & \multirow{3}{*}{ Válvula CrossOver } & Vazamento Externo (EL) \\
\hline & & Falha em Fechar (FTC) \\
\hline & & Vazamento na Posição Fechada (LCP) \\
\hline S1 & Válvula Swab 1 & Vazamento Externo (EL) \\
\hline $\mathbf{S 2}$ & Válvula Swab 2 & Vazamento Externo (EL) \\
\hline
\end{tabular}

Fonte: Próprio Autor

Obs.: Conforme tabela acima foi utilizado um total de 33 modos de falhas para a modelagem.

As válvulas da Árvore de Natal, por exemplo, podem falhar de outras formas além dos modos de falha considerados. Outras formas previstas no OREDA (SINTEF, 2015) são “Fail to open/unlock (FTO)", "Plugged/choked (PLU)" ou "Spurious operation (SPO)", entretanto estes modos de falha apesar de impactarem a operação do poço não afetam a integridade, uma vez que apenas mantém a válvula em sua posição de falha segura, ou seja, fechada.

De forma geral, os modos de falha considerados são os que levam a barreira a não cumprir com sua função de segurança para a integridade do poço. 
Todas as falhas de componentes foram modeladas como não-detectáveis (undetected failure), ou seja, não são imediatamente evidentes. Os modos de falha mapeados são detectados apenas através de testes e inspeções periódicas. Por exemplo: uma falha perigosa em alguma das válvulas da Árvore de Natal Molhada (ANM) pode ocorrer a qualquer momento, mas só será detectada quando da execução do próximo teste; e um vazamento externo na ANM só será detectado quando da execução da inspeção visual por Remotely Operated Underwater Vehicle ou ROV (a não ser no caso de um vazamento catastrófico que cesse o fluxo de óleo do poço para a plataforma e leve a rápida formação e visualização de mancha de óleo na superfície do mar), o que é uma premissa consistente para poços submarinos em grande profundidade e com baixo nível de instrumentação, pois grande faixa de vazões de vazamento não são detectadas facilmente por parâmetros operacionais do poço, mas apenas em inspeções periódicas com ROV ou por visualização de mancha de óleo seguida de investigação de onde é a fonte do vazamento.

Segue um detalhamento dos modos de falha utilizados:

- Comunicação Coluna-Anular (TAC - Tubing-Annulus Leak): modo de falha associado a comunicação entre o caminho da coluna e o caminho do anular-A do poço.

- Vazamento através do Obturador de Produção (LAP - Leakage Across Packer): modo de falha associado a passagem de fluido pelo Obturador de Produção, comunicando o fluido da formação com o anular-A do poço, tendo um efeito prático equivalente a Comunicação Coluna-Anular (TAC).

- Falha em Fechar (FTC - Fail to Close): modo de falha associado a uma válvula de segurança, que opera aberta, não fechar quando requerida.

- Vazamento na Posição Fechada (LCP - Leakage in Closed Position): modo de falha associado a uma válvula de segurança permitir certa passagem de fluido mesmo na posição fechada.

- Vazamento Externo (EL - External Leakage): modo de falha associado a uma perda de contenção para o meio externo às barreiras do poço (meio-ambiente).

- Vazamento Interno (IL - Internal Leakage): modo de falha associado a uma perda de contenção da barreira comunicando o fluido com outra cavidade ainda interna ao poço. 
Neste trabalho foram considerados apenas modos de falha relacionados diretamente a características intrínsecas dos elementos de barreira; não foram consideradas falhas resultantes de erro humano ou causas externas.

Por exemplo, o risco de eventos catastróficos na ANM (ex.: arrancamento ou desconexão espúria) e riscos motivados por causas externas (ex.: queda de objetos ou arraste de âncoras) não foram considerados. Dessa forma, o fato de um poço ser isolado (ou seja, o poço estar distante de outra instalação submarina ou flutuante) ou não-isolado não impacta em sua curva de probabilidade de falha e a importância do dispositivo de subsuperfície (DSSS) é reduzida (Alves, 2012).

Outra observação é que as válvulas AI1 e AI2 foram modeladas como sendo itens redundantes, mas compondo um único elemento (elemento AIs). Essa abordagem foi escolhida pois durante a etapa de produção do poço os testes funcionais e de estanqueidade realizados usualmente verificam a integridade das AIs (conjunto AI1 e AI2) simultaneamente e não de cada válvula individualmente.

\section{- Etapa 4: Construção do Diagrama de Barreiras}

Foi elaborado o seguinte diagrama de barreiras para o poço exemplo (poço de petróleo submarino típico do pré-sal brasileiro na etapa de produção):

Figura 16 - Diagrama de Barreiras do Poço Exemplo

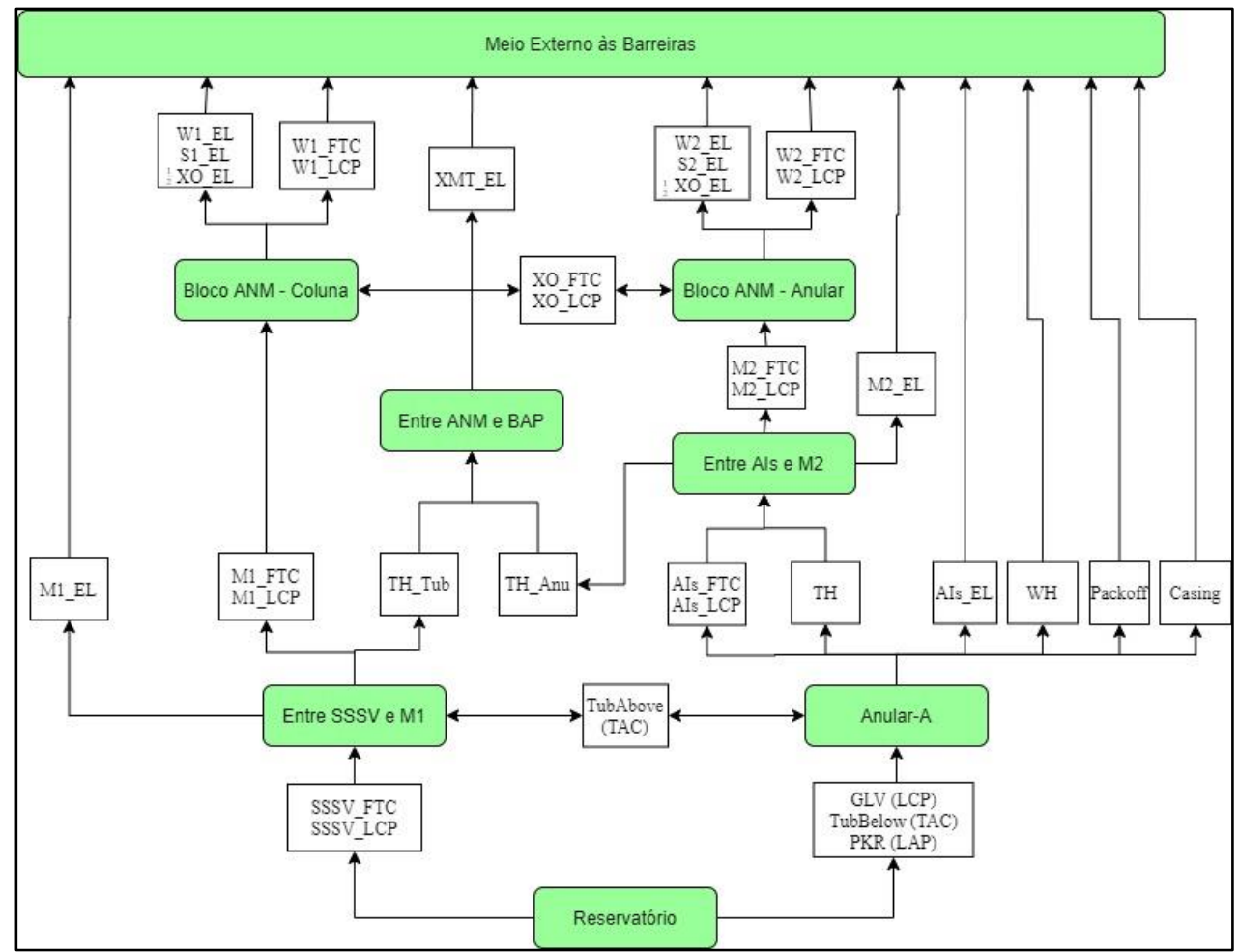

Fonte: Próprio Autor 
Os retângulos em branco são os possíveis modos de falha que levam a comunicação entre blocos em verde que representam as cavidades internas do poço.

Por vezes, existe mais de um modo de falha em um retângulo branco, isso significa que se qualquer um dos modos de falha ocorrer haverá a comunicação entre as cavidades (em verde). Também é possível constatar que, para haver comunicação entre o reservatório e o meio externo às barreiras, existe a necessidade de falhar no mínimo dois componentes por qualquer caminho de vazamento, o que significa que o poço exemplo possui dois conjuntos solidários de barreiras para os caminhos de vazamento mapeados.

Dentre os possíveis caminhos de vazamento em que apenas duas falhas levam ao vazamento ao meio externo às barreiras podemos citar, por exemplo: o travamento aberto da DHSV (SCSSV_FTC) seguido de um vazamento externo na região da M1 (M1_EL) ou uma passagem através do packer de produção (PKR_LAP) seguida de uma falha de vedação do packoff (Packoff_EL). Percebe-se que o vazamento para o meio ambiente pode apresentar diferentes níveis de severidade da consequência a depender das restrições ao fluxo existentes em cada barreira de cada caminho de vazamento identificado. Tal discussão a respeito das consequências não é escopo deste trabalho.

Com o diagrama de barreiras elaborado é possível uma visualização simplificada de todas as possibilidades de caminho de vazamento entre o reservatório e o meio externo às barreiras do poço (meio ambiente), o que auxilia na modelagem da confiabilidade do sistema.

\section{- Etapa 5: Modelagem do Sistema}

Neste trabalho a modelagem considera os componentes de barreira mais relevantes de poços em operação para a gestão de integridade. Para tanto é utilizado um Diagrama de Blocos de Confiabilidade (RBD - Reliability Block Diagram). Outras técnicas de modelagem de sistemas também poderiam ser utilizadas, todavia a escolha do Diagrama de Blocos se mostrou bastante adequada aos objetivos do trabalho e coerente com o fluxo proposto na Figura 12, o qual poderia ser respondido da seguinte forma para tal sistema:

1) Necessidade de Resultados Quantitativos? SIM, trata-se de uma análise de confiabilidade. 
2) Dependências Fortes? NÃO, de forma geral as barreiras de segurança de poços são independentes, quando existe alguma causa de falha comum pode-se utilizar a modelagem do fator beta por exemplo.

3) Componentes Reparáveis? NÃO, a análise considera que o tempo de missão termina quando o poço é entregue para reparação com sonda, dessa forma a disponibilidade do sistema é equivalente a confiabilidade.

4) Grande Número de Estados? SIM, foram identificados 33 modos de falha para a modelagem.

5) Relevância do Modelo Série-Paralelo? SIM, um poço possui barreiras em série por determinado caminho de vazamento com associações em paralelo formando os conjuntos solidários de barreiras.

Segue na Figura 17 o Diagrama de Blocos proposto para modelagem do sistema. O modelo é composto por 30 blocos e as relações funcionais entre eles, visando representar a integridade do poço em produção considerando os caminhos de vazamento pela coluna, anular-A e interligações entre eles.

Cada bloco representa um modo de falha de componente, os quais foram detalhados na Tabela 3.

Atentar que, para simplificação do diagrama de blocos, os modos de falha Vazamento Externo (EL) dos componentes W1, S1, W2, S2 e XO foram acoplados em apenas dois blocos de confiabilidade, a saber: [W1_EL + S1_EL + $\frac{1}{2}$ XO_EL] e [W2_EL + S2_EL + $\frac{1}{2}$ XO_EL]. Por isso, apesar de haver 33 modos de falha listados na Tabela 3 existem apenas 30 blocos no diagrama. Essa simplificação não traz perda para o modelo, pois a verificação do modo de falha "Vazamento Externo (EL)" nesses componentes é feita em conjunto (e não individualmente) pela verificação do bloco da ANM: lado da produção $>$ [W1_EL + S1_EL + $\left.{ }_{2}^{1} \mathrm{XO} \_E L\right]$ e lado do anular -> [W2_EL + S2_EL + $\left.\frac{1}{2} \mathrm{XO} \_E L\right]$. 
Figura 17 - Diagrama de Blocos de Confiabilidade do Poço Exemplo

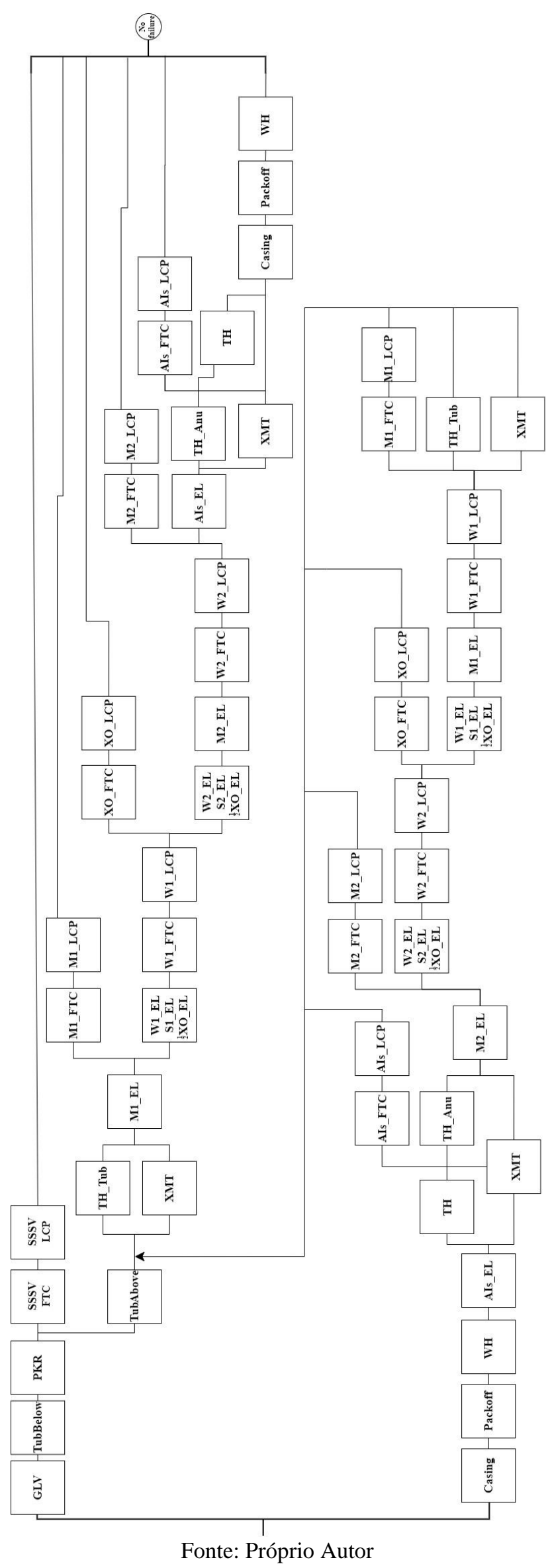




\section{- Etapa 6: Dados de Confiabilidade dos Componentes}

Foram utilizados valores de taxas de falha constantes provenientes de bancos de dados genéricos da indústria, obtidos de três fontes: OREDA (SINTEF, 2015), WellMaster RMS Project (Molnes \& Strand, 2009) e (Colombo, et al., 2020).

Os valores de taxa de falha publicados em (SINTEF, 2015) são dados genéricos representando uma média da experiência das empresas de óleo e gás participantes do projeto OREDA até sua fase IX (2006-2008). Em (Molnes \& Strand, 2009) também são apresentados apenas valores médios de taxa de falha para componentes de poço relacionados às empresas participantes do WellMaster RMS Project até sua fase VI (2005-2009).

Para alguns componentes considerados não existe uma referência direta das taxas de falha nos bancos de dados utilizados, entretanto são de componentes que possuem semelhança com algum outro componente, dessa forma a taxa de falha foi estimada por similaridade. Por exemplo, a válvula AI é uma válvula gaveta que fica instalada na BAP, mas que possui a mesma forma construtiva e de atuação hidráulica que a válvula gaveta M2 que fica instalada na ANM, sendo assim é de se esperar que suas taxas de falha tenham valores semelhantes. Da mesma forma, a taxa de falha da Interface Cabeça de Poço / Base Adaptadora de Produção (WH) foi considerada a mesma da Interface Árvore de Natal / Base Adaptadora de Produção (XMT) visto que se referem a conexões similares.

Seguem na Tabela 4 os valores utilizados de taxa de falha para cada modo de falha com a respectiva referência: 
Tabela 4 - Taxas de Falha e referências

\begin{tabular}{|c|c|c|c|}
\hline $\begin{array}{l}\text { Elemento de } \\
\text { Barreira }\end{array}$ & Modo de Falha & \begin{tabular}{|l|} 
falhas \\
$/ 1^{6}$ \\
horas
\end{tabular} & Referência \\
\hline GLV & Vazamento da Posição Fechada (LCP) & 10,152 & Molnes \& Strand (2009) \\
\hline TubBelow $-2 \mathrm{~km}$ & Comunicação Coluna-Anular (TAC) & 0,598 & Molnes \& Strand (2009) \\
\hline PKR & $\begin{array}{l}\text { Vazamento através do Obturador de } \\
\text { Produção (LAP) }\end{array}$ & 0,077 & Molnes \& Strand (2009) \\
\hline \multirow{2}{*}{ SSSV } & Falha em Fechar (FTC) & 0,965 & Molnes \& Strand (2009) \\
\hline & Vazamento na Posição Fechada (LCP) & 1,434 & Molnes \& Strand (2009) \\
\hline TubAbove $-30 \mathrm{~m}$ & Comunicação Coluna-Anular (TAC) & 0,009 & Molnes \& Strand (2009) \\
\hline Casing & Vazamento Externo (EL) & 0,082 & Colombo et al. (2020) \\
\hline Packoff(CVU) & Vazamento Externo (EL) & 0,06 & SINTEF (2015) \\
\hline WH & Vazamento Externo (EL) & 0,14 & SINTEF (2015) - Similaridade com XMT \\
\hline XMT & Vazamento Externo (EL) & 0,14 & SINTEF (2015) \\
\hline TH & Vazamento Interno (IL) & 0,05 & SINTEF (2015) \\
\hline TH_Anu & Vazamento Interno (IL) & 0,05 & SINTEF (2015) - Similaridade com TH \\
\hline TH_Tub & Vazamento Interno (IL) & 0,05 & SINTEF (2015) - Similaridade com TH \\
\hline \multirow{3}{*}{ M1 } & Vazamento Externo (EL) & 0,01 & SINTEF (2015) \\
\hline & Falha em Fechar (FTC) & 0,11 & SINTEF (2015) \\
\hline & Vazamento na Posição Fechada (LCP) & 0,19 & SINTEF (2015) \\
\hline \multirow{2}{*}{ W1 } & Falha em Fechar (FTC) & 0,11 & SINTEF (2015) \\
\hline & Vazamento na Posição Fechada (LCP) & 0,19 & SINTEF (2015) \\
\hline \multirow{3}{*}{ M2 } & Vazamento Externo (EL) & 0,01 & SINTEF (2015) \\
\hline & Falha em Fechar (FTC) & 0,11 & SINTEF (2015) \\
\hline & Vazamento na Posição Fechada (LCP) & 0,19 & SINTEF (2015) \\
\hline \multirow{3}{*}{ AI } & Vazamento Externo (EL) & 0,01 & SINTEF (2015) - Similaridade com M2 \\
\hline & Falha em Fechar (FTC) & 0,11 & SINTEF (2015) - Similaridade com M2 \\
\hline & Vazamento na Posição Fechada (LCP) & 0,19 & SINTEF (2015) - Similaridade com M2 \\
\hline \multirow{2}{*}{ W2 } & Falha em Fechar (FTC) & 0,11 & SINTEF (2015) \\
\hline & Vazamento na Posição Fechada (LCP) & 0,19 & SINTEF (2015) \\
\hline \multirow{2}{*}{ XO } & Falha em Fechar (FTC) & 0,11 & SINTEF (2015) \\
\hline & Vazamento na Posição Fechada (LCP) & 0,19 & SINTEF (2015) \\
\hline EL1->W1+S1+ $\frac{1}{2} \mathrm{XO}$ & Vazamento Externo (EL) & 0,025 & SINTEF (2015) \\
\hline EL2->W2+S2+ $\mathrm{x}$ XO & Vazamento Externo (EL) & 0,025 & SINTEF (2015) \\
\hline
\end{tabular}

Fonte: Próprio Autor

Importante destacar que os dados de falha OREDA (SINTEF, 2015) são separados em categorias de severidade, a saber:

- Falha Crítica: uma falha que causa a perda imediata e completa da capacidade do equipamento em executar sua função.

- Falha Degradada: uma falha que não é crítica, mas impede o equipamento de executar sua função dentro das especificações. Tal falha normalmente, mas não necessariamente, é gradual ou parcial e pode evoluir para uma falha crítica com o tempo.

- Falha Incipiente: uma falha que não cause imediatamente a perda da capacidade do equipamento em executar sua função, mas que, se não for tratada, poderá resultar em uma falha crítica ou degradada num futuro próximo. 
Quanto aos dados procedentes do OREDA foram utilizadas as falhas críticas. Os dados de falha degradada e incipiente não foram usados neste trabalho, pois, no caso de ocorrência desta falha, o equipamento continua a executar sua função, seja de forma degradada ou seja dentro do especificado.

Todas as simulações neste trabalho foram realizadas considerando o tempo até a falha de um componente representado por uma distribuição exponencial, o que resulta em uma taxa de falha constante, mas é possível estender as simulações para a consideração de taxas de falha variáveis no tempo utilizando distribuições como Weibull, Normal, Lognormal para a modelagem do tempo até a falha do componente.

A distribuição exponencial foi utilizada pois é possível obter uma estimativa do valor médio da taxa de falha por meio de bancos de dados da indústria e porque representa grande parte da vida operacional de um componente (região central da curva da banheira). Se a empresa operadora do poço tiver um banco de dados com o histórico operacional e as falhas dos componentes, é possível realizar uma análise de dados para verificar qual(is) a(s) função(ões) de densidade de probabilidade mais adequada(s) para representar o comportamento do componente ao longo do tempo até a falha.

\section{- Etapa 7: Cálculo da Confiabilidade do Sistema}

A modelagem do poço exemplo via Diagrama de Blocos (Figura 17) proposta neste trabalho é composta por 30 blocos (modos de falha de componentes). Para o cálculo da confiabilidade do sistema foi primeiro identificado o conjunto de path-sets. No caso concreto foram identificados 29 path-sets mínimos.

Neste trabalho os 29 path-sets mínimos identificados foram transformados em um conjunto disjunto para possibilitar o cálculo computacional da confiabilidade exata do sistema em um tempo computacional aceitável. Foi utilizado o algoritmo proposto por (Abraham, 1979) e rememorado em (Abreu \& Martins, 2017).

Os cálculos de confiabilidade são executados para a expressão equivalente obtida de união de produtos disjuntos entre si, a qual simplifica substancialmente o cálculo da probabilidade exata de ocorrência do evento topo.

O algoritmo foi programado em Python 3 e encontra-se no APÊNDICE. 
Sem executar a transformação dos sets em um conjunto disjunto o cálculo exato da confiabilidade seria inviável devido ao elevado tempo computacional necessário, uma vez que pelo método combinatório seriam necessárias $2^{30}$ combinações e pela equação exata de path-sets não disjuntos seriam $2^{28}$ termos. Outra opção seria a aproximação de eventos raros no cálculo da confiabilidade por cut-sets, mas esta não traz resultados satisfatórios, pois nem todos os eventos podem ser considerados raros. Por exemplo, uma válvula de gás lift (VGL) com uma taxa de falha constante na ordem de grandeza de 10 falhas / $10^{6}$ horas, leva a uma confiabilidade de $\sim 77 \%$ ao final de 3 anos.

É importante notar que adotou-se trabalhar com path-sets em vez de cut-sets devido a característica do sistema modelado, que, por possuir mais característica de um sistema em série do que em paralelo, apresenta menor número de path-sets do que de cut-sets. Porém, esta escolha só foi possível devido a implementação da transformação do conjunto de sets em um conjunto disjunto para cálculo exato da probabilidade de sucesso, caso contrário a análise via path-sets traria o limite superior para a confiabilidade do sistema, o que não teria valia alguma.

Segundo (Jensen \& Bard, 2003, pp. 14 do capítulo 26, tradução nossa):

Estruturas complexas terão diferentes números de cut-sets e path-sets mínimos. Como uma análise exata pode ser feita usando qualquer um deles, é melhor usar o método com o menor número. Por exemplo, um sistema em série com n componentes possui $\mathrm{n}$ cut-sets, mas apenas um path-set. Um sistema em paralelo com $n$ componentes possui $n$ path-sets, mas apenas um cut-set.

Todos os componentes do sistema são considerados independentes não sendo analisadas possíveis causas comuns de falha.

- Etapa 8: Atualização da Confiabilidade com Evidências (Teorema de Bayes)

Com a modelagem do poço elaborada foi feita a atualização da informação de confiabilidade instantânea do sistema a partir de novas informações (evidências) de sucesso ou falha de seus componentes usando o Teorema de Bayes e os resultados foram comparados com a confiabilidade previamente estabelecida pelo projeto do poço. Seguem algumas premissas da metodologia: 
- O tempo de missão da análise termina quando o poço é entregue para manutenção com sonda (Well Handover), dessa forma pode-se dizer que o sistema é não reparável durante seu tempo de missão, então a confiabilidade coincide com a disponibilidade;

- Não é considerada degradação de componentes, apenas falha ou não-falha;

- Durante a etapa de produção apenas parte dos elementos de barreira são testados, alguns elementos de barreira são testados apenas na construção do poço ou em intervenções com sonda;

- É assumido que a probabilidade de falha de componentes não é influenciada pelo fato de o poço estar produzindo ou fechado;

- O foco são os elementos técnicos da integridade de poço, dessa forma o erro humano está fora do escopo deste trabalho;

- Foi considerado que a única forma de identificar falha ou sucesso (não-falha) de um componente é via teste, sendo este $100 \%$ preciso na identificação de se o componente testado está ou não falho;

- Não foi considerada a possibilidade de testes induzirem danos nos componentes;

Na seção 5.3 será discutido a flexibilização das premissas de que os testes são perfeitos (com 100\% de cobertura) e a não indução de danos aos componentes durante os testes.

\section{- Etapa 9: Escolha da Base Comparativa}

A metodologia desta dissertação propõe que os resultados sejam comparados com o previsto no projeto do poço. Sendo assim, para definir uma base comparativa foi construído um caso de referência (caso base) no qual a confiabilidade ao longo do tempo foi calculada considerando todos os elementos de barreira modelados (conforme disposto no Diagrama de Blocos presente na Figura 17) e uma política padrão de testes desses componentes para a etapa de produção, a qual deve ser entendida como aprovada e aceita pelo gestor de integridade do poço. Para o Poço Exemplo foi escolhida uma política de testes de elementos de barreira conforme a Tabela 5 .

Para o cálculo da curva de confiabilidade do caso base é considerado que todos os testes e inspeções previstos para etapa de produção são atendidos e que o resultado é sempre positivo, ou seja, a barreira sempre que testada é verificada como íntegra. 
Tabela 5 - Periodicidade de Testes para o Poço Exemplo

\begin{tabular}{|c|c|c|}
\hline $\begin{array}{l}\text { Elemento de } \\
\text { Barreira }\end{array}$ & Modo de Falha & $\begin{array}{l}\text { Intervalo de Teste padrão durante a Etapa de } \\
\text { Produção do poço }\end{array}$ \\
\hline GLV & Vazamento da Posição Fechada (LCP) & anual (teste de pressão) \\
\hline TubBelow & Comunicação Coluna-Anular (TAC) & anual (teste de pressão) \\
\hline PKR & $\begin{array}{l}\text { Vazamento através do Obturador de } \\
\text { Produção (LAP) }\end{array}$ & anual (teste de pressão) \\
\hline \multirow{2}{*}{ SSSV } & Falha em Fechar (FTC) & anual (teste funcional) \\
\hline & Vazamento na Posição Fechada (LCP) & anual (teste de estanqueidade) \\
\hline TubAbove & Comunicação Coluna-Anular (TAC) & anual (teste de pressão) \\
\hline Casing & Vazamento Externo (EL) & $\begin{array}{l}\text { somente com sonda durante workover - não é testado } \\
\text { durante a etapa de produção, a não ser que existam } \\
\text { outras falhas no poço que exponham este elemento }\end{array}$ \\
\hline $\operatorname{Packoff}(\mathrm{CVU})$ & Vazamento Externo (EL) & $\begin{array}{l}\text { somente com sonda durante } \text { workover - não é testado } \\
\text { durante a etapa de produção, a não ser que existam } \\
\text { outras falhas no poço que exponham este elemento }\end{array}$ \\
\hline WH & Vazamento Externo (EL) & $\begin{array}{l}\text { somente com sonda durante workover - não é testado } \\
\text { durante a etapa de produção, a não ser que existam } \\
\text { outras falhas no poço que exponham este elemento }\end{array}$ \\
\hline XMT & Vazamento Externo (EL) & $\begin{array}{l}\text { somente com sonda durante workover - não é testado } \\
\text { durante a etapa de produção, a não ser que existam } \\
\text { outras falhas no poço que exponham este elemento }\end{array}$ \\
\hline TH & Vazamento Interno (IL) & $\begin{array}{l}\text { somente com sonda durante workover - não é testado } \\
\text { durante a etapa de produção, a não ser que existam } \\
\text { outras falhas no poço que exponham este elemento }\end{array}$ \\
\hline TH_Anu & Vazamento Interno (IL) & $\begin{array}{l}\text { somente com sonda durante workover - não é testado } \\
\text { durante a etapa de produção, a não ser que existam } \\
\text { outras falhas no poço que exponham este elemento }\end{array}$ \\
\hline TH_Tub & Vazamento Interno (IL) & $\begin{array}{l}\text { somente com sonda durante workover - não é testado } \\
\text { durante a etapa de produção, a não ser que existam } \\
\text { outras falhas no poço que exponham este elemento }\end{array}$ \\
\hline \multirow{3}{*}{ M1 } & Vazamento Externo (EL) & trienal (inspeção visual) \\
\hline & Falha em Fechar (FTC) & anual (teste de funcional) \\
\hline & Vazamento na Posição Fechada (LCP) & trienal (teste de estanqueidade) \\
\hline \multirow{2}{*}{ W1 } & Falha em Fechar (FTC) & anual (teste de funcional) \\
\hline & Vazamento na Posição Fechada (LCP) & trienal (teste de estanqueidade) \\
\hline \multirow{3}{*}{ M2 } & Vazamento Externo (EL) & trienal (inspeção visual) \\
\hline & Falha em Fechar (FTC) & anual (teste de funcional) \\
\hline & Vazamento na Posição Fechada (LCP) & trienal (teste de estanqueidade) \\
\hline \multirow{3}{*}{ AI } & Vazamento Externo (EL) & trienal (inspeção visual) \\
\hline & Falha em Fechar (FTC) & anual (teste de funcional) \\
\hline & Vazamento na Posição Fechada (LCP) & trienal (teste de estanqueidade) \\
\hline \multirow{2}{*}{ W2 } & Falha em Fechar (FTC) & anual (teste de funcional) \\
\hline & Vazamento na Posição Fechada (LCP) & trienal (teste de estanqueidade) \\
\hline \multirow{2}{*}{ XO } & Falha em Fechar (FTC) & anual (teste de funcional) \\
\hline & Vazamento na Posição Fechada (LCP) & trienal (teste de estanqueidade) \\
\hline $\mathrm{EL} 1->\mathrm{W} 1+\mathrm{S} 1+\frac{1}{2} \mathrm{XO}$ & Vazamento Externo (EL) & trienal (inspeção visual) \\
\hline $\mathrm{EL} 2->\mathrm{W} 2+\mathrm{S} 2+\frac{1}{2} \mathrm{XO}$ & Vazamento Externo (EL) & trienal (inspeção visual) \\
\hline
\end{tabular}

Fonte: Próprio Autor 


\section{RESULTADOS OBTIDOS}

Neste capítulo serão apresentados alguns resultados da aplicação da metodologia ao Poço Exemplo.

Como exemplo de aplicação da metodologia, taxas de falha constantes dos elementos de barreira do poço foram usadas de acordo com a Tabela 4. O projeto do poço foi considerado para uma vida operacional de 27 anos e os testes durante a etapa de produção do ciclo de vida do poço de acordo com a Tabela 5, determinando assim o Caso de Referência (Caso Base), como mostra a linha contínua na Figura 18. Vale ressaltar que, no caso sem testes nem reparo (linha tracejada na Figura 18), a probabilidade de vazamento ao final de 27 anos é de 6,73\%. Tal resultado é da mesma ordem de grandeza que os resultados obtidos em (Colombo, 2018), (Colombo, et al., 2020), (da Fonseca, 2012) e (Mendes, Fonseca, \& Miura, 2016). O resultado é alto porque inclui tanto pequenos vazamentos quanto blowouts e não considera a existência de dutos submarinos interligando o poço, de forma que se não for possível evitar que o fluxo de óleo chegue ao duto é considerado que o poço perdeu sua integridade - sua capacidade de conter fluidos - independentemente de o fluido ter ficado ou não contido no duto. Mas isso não é um problema, pois trata-se de uma análise comparativa / relativa.

Outro aspecto é que a taxa de falha da válvula de gas lift é extremamente alta e geralmente um poço passa por manutenção durante a sua vida útil, o que, dentre outras coisas, quase sempre substitui a válvula de gas lift, que pode ser trocada em light workover na maioria das vezes. 
Figura 18 - Caso Base

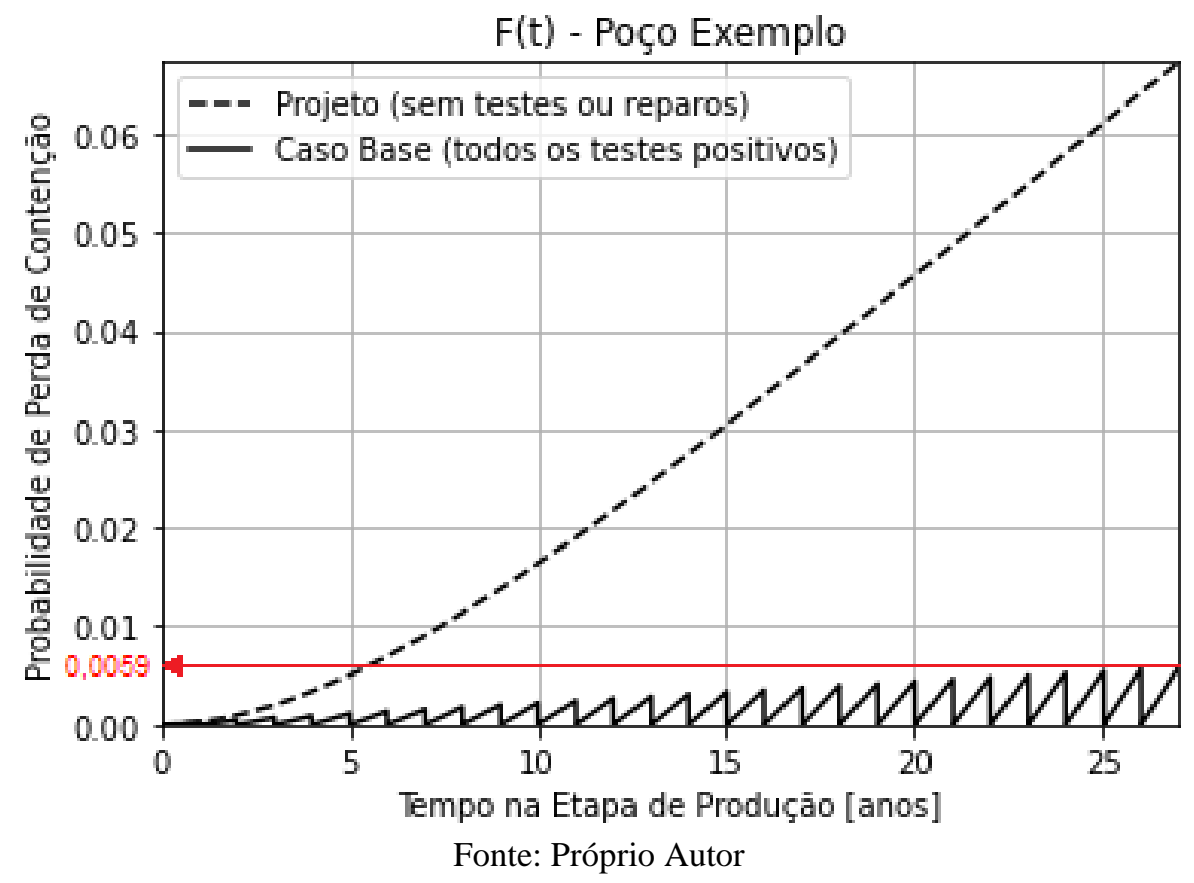

Como mostra a linha contínua da Figura 18 a probabilidade de falha aceita pelo operador para o final da vida útil do poço (27 anos) pelo Caso Base é de 0,59\%. Esse é o valor que será utilizado como referência para esse exemplo de aplicação.

Observe que a confiabilidade do sistema no Caso Base diminui com o tempo, mesmo usando taxas de falha constantes (distribuição exponencial para o tempo da falha - sem memória). Isso ocorre porque nem todos os elementos da barreira do poço são testados durante a fase operacional, portanto, a confiabilidade dos componentes das barreiras não testadas sempre diminui com o tempo, fazendo com que a confiabilidade do sistema também diminua.

A linha contínua do Caso Base forma um "dente de serra" com a probabilidade de perda de contenção sempre voltando para zero anualmente. Isso ocorre pois, conforme Tabela 5, todos os componentes constituintes do conjunto solidário de barreiras primário são testados juntos (na mesma data) com periodicidade anual.

Em seguida dois exemplos de aplicação da metodologia em casos de falhas em barreiras do poço são demonstrados, mas antes é pertinente fazer mais as seguintes considerações:

- A metodologia de análise compara apenas a dimensão da probabilidade de falha do sistema, e não as consequências da falha. Ou seja, trata-se de uma comparação de confiabilidade do sistema e não do risco do sistema, pois não considera a severidade das possíveis consequências. Nesta metodologia, para se fazer uma inferência sobre a 
comparação do risco previsto no projeto e o executado na operação é necessário que a severidade das consequências esperadas pelo projeto para a fase operacional seja sempre a mesma (não há alteração na severidade das consequências);

- Como a análise comparativa termina quando o poço é entregue para intervenção, podese dizer que é uma análise de sistema não reparável; portanto, a disponibilidade coincide com a confiabilidade. Após o reparo nova análise comparativa pode ser retomada considerando a condição do poço após o reparo, confrontando-a com o mesmo caso base.

Nas subseções seguintes serão apresentados dois exemplos práticos de aplicação e, na sequência, serão discutidas a flexibilização das premissas de que os testes são perfeitos (com 100\% de cobertura) e a não indução de danos aos componentes durante os testes.

\subsection{IDENTIFICAÇÃO DE FALHA NA DHSV}

Imaginemos que no terceiro ano de operação do poço foi identificado em teste da DHSV que ela não está funcional. Segue Figura 19 com a probabilidade de perda de contenção desta situação.

Figura 19 - DHSV falha

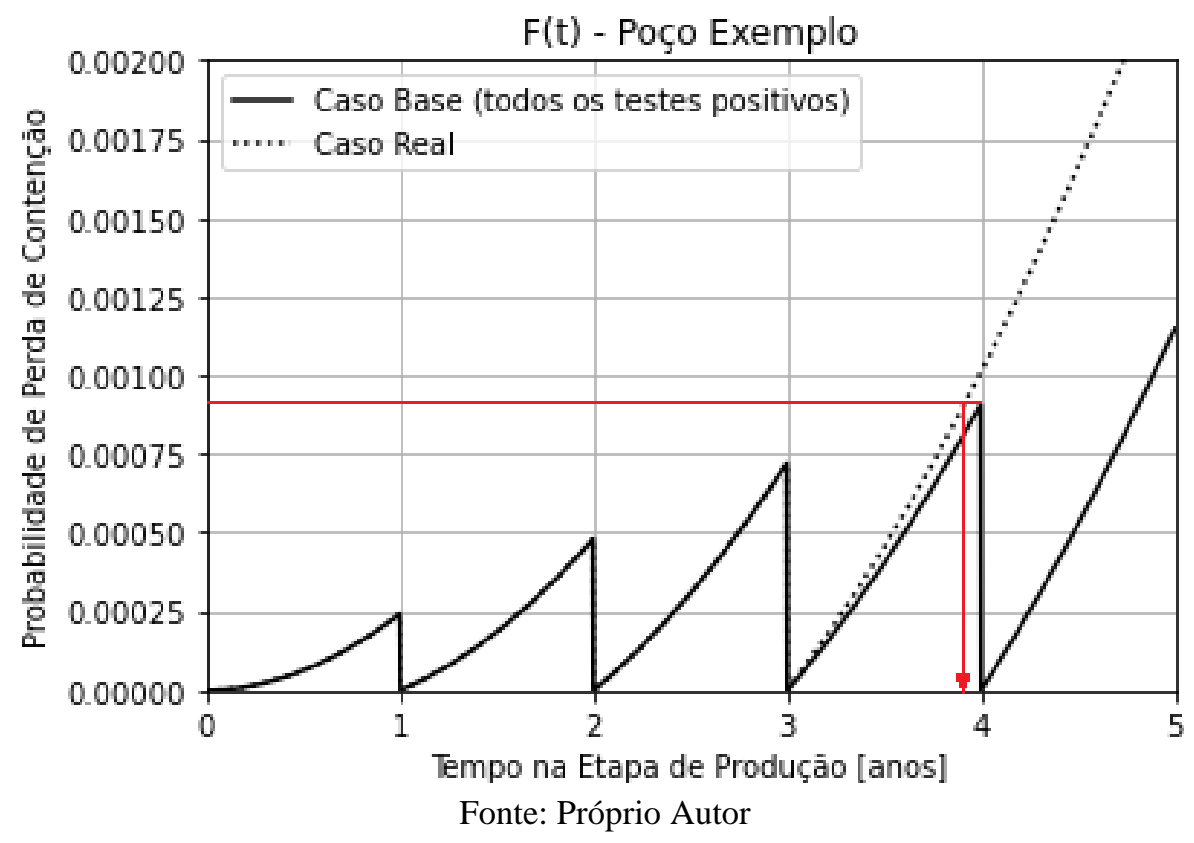

Comparando a curva de não-confiabilidade do Caso Real (linha pontilhada) com a probabilidade de falha considerada como aceitável do pelo operador, verifica-se que, para manter o mesmo nível de confiabilidade deve-se antecipar testes dos demais componentes que possam contribuir para aumentar a confiabilidade instantânea do poço (como por 
exemplo das válvulas M1 e W1) anteriormente previstos para daqui a 12 meses. No caso concreto, tais testes devem ser realizados em até 10,9 meses.

Neste ponto é importante lembrar que o modelo proposto não leva em conta o risco de eventos catastróficos na ANM (ex.: arrancamento ou desconexão espúria) nem riscos motivados por causas externas (ex.: queda de objetos ou arraste de âncoras), dessa forma a modelagem elaborada reduz a importância da DHSV - ou de qualquer outro dispositivo de subsuperfície - sendo não conservadora neste aspecto.

\subsection{IDENTIFICAÇÃO DE COMUNICAÇÃO COLUNA-ANULAR POR FALHA NA VGL}

Imaginemos que no terceiro ano de operação do poço foi identificado em teste de estanqueidade da coluna de produção a presença do modo de falha comunicação colunaanular por falha na VGL. Segue Figura 20 com a probabilidade de perda de contenção desta situação.

Figura 20 - VGL falha

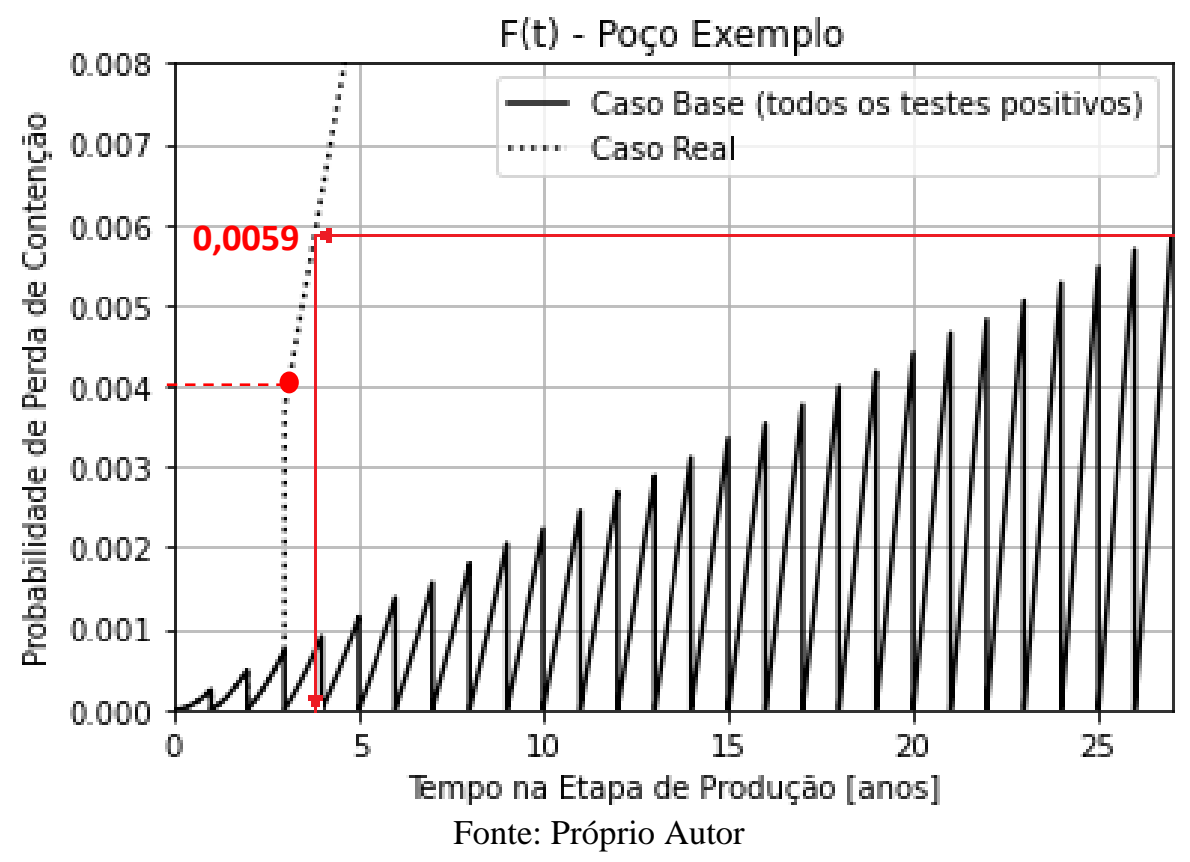

Com a metodologia proposta é possível auxiliar na tomada de decisão quanto à continuidade operacional de poços em estado degradado, a necessidade ou não de uma intervenção com sonda e o prazo para a manutenção.

Comparando a curva de não-confiabilidade do Caso Real (linha pontilhada) com a probabilidade de falha considerada como aceitável do pelo operador, verifica-se que, apesar de probabilidade de falha estar maior do que o esperado pelo projeto para esse 
instante da vida do poço, ela ainda está inferior a probabilidade de falha aceita pelo operador para o final da vida útil do poço (27 anos neste exemplo) de 0,59\%. Portanto, para não exceder essa probabilidade de falha a intervenção para reparo deve ocorrer em no máximo 9,9 meses a partir da data da identificação da falha. Como medida mitigadora pode-se prever reduzir a periodicidade de testes/verificação em demais componentes que possam contribuir para aumentar a confiabilidade instantânea do poço. A partir dos resultados destes testes a curva de confiabilidade atual do poço pode ser atualizada.

Uma informação importante é que com a presença do fluido produzido no anular-A do poço - devido a comunicação coluna-anular pela VGL - torna-se coerente considerar que a inspeção visual por ROV pode agora constatar a não-falha ou falha (vazamento externo) do componente WH, componente este que foi considerado como não testado durante a etapa de produção, a não ser que existissem outras falhas no poço que expusessem este elemento.

Para esse modo de falha da VGL, que levou a comunicação coluna-anular, é necessário verificar se o revestimento de produção terá aumento na taxa de corrosão, pois caso positivo, haverá uma elevação em sua taxa de falha sendo necessário realimentar o modelo com a nova curva de confiabilidade do revestimento de produção para essa situação.

Para verificar a eficácia de medidas mitigadoras de redução da periodicidade de testes/verificação em demais componentes que possam contribuir para aumentar a confiabilidade instantânea do poço, está representada na Figura 21 a curva de confiabilidade do sistema considerando que todos os testes/verificações possíveis passaram a ser feitos de 3 em 3 meses e os resultados foram sempre positivos, ou seja, não identificaram novas falhas. 
Figura 21 - VGL falha e testes trimestrais

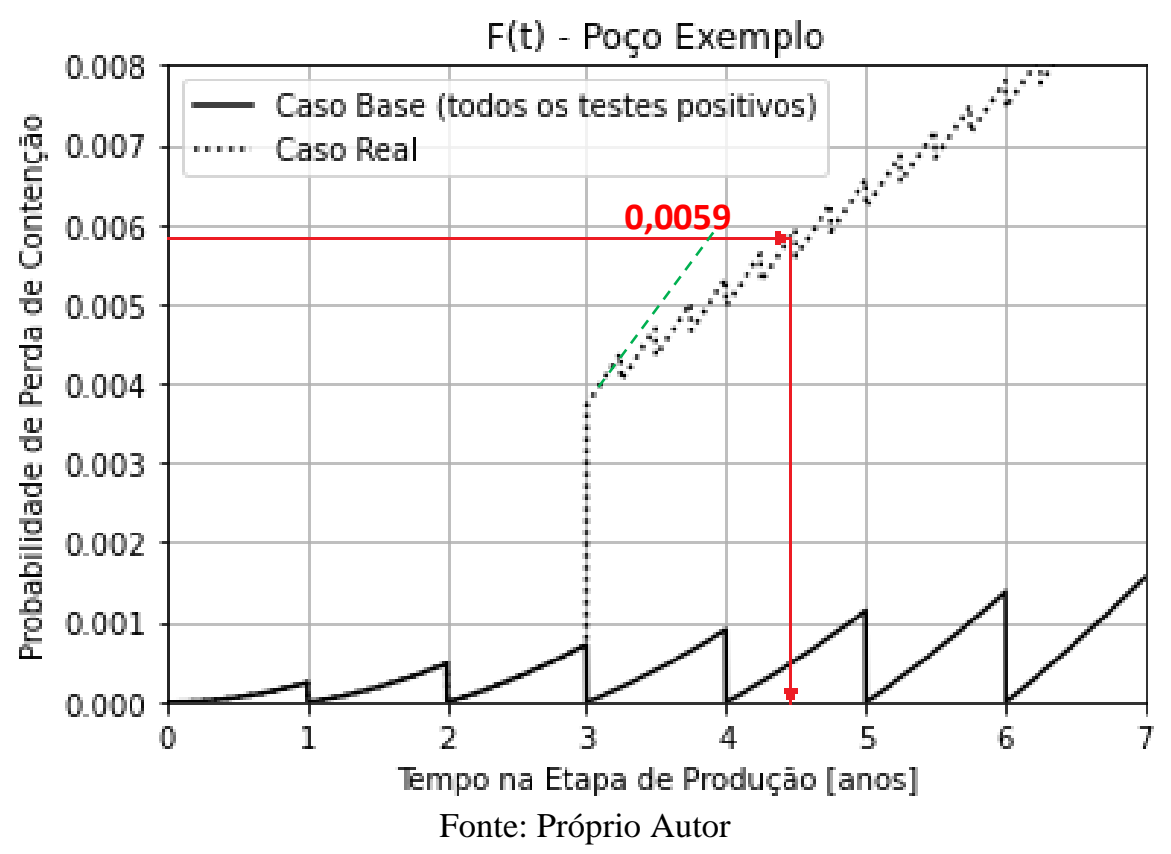

Como pode-se observar na Figura 21, para não exceder a probabilidade de falha de 0,59\% a intervenção para reparo deve ocorrer em no máximo 17,8 meses a partir da data da identificação da falha, ou seja, a obtenção de novas informações sobre o estado de integridade das demais barreiras do poço, caso os resultados dos testes sejam sempre positivos, pode embasar uma intervenção em prazo superior aos 9,9 meses previstos inicialmente mantendo os mesmos níveis de confiabilidade do poço.

\subsection{FLEXIBILIZAÇÃO DE PREMISSAS SOBRE OS TESTES}

Testes não-perfeitos podem ser modelados por um fator de cobertura do teste, sendo este definido como a fração de falhas detectáveis durante um teste. Dessa forma pode-se separar as falhas perigosas não-detectáveis em duas partes: detectáveis durante teste e não detectáveis durante teste. Sendo assim, uma parte das falhas, caso ocorra, permanecerá oculta até o fim do tempo de missão do componente ou uma efetiva falha do sistema como um todo. Segue na Figura 22 o comportamento esperado da Probabilidade de Falha na Demanda (PFD) em função do tempo de um componente com taxa de falha constante testado periodicamente com Test Coverage (TC) < 100\%: 
Figura 22 - Testes não-perfeitos com fator de cobertura $<100 \%$

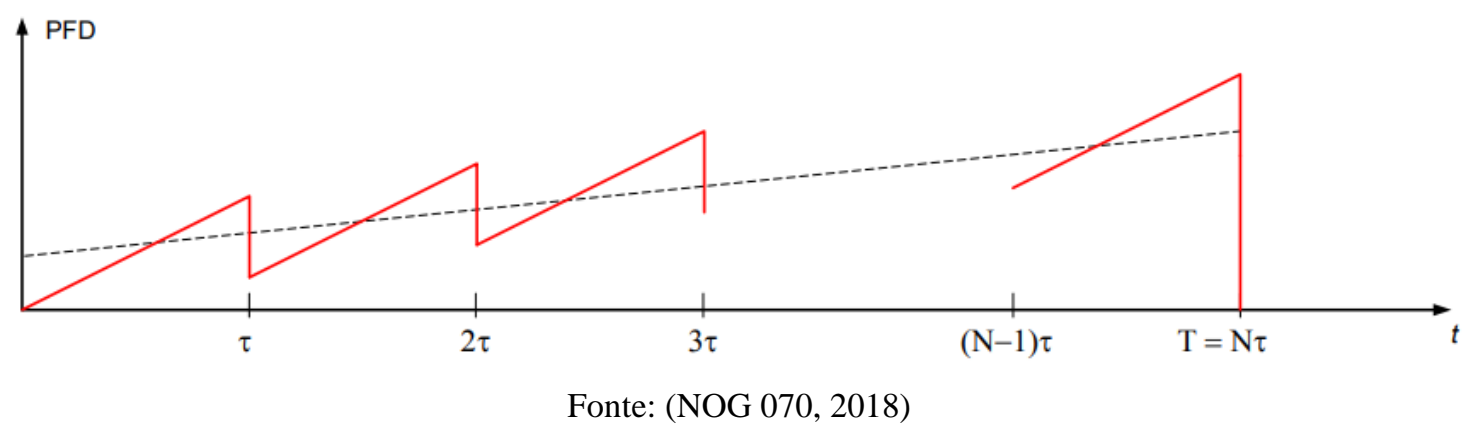

As falhas perigosas detectáveis durante teste ficam com taxa de falha igual a $T C \times \lambda \mathrm{e}$ intervalo de teste igual a $\tau$. Já a parte não detectável durante teste possui taxa de falha igual a $(1-T C) \times \lambda$ e "intervalo de teste" igual ao tempo de missão $\mathrm{T}$, obtendo assim o comportamento para a Probabilidade de Falha na Demanda conforme Figura 22.

Para verificação do impacto da cobertura do teste nos resultados obtidos para o poço exemplo foi considerado um fator de cobertura de 95\% para testes de pressão, estanqueidade e funcionais e um fator de cobertura de $80 \%$ para inspeções visuais com ROV. Importante ter em mente os fatores utilizados foram totalmente arbitrários, tendo a função apenas de permitir uma visualização do comportamento do sistema, não estando ancorados em nenhum embasamento técnico.

Com a utilização desses fatores a probabilidade de perda de contenção esperada pelo projeto no caso base (em que os testes não identificaram nenhuma falha ao longo da vida útil) para o final da vida útil do poço seria de $1,3 \%$ e, para o caso de falha na VGL discutido no item anterior, seria possível realizar a intervenção em um prazo maior mantendo a probabilidade de perda de contenção do sistema abaixo de 1,3\%, conforme pode ser visto na Figura 23. 
Figura 23 - VGL falha e testes não perfeitos

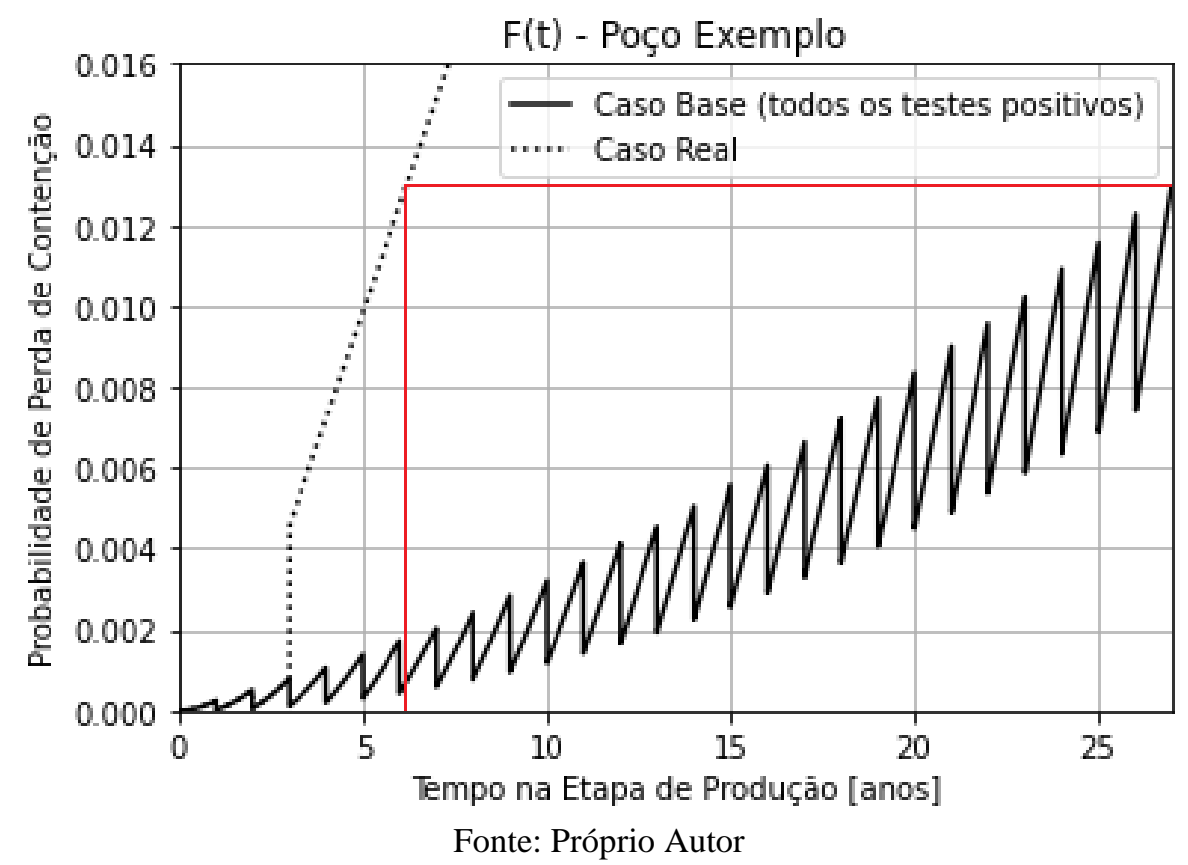

Testes de componentes também podem induzir dano nos mesmos, aumentando o valor de sua taxa de falha. Como análise de sensibilidade supõe-se que a cada teste a taxa de falha do componente é aumentada em 5\%. Dessa forma, a probabilidade de perda de contenção esperada pelo projeto para o final da vida útil do poço seria de $1,8 \%$ e, para o caso de falha na VGL discutido no item anterior, seria possível realizar a intervenção em um prazo maior mantendo a probabilidade de perda de contenção do sistema abaixo de $1,8 \%$, conforme pode ser visto na Figura 24.

Figura 24 - VGL falha e testes induzindo danos

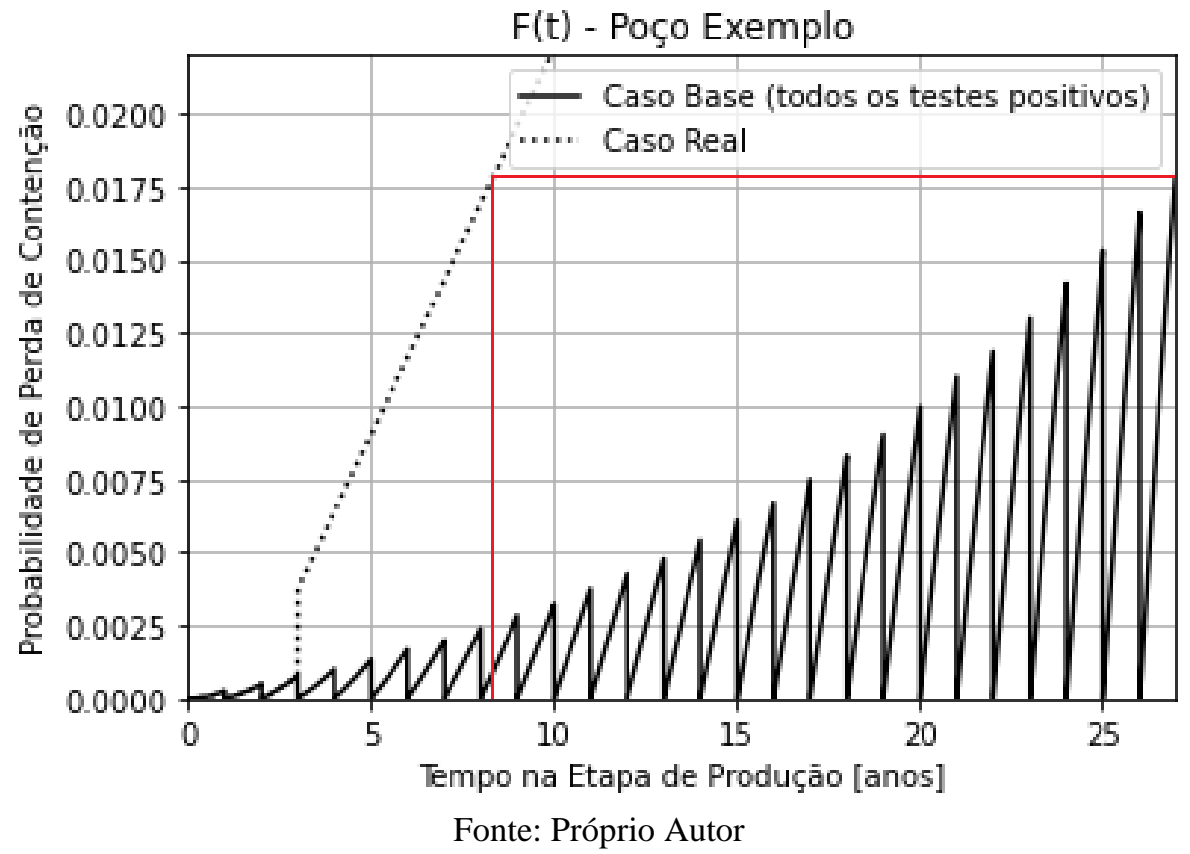




\section{CONCLUSÕES E RECOMENDAÇÕES PARA TRABALHOS FUTUROS}

Este trabalho apresentou uma metodologia para estimar a confiabilidade de um poço de petróleo na etapa de produção e abandono temporário ao longo do tempo. Sendo assim, foi possível avaliar o impacto na curva de confiabilidade do poço quando identificada falha em algum componente de barreira ou quando ocorre atraso ou antecipação de algum teste. Além disso, a metodologia permitiu definir um prazo máximo baseado em confiabilidade para a intervenção em um poço com alguma falha de barreira durante a etapa de produção do ciclo de vida. Para tanto, um modelo de diagrama de blocos de confiabilidade do sistema de poço de petróleo submarino durante a fase operacional foi construído e a partir dessa modelagem, foi possível estimar uma curva de confiabilidade. Os impactos na confiabilidade do sistema de poço em caso de falha ou sucesso de componente foram verificados e a confiabilidade instantânea do poço foi comparada com a prevista pelo projeto. Além disso foi possível verificar que a periodicidade de execução de testes em componentes, bem como o fator de cobertura deles influencia significativamente na curva de confiabilidade do sistema.

Com a confiabilidade instantânea de cada poço e uma visão temporal para restaurar a integridade com base na confiabilidade, o operador pode, em seu conjunto de poços, priorizar a manutenção com base em confiabilidade. Assim, os resultados obtidos neste trabalho são fundamentais como base técnica para o suporte ao gerenciamento de integridade e a tomadas de decisão em relação à integridade de poços.

É oportuno destacar que a metodologia pode ser aplicada a qualquer tipo de poço e, como se pôde ver pelos resultados apresentados, uma análise relativa/comparativa é tão valiosa quanto resultados absolutos em abordagens quantitativas.

Uma vez que foram feitas premissas e considerações para a aplicação da metodologia e a elaboração do modelo que suportou a análise da probabilidade de perda de contenção do poço é apresentado o julgamento do atendimento das condições abaixo:

- As suposições consideradas foram razoáveis? As suposições consideradas nessa dissertação são um ponto de partida para relaxamentos futuros de premissas. De forma geral, buscou-se sempre adotar premissas simplificadoras, no entanto plausíveis. E cujas limitações e vulnerabilidades foram discutidas e explicitadas. Além disso, foram apresentadas flexibilizações de premissas sobre os testes e seus impactos nos resultados. 
- Dados confiáveis estão disponíveis? Dados de entrada confiáveis são fator decisivo para os resultados de qualquer modelo de confiabilidade. Para o objetivo desta dissertação entende-se que foram utilizados os melhores dados disponíveis de uso público, uma vez que as fontes utilizadas são as recomendados pela (IOGP 434-20, 2019).

- Existe ampla concordância/consenso entre especialistas? Diversos trabalhos sobre confiabilidade de equipamentos de integridade de poços em produção vêm sendo realizados nas últimas décadas tendo esta dissertação se apoiado no conhecimento gerado até então sobre o tema.

- Os fenômenos envolvidos são bem compreendidos e os modelos utilizados são conhecidos por fornecer previsões com a precisão necessária? Tanto os modelos de representação dos elementos de barreiras de integridade de poço utilizados, quanto a modelagem de confiabilidade de sistemas por meio de Diagrama de Blocos e o cálculo por sets mínimos são teorias consolidadas e reconhecidas.

Pelo exposto no julgamento às condições acima entende-se que a força do conhecimento utilizada atende aos objetivos da dissertação. Entretanto, (Shortridge, Aven, \& Guikema, 2017) alertam que esse julgamento é uma reflexão subjetiva podendo haver diferentes conclusões. Por isso a importância de explicitar as premissas, incertezas e entendimentos para possibilitar identificar pontos em que melhorias e aprofundamentos podem ser explorados.

Nesse contexto seguem sugestões de trabalhos futuros para relaxar algumas premissas simplificadoras utilizadas: incluir falhas de causa comum em componentes semelhantes e que podem estar exposto aos mesmos mecanismos de falha como por exemplo as válvulas da Árvore de Natal; detalhar os possíveis danos induzidos por testes em componentes e melhor entender a cobertura dos testes em identificar falhas perigosas; considerar não apenas sucesso e falha, mas também a possibilidade de degradação de componentes; considerar taxas de falha variáveis no tempo e avaliar o impacto da incerteza nos parâmetros de confiabilidade de cada componente.

Por fim, sugere-se também ponderar os efeitos e a severidade das consequências do vazamento do poço para uma completa avaliação do risco; considerar eventos externos e aspectos não-técnicos como o fator humano na avaliação do risco; além de discorrer sobre tópicos de aceitabilidade de risco e tomada de decisão na gestão de integridade de poço. 


\section{REFERÊNCIAS}

Abraham, J. A. (1979). An Improved Algorithm for Network Reliability. IEEE Transactions on Reliability, R-28(1), pp. 58-61. doi:https://doi.org/10.1109/TR.1979.5220476

Abreu, D. T., \& Martins, M. R. (2017). Cálculo da Probabilidade do Evento Topo de uma Árvore de Falhas a partir da Utilização de Produtos Disjuntos. III Congresso Nacional de Análise de Riscos, Segurança Operacional e Confiabilidade (ABRISCO). Rio de Janeiro.

Abreu, D. T., Morais, C. H., Santos, J. R., Colombo, D., \& Martins, M. R. (2019). Well Integrity: Preliminary Risk Analysis for Different Well Life Cycle Phases. ASME 2019 38th International Conference on Ocean, Offshore \& Arctic Engineering (OMAE). Glasgow. doi:https://doi.org/10.1115/OMAE2019-96280

Alves, A. L. (2012). Disponibilidade Instantânea de Poços Submarinos durante a Fase de Produção - Visão de Segurança Operacional. Dissertação (Mestrado), Universidade Federal do Rio de Janeiro, Rio de Janeiro.

Alves, A. L., \& Netto, T. A. (2013). Instantaneous Probability of Uncontrolled External Leakage During the Production Phase of a Subsea Well. ASME 2013 32nd International Conference on Ocean, Offshore and Arctic Engineering (OMAE). Nantes. doi:https://doi.org/10.1115/OMAE2013-10558

ANP. (2007). SGSO - Regulamento Técnico do Sistema de Gerenciamento da Segurança Operacional das Instalações Marítimas de Perfuração e Produção de Petróleo e Gás Natural. Resolução ANP no 43 de 06/12/2007, Agência Nacional do Petróleo, Gás Natural e Biocombustíveis.

ANP. (2016). SGIP - Regulamento Técnico do Sistema de Gerenciamento da Integridade de Poços. Resolução ANP no 46 de 01/11/2016, Agência Nacional do Petróleo, Gás Natural e Biocombustíveis.

ANP. (24 de Junho de 2016a). Nota Técnica $n^{\circ}$ 258/SSM/2016 - Proposta de Regulamentação para o Sistema de Gerenciamento da Integridade de Poços (SGIP) e Análise dos Impactos Regulatórios (AIR). Agência Nacional do Petróleo, Gás Natural e Biocombustíveis, Rio de Janeiro. Acesso em 01 de maio de 2021, disponível em http://www.anp.gov.br/images/Consultas_publicas/Concluidas/2016/n13/NotaTecnica-258-SSM-2016.pdf

Apostolakis, G. E. (2004). How Useful Is Quantitative Risk Assessment? Risk Analysis, 24(3), pp. 515-520. doi:https://doi.org/10.1111/j.0272-4332.2004.00455.x

Aven, T. (2013). Practical implications of the new risk perspectives. Reliability Engineering \& System Safety, 115, pp. 136-145. doi:https://doi.org/10.1016/j.ress.2013.02.020

Aven, T. (2017). Improving risk characterisations in practical situations by highlighting knowledge aspects, with applications to risk matrices. Reliability Engineering \& System Safety, 167, pp. 42-48. doi:https://doi.org/10.1016/j.ress.2017.05.006 
Aven, T. (2020). Three influential risk foundation papers from the 80s and 90s: Are they still state-of-the-art? Reliability Engineering \& System Safety, 193. doi:https://doi.org/10.1016/j.ress.2019.106680

Aven, T., \& Zio, E. (2011). Some considerations on the treatment of uncertainties in risk assessment for practical decision making. Reliability Engineering \& System Safety, 96(1), pp. 64-74. doi:https://doi.org/10.1016/j.ress.2010.06.001

Birolini, A. (2017). Reliability Engineering - Theory and Practice (8a ed.). Berlim, Alemanha: Springer. doi:https://doi.org/10.1007/978-3-662-54209-5

Bouças, M. H. (2017). Confiabilidade de sistemas de barreiras de segurança em poços de petróleo pelo Método de Monte Carlo. Dissertação (Mestrado), Pontifícia Universidade Católica do Rio de Janeiro, Rio de Janeiro.

Cai, B., Kong, X., Liu, Y., Lin, J., Yuan, X., Xu, H., \& Ji, R. (2019). Application of Bayesian Networks in Reliability Evaluation. IEEE Transactions on Industrial Informatics, 15(4), pp. 21462157. doi:https://doi.org/10.1109/TII.2018.2858281

Chambriard, M. (26 de Novembro de 2014). CPMI - Petro, Requerimentos n. 539/2014 e 456/2014. Brasília, Brasil. Acesso em 01 de maio de 2021, disponível em http://legis.senado.leg.br/sdleg-getter/documento/download/9a450920-7ceb-4b62ae7a-a3f58cc1dd9c

Churchman, C. W. (1973). Reliability of Models in the Social Sciences. Interfaces, 4(1), pp. 1-12. Acesso em 01 de maio de 2021, disponível em https://www.jstor.org/stable/25059040

Colombo, D. (2018). Proposição de uma modelo markoviano de apoio ao gerenciamento de riscos à integridade de poços submarinos. Dissertação (Mestrado), Universidade Federal Fluminense, Niterói.

Colombo, D., Abreu, D. T., \& Duim, F. A. (2019). Avaliação do Impacto da Frequência de Testes na Disponibilidade e Segurança de Operações com BOP. IV Congresso Nacional de Análise de Riscos, Segurança Operacional e Confiabilidade (ABRISCO). Rio de Janeiro.

Colombo, D., Abreu, D. T., Martins, M. R., Lima, G. B., Júnior, M. M., Garcia, P. A., \& Melo, P. F. (2020). Quantitative Analysis of Integrity Failures in Subsea Oil Wells Using a Markovian Model. Society of Petroleum Engineers - SPE Production \& Operations, 35(01), pp. 98 - 110. doi:https://doi.org/10.2118/198891-PA

Corneliussen, K. (2006). Well Safety: Risk Control in the Operational Phase of Offshore Wells. Tese (Doutorado), The Norwegian University of Science and Technology, Trondheim.

Corneliussen, K. (2017). Well Integrity and Reliability Management in a Life Cycle Perspective. SPE Bergen One Day Seminar. Bergen: Society of Petroleum Engineers. doi:https://doi.org/10.2118/185933-MS 
da Fonseca, T. C. (2012). Metodologia de Análise de Integridade para Projetos de Poços de Desenvolvimento da Produção. Dissertação (Mestrado), Universidade Estadual de Campinas, Campinas.

da Fonseca, T. C., Miura, K., \& Mendes, J. R. (2013). Well Integrity Analysis Applied to Workover Prediction. Offshore Technology Conference Brasil (OTC). Rio de Janeiro. doi:https://doi.org/10.4043/24369-MS

de Oliveira, P. G. (2016). Estudo de Confiabilidade de Sistemas de Controle de Dispositivos de Segurança de Sub-superfície em Poços de Petróleo. Dissertação (Mestrado), Pontifícia Universidade Católica do Rio de Janeiro, Rio de Janeiro.

Dethlefs, J., \& Chastain, B. (2012). Assessing Well Integrity Risk: A Qualitative Model. Society of Petroleum Engineers - SPE Drilling \& Completion, 27(02), pp. 294 - 302. doi:https://doi.org/10.2118/142854-PA

Eliot, T. S. (1934). The Rock. London: Faber and Faber.

Flage, R., \& Aven, T. (2009). Expressing and communicating uncertainty in relation to quantitative risk analysis (QRA). Reliability and Risk Analysis: Theory and Applications, 2(13), pp. 9-18. Acesso em 01 de maio de 2021, disponível em https://www.researchgate.net/publication/228623141_Expressing_and_communicati ng_uncertainty_in_relation_to_quantitative_risk_analysis_QRA

Greenberger, M., Crenson, M., \& Crissey, B. (1976). Models in the Policy Process. New York: Russell Sage Foundation.

Haaland, B. (2017). Life Cycle Well Integrity and Reliability. Dissertação (Mestrado), University of Stavanger, Faculty of Science and Technology, Stavanger.

Hafver, A., Oliveria, L. F., \& Pedersen, F. B. (2019). Optimal Scheduling of Tests of Safety Systems, Considering Test-Induced Degradation. 29th European Safety and Reliability Conference (ESREL). Hannover. doi:https://doi.org/10.3850/978-981-11-2724-3_0519$\mathrm{cd}$

Holand, P., \& Andersen, A. (2012). Risk analysis of Subsea Wells Completed with or without a Surface Controlled Subsurface Safety Valve (SCSSV). Report ES 201236/01, Exprosoft.

IBP. (2017). Diretrizes para Abandono de Poços. Instituto Brasileiro de Petróleo, Gás e Biocombustíveis.

IEC 61511-1. (2017). Functional safety - Safety instrumented systems for process industry sector - Part 1: Framework, definitions, system, hardware and application programming requirements. International Electrotechnical Commission.

IOGP 434-20. (2019). Guide to finding and using reliability data for QRA. International Association of Oil \& Gas Producers. 
ISO 14224. (2016). Petroleum, petrochemical and natural gas industries - Collection and exchange of reliability and maintenance data for equipment. International Organization for Standardization.

ISO 16530-1. (2017). Petroleum and natural gas industries - Well integrity - Life Cycle Governance. International Organization for Standardization.

ISO. (01 de Março de 2011). Proposed ISO/TC 67 Programme for drilling, well construction and well operations standards, resulting from the Montara and Macondo accidents. International Organization for Standardization, Delft. Acesso em 01 de maio de 2021, disponível em http://www.iso.org/iso/tc67actionplan.pdf

ISO TR 12489. (2013). Petroleum, petrochemical and natural gas industries - Reliability modelling and calculation of safety systems. Technical Report, International Organization for Standardization.

Jensen, P. A., \& Bard, J. F. (2003). Operations Research Models and Methods. Acesso em 01 de maio de 2021, disponível em https://utw11041.utweb.utexas.edu/ORMM/supplements/units/reliability/reliability.p df

Júnior, M. M., Lima, G. B., Colombo, D., Abreu, D. T., \& Salvalagio, J. S. (2020). Seleção de configurações de poços de petróleo baseada em gerenciamento de integridade, utilizando diagrama de blocos de confiabilidade. XIX Simpósio de Pesquisa Operacional \& Logística da Marinha, 3, pp. 882-898. Rio de Janeiro. doi:https://doi.org/10.5151/spolm2019-064

Kaplan, S., \& Garrick, B. J. (1981). On The Quantitative Definition of Risk. Risk Analysis, 1(1), pp. 11-27. doi:https://doi.org/10.1111/j.1539-6924.1981.tb01350.x

Kostøl, K. N. (2014). New risk categorization system for well integrity - wells in operation. Dissertação (Mestrado), University of Stavanger, Faculty of Science and Technology, Stavanger.

Lavasani, S. M., Ramzali, N., Sabzalipour, F., \& Akyuz, E. (2015). Utilisation of Fuzzy Fault Tree Analysis (FFTA) for quantified risk analysis of leakage in abandoned oil and natural-gas wells. Ocean Engineering, 108(1), 729-737. doi:https://doi.org/10.1016/j.oceaneng.2015.09.008

Martins, M. R. (2013). Considerações sobre análise de confiabilidade e risco. Tese (Livre Docência), Universidade de São Paulo, Escola Politécnica, São Paulo. Acesso em 01 de maio de 2021, disponível em http://www.labrisco.usp.br/ marcelo/LivreDocencia/

Mendes, J. R., Fonseca, T. C., \& Miura, K. (2016). An Integrity analysis approach for development wells. Journal of the Brazilian Society of Mechanical Sciences and Engineering, 38, pp. 1239-1248. doi:https://doi.org/10.1007/s40430-015-0479-1 
Miura, K. (2004). Um Estudo sobre a Segurança Operacional na Construção e Reparo de Poços Marítimos de Petróleo. Tese (Doutorado), Universidade Estadual de Campinas, Campinas.

Miura, K., Morooka, C. K., Mendes, J. R., \& Guilherme, I. R. (2006). Characterization of operational safety in offshore oil wells. Journal of Petroleum Science \& Engineering, 51(1-2), pp. 111-126. doi:https://doi.org/10.1016/j.petrol.2005.11.018

Modarres, M., Kaminskiy, M. P., \& Krivtsov, V. (2017). Reliability Engineering and Risk Analysis A Practical Guide (3a ed.). Boca Raton: Taylor \& Francis Group, CRC Press.

Molnes, E., \& Strand, G. (2009). Reliability of Well Completion Equipment - Phase VI Main Report. Report 1611146/02/2009, Exprosoft.

Morais, C. H., Abreu, D. T., Santos, J. R., Maturana, M. C., Colombo, D., \& Martins, M. R. (2019). The Influence of Non-prescriptive Legislation in the Evolution of Offshore Well Integrity Practices: an Exploratory Review. ASME 2019 38th International Conference on Ocean, Offshore \& Arctic Engineering (OMAE). Glasgow. doi:https://doi.org/10.1115/OMAE2019-96269

NOG 070. (2018). Application of IEC 61508 and IEC 61511 in the Norwegian Petroleum Industry (Recommended SIL requirements). Norwegian Oil and Gas Association.

NOG 117. (2017). Recommended Guidelines for Well Integrity. Norwegian Oil and Gas.

NORSOK D-010. (2021). Well integrity in drilling and well operations. Norsk Sokkels Konkurranseposisjon.

Pearl, J. (1988). Probabilistic Reasoning in Intelligent Systems: Network of Plausive Inference. San Mateo: Morgan Kaufmann.

Santos, J. R. (2012). A indústria da cana-de-açúcar: uma análise sob a perspectiva da dinâmica de sistemas. Tese (Doutorado), Universidade de São Paulo, Escola Politécnica, São Paulo.

Santos, J. R., Abreu, D. T., Morais, C. H., Colombo, D., \& Martins, M. R. (2019). Oil Well Life Cycle - A Perspective from System Thinking. 29th European Safety and Reliability Conference (ESREL). Hannover. doi:https://doi.org/10.3850/978-981-11-2724-3_0645$\mathrm{cd}$

Shortridge, J., Aven, T., \& Guikema, S. (2017). Risk assessment under deep uncertainty: A methodological comparison. Reliability Engineering \& System Safety, 159, pp. 12-23. doi:https://doi.org/10.1016/j.ress.2016.10.017

SINTEF. (2015). Offshore and Onshore Reliability Data (OREDA): Volume 2 - Subsea Equipment. (6a ed.). OREDA Participants.

Stamatelatos, M., \& Dezfuli, H. (2011). Probabilistic Risk Assessment Procedure Guide for NASA Managers and Practitioners. NASA/SP-2011-3421, National Aeronautic and Space 
Administration (NASA), Washington, D.C.

doi:https://doi.org/10.13140/RG.2.2.18206.13122

Stamatelatos, M., Vesely, W., Dugan, J., Fragola, J., Minarick, J., \& Railsback, J. (2002). Fault Tree Handbook with Aerospace Applications. Washington, D.C.: National Aeronautics and Space Administration (NASA).

Sterman, J. D. (2000). Business Dynamics: System Thinking and Modeling for a Complex World. New York: Irwin McGraw-Hill.

Takashina, N. T. (1989). O Conceito de Barreira de Segurança e sua Confiabilidade em um Poço de Petróleo. Boletim Técnico da Petrobras, 32(1-2), pp. 59-66.

UK Statutory Instruments. (1992). The Offshore Installations (Safety Case) Regulations 1992. No. 2885. Acesso em 01 de maio de 2021, disponível em https://www.legislation.gov.uk/uksi/1992/2885/made

Vargas, R. E., Munaro, C. J., Ciarelli, P. M., Medeiros, A. G., Amaral, B. G., Barrionuevo, D. C., . . . Magalhães, L. P. (2019). A realistic and public dataset with rare undesirable real events in oil wells. Journal of Petroleum Science and Engineering, 181.

doi:https://doi.org/10.1016/j.petrol.2019.106223

Zanetti, A. A. (2014). Avaliação Comparativa de Disponibilidade de Poços Submarinos em Diferentes Cenários na Fase Operacional. Dissertação (Mestrado), Universidade Federal do Rio de Janeiro, Rio de Janeiro.

Zulqarnain, M., \& Tyagi, M. (2015). Quantification of Risks Associated with a Representative Production Well in the Gulf of Mexico. ASME 2015 34th International Conference on Ocean, Offshore and Arctic Engineering (OMAE). St. John's. doi:https://doi.org/10.1115/OMAE2015-42115 


\section{APÊNDICE}

Código de Programação em Python 3 
$\# 1^{\circ}$ ) TRANSFORMAR OS PATH-SETs (ou CUT-SETs) EM UM CONJUNTO DISJUNTO

\#OBJETIVO: Realizar posteriormente o cálculo exato da confiabilidade do sistema a um baixo custo computacional

import numpy as np \#arrays e matrizes

import math

import timeit

\#O subprograma "compare" implementado abaixo está previsto algoritmo proposto por (Abraham, 1979)

def compare(p,s):

"1""

-> Compara dois vetores de PATH-SETs (ou CUT-SETs) e retorna:

a) they are disjoint, b)"p" is contained in "s" or c) otherwise (in this case the set X of variables in "s" but not in "p" is returned)

:param s: PATH-SET s (ou CUT-SET)

:param p: PATH-SET p (ou CUT-SET)

:return 'disjoint', 'contained' ou X

"'"!

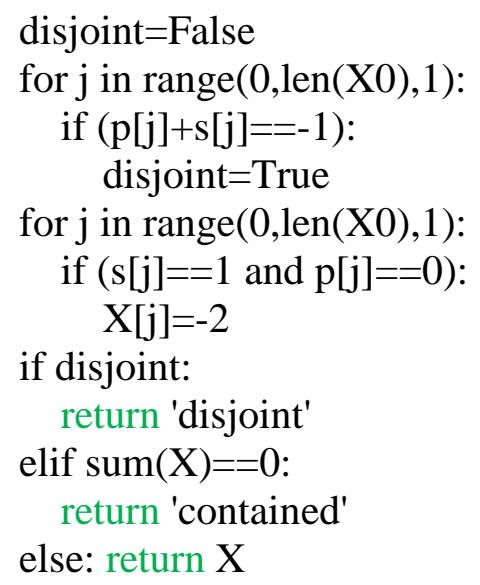

\#PROGRAMA PRINCIPAL

start=timeit.default_timer()

\#Preencher o vetor X0: $\mathrm{n}^{\circ}$ de linhas $=1, \mathrm{n}^{\circ}$ de colunas=número total de eventos básicos (ou componentes) \& elementos=todos iguais a " 0 "

\#Como a modelagem do Poço Exemplo tem 30 blocos de confiabilidade, o vetor X0 deve ter ao menos 30 colunas.

$\mathrm{X} 0=\mathrm{np} \cdot \operatorname{array}([0,0,0,0,0,0,0,0,0,0,0,0,0,0,0,0,0,0,0,0,0,0,0,0,0,0,0,0,0,0,0])$

\#Preencher os vetores dos PATH-SETs (ou CUT-SETs): 1->evento básico presente, 0>evento básico não-presente ou -2->complementar do evento básico presente \#Como foram identificados 29 path-sets existirão 29 vetores abaixo, para representar cada um dos path-sets.

$\mathrm{p} 1=\mathrm{np} \cdot \operatorname{array}([1,1,1,1,1,0,0,0,0,0,0,0,0,0,0,0,0,0,0,0,0,0,0,0,0,0,0,0,0,0,0])$

$\mathrm{p} 2=\mathrm{np} \cdot \operatorname{array}([1,1,1,0,0,1,0,0,0,0,0,0,1,1,1,1,0,0,0,0,0,0,0,0,0,0,0,0,0,0,0])$

p3 $=\mathrm{np}$.array $([1,1,1,0,0,1,0,0,0,1,0,0,0,1,1,1,0,0,0,0,0,0,0,0,0,0,0,0,0,0,0])$

p4=np.array $([1,1,1,0,0,1,0,0,0,0,0,0,1,1,0,0,1,1,0,0,0,0,0,0,0,0,1,1,1,0,0])$

p5=np.array $([1,1,1,0,0,1,0,0,0,1,0,0,0,1,0,0,1,1,0,0,0,0,0,0,0,0,1,1,1,0,0])$ 
p6=np.array $([1,1,1,0,0,1,0,0,0,0,0,0,1,1,0,0,1,1,1,1,1,0,0,0,1,1,0,0,1,1,1])$ p7 $=$ np.array $([1,1,1,0,0,1,0,0,0,1,0,0,0,1,0,0,1,1,1,1,1,0,0,0,1,1,0,0,1,1,1])$ $\mathrm{p} 8=\mathrm{np}$.array $([1,1,1,0,0,1,0,0,0,0,0,1,1,1,0,0,1,1,1,0,0,1,1,1,1,1,0,0,1,1,1])$ p9=np.array $([1,1,1,0,0,1,0,0,0,1,0,0,0,1,0,0,1,1,1,0,0,1,1,1,1,1,0,0,1,1,1])$ p10=np.array $([0,0,0,1,1,1,1,1,1,0,1,0,0,0,0,0,0,0,0,0,0,1,1,1,0,0,0,0,0,0,1])$ p1 $1=$ np.array $([0,0,0,1,1,1,1,1,1,1,0,0,0,0,0,0,0,0,0,0,0,1,1,1,0,0,0,0,0,0,1])$ p12=np.array $([0,0,0,1,1,1,1,1,1,0,1,1,0,0,0,0,0,0,1,1,1,1,0,0,0,0,0,0,0,0,1])$ p13=np.array $([0,0,0,1,1,1,1,1,1,1,0,0,0,0,0,0,0,0,1,1,1,1,0,0,0,0,0,0,0,0,1])$ p14=np.array $([0,0,0,1,1,1,1,1,1,0,1,1,0,0,0,0,0,0,1,0,0,1,0,0,1,1,1,1,0,1,0])$ p15=np.array $([0,0,0,1,1,1,1,1,1,1,0,0,0,0,0,0,0,0,1,0,0,1,0,0,1,1,1,1,0,1,0])$ p16=np.array $([0,0,0,1,1,1,1,1,1,0,1,1,0,1,1,1,1,1,1,0,0,1,0,0,1,1,0,0,1,1,0])$ p17=np.array $([0,0,0,0,0,0,1,1,1,0,1,0,1,1,1,1,0,0,0,0,0,1,1,1,0,0,0,0,0,0,1])$ p18=np.array $([0,0,0,0,0,0,1,1,1,1,0,0,0,1,1,1,0,0,0,0,0,1,1,1,0,0,0,0,0,0,1])$ p19=np.array $([0,0,0,0,0,0,1,1,1,0,1,0,1,1,0,0,1,1,0,0,0,1,1,1,0,0,1,1,1,0,1])$ p20 =np.array $([0,0,0,0,0,0,1,1,1,1,0,0,0,1,0,0,1,1,0,0,0,1,1,1,0,0,1,1,1,0,1])$ p21=np.array $([0,0,0,0,0,0,1,1,1,0,1,0,1,1,0,0,1,1,1,1,1,1,1,1,1,1,0,0,1,1,1])$ p22=np.array $([0,0,0,0,0,0,1,1,1,0,1,1,1,1,1,1,0,0,1,1,1,1,0,0,0,0,0,0,0,0,1])$ p23=np.array $([0,0,0,0,0,0,1,1,1,1,0,0,0,1,1,1,0,0,1,1,1,1,0,0,0,0,0,0,0,0,1])$ p24=np.array $([0,0,0,0,0,0,1,1,1,0,1,1,1,1,0,0,1,1,1,1,1,1,0,0,0,0,1,1,1,0,1])$ p25=np.array $([0,0,0,0,0,0,1,1,1,1,0,0,0,1,0,0,1,1,1,1,1,1,0,0,0,0,1,1,1,0,1])$ p26=np.array $([0,0,0,0,0,0,1,1,1,0,1,1,1,1,1,1,0,0,1,0,0,1,0,0,1,1,1,1,0,1,0])$ p27=np.array $([0,0,0,0,0,0,1,1,1,1,0,0,0,1,1,1,0,0,1,0,0,1,0,0,1,1,1,1,0,1,0])$ p28=np.array $([0,0,0,0,0,0,1,1,1,0,1,1,1,1,0,0,1,1,1,0,0,1,0,0,1,1,0,0,1,1,0])$ p29=np.array $([0,0,0,0,0,0,1,1,1,1,0,0,0,1,0,0,1,1,1,0,0,1,0,0,1,1,0,0,1,1,0])$

\#Preencher matriz S: colocar todos os vetores dos PATH-SETs (ou CUT-SETs)

$\mathrm{S}=\mathrm{np} \cdot \operatorname{array}([\mathrm{p} 1, \mathrm{p} 2, \mathrm{p} 3, \mathrm{p} 4, \mathrm{p} 5, \mathrm{p} 6, \mathrm{p} 7, \mathrm{p} 8, \mathrm{p} 9, \mathrm{p} 10, \mathrm{p} 11, \mathrm{p} 12, \mathrm{p} 13, \mathrm{p} 14, \mathrm{p} 15, \mathrm{p} 16, \mathrm{p} 17, \mathrm{p} 18, \mathrm{p} 19, \mathrm{p} 20$ ,p21,p22,p23,p24,p25,p26,p27,p28,p29])

\#Escolher o número multiplicativo de linhas para caber os termos que forem sendo gerados na matriz $\mathrm{D}$.

linhas=110 \#Foi verificado, por tentativa e erro, que para esse caso específico 110 era suficiente

\#Demais matrizes criadas para o algoritmo

$\mathrm{X}=\mathrm{X} 0 \cdot \operatorname{copy}()$

$\mathrm{D}=\mathrm{p} 1 . \operatorname{copy}()$ \#coloco "p1" no conjunto "D" (disjoint)

$\mathrm{PD}=$ np.zeros $((\operatorname{linhas} * \operatorname{len}(\mathrm{X} 0), \operatorname{len}(\mathrm{X} 0)))$ \#faço linhas*len(X0) de linhas para caber os termos que forem sendo gerados

print(f'Número total de linhas é $\{$ linhas*len $(\mathrm{X} 0)\}$, que deve ser maior que o número de linhas da matriz D para o algoritmo funcionar corretamente.')

\#ALGORITMO: $1^{\circ}$ ) Comparo um SET de vetores (PD) contra um "s", começo contra o $\mathrm{S}[0]$

for set in range $(1, \operatorname{len}(\mathrm{S}), 1)$ :

$\mathrm{PD}[0]=\mathrm{S}[\mathrm{set}] . \operatorname{copy}()$ \#SET inicial, que contém só um elemento

if set>0: \#primeiro comparo com $\mathrm{S}[0]$ $\mathrm{a}=$ compare $(\mathrm{PD}[0], \mathrm{S}[0])$

$\mathrm{X}=\mathrm{X} 0 . \operatorname{copy}()$ \#Reinicio o $\mathrm{X}$ 
if type $(\mathrm{a})==$ str and $\mathrm{a}==$ 'disjoint': \#they are disjoint

a

\#print(f'DISJOINT: Matriz PD gerada após comparar com S0:')

\#print(PD)

elif type (a)==str and a=='contained': \#" $p$ " is contained in "s"

$\mathrm{PD}[0]=\mathrm{X} 0 . \operatorname{copy}()$

\#print(f'CONTAINED')

else:

quantidade $=\operatorname{int}(-n p \cdot \operatorname{sum}(a) / 2)$

if quantidade $==1$ :

$\mathrm{PD}[0]=\mathrm{PD}[0]+\mathrm{a}$

if quantidade $>1$ :

for $\mathrm{n}$ in range (1, quantidade+1,1):

$\mathrm{b}=\mathrm{a} \cdot \operatorname{copy}()$

$\mathrm{m}=0$

while $\mathrm{m}<\mathrm{len}(\mathrm{X} 0)$ :

if $b[m]==-2$ :

$\mathrm{a}[\mathrm{m}]=1$

$\mathrm{b}[\mathrm{m}+1:]=0$

$\mathrm{m}=\operatorname{len}(\mathrm{X} 0)+1$

$\mathrm{m}=\mathrm{m}+1$

$\mathrm{PD}[\mathrm{n}]=\mathrm{PD}[0]+\mathrm{b}$

$\mathrm{PD}[0]=\mathrm{X} 0 . \operatorname{copy}()$ \#Se gerou mais de 1 termo, então o $\mathrm{PD}[0]$ fica igual a zero \#print(f'Matriz PD gerada após comparar com S0:')

\#print(PD)

if set $>1$ :

for passagem in range $(2$, set $+1,1)$ :

\#Verifico o número de termos diferentes de 0 em PD, e coloco a quantidade deles na variável "termos"

termos $=0$

for $\mathrm{i}$ in range $(0$,linhas*len $(\mathrm{X} 0), 1)$ :

if (np.count_nonzero(PD[i])!=0):

termos $=$ termos +1

while termos>0:

\#Fazer esse IF antes do próximo, senão PD[0] já não é mais igual a zero. Obs.:

Se gerou mais de 1 termo, então o PD[0] está igual a zero

if np.count_nonzero(PD[0])!=0: \#se o $\mathrm{PD}[0]$ é diferente de 0 , então...

$\mathrm{c}=\mathrm{PD}[0] \cdot \operatorname{copy}()$

$\mathrm{PD}[0]=\mathrm{PD}[$ termos $] . \operatorname{copy}()$

$\mathrm{PD}[$ termos $]=$ c. $\operatorname{copy}()$

\#Se o FOR anterior gerou mais de 1 termo o PD[0] é igual a zero, então trago o $\mathrm{PD}[1]$ para $\mathrm{PD}[0]$ pois a comparação é sempre com $\mathrm{PD}[0]$

if np.count_nonzero $(\mathrm{PD}[0])==0$ :

for $\mathrm{i}$ in range $(1$, linhas*len $(\mathrm{X} 0), 1)$ :

$\mathrm{PD}[\mathrm{i}-1]=\mathrm{PD}[\mathrm{i}]$

$\# 2^{\circ}$ ) Comparo todos os vetores do SET (PD) contra os termos com S[1], depois contra $\mathrm{S}[2]$ e assim por diante

$\mathrm{a}=$ compare $(\mathrm{PD}[0], \mathrm{S}[$ passagem-1]) 


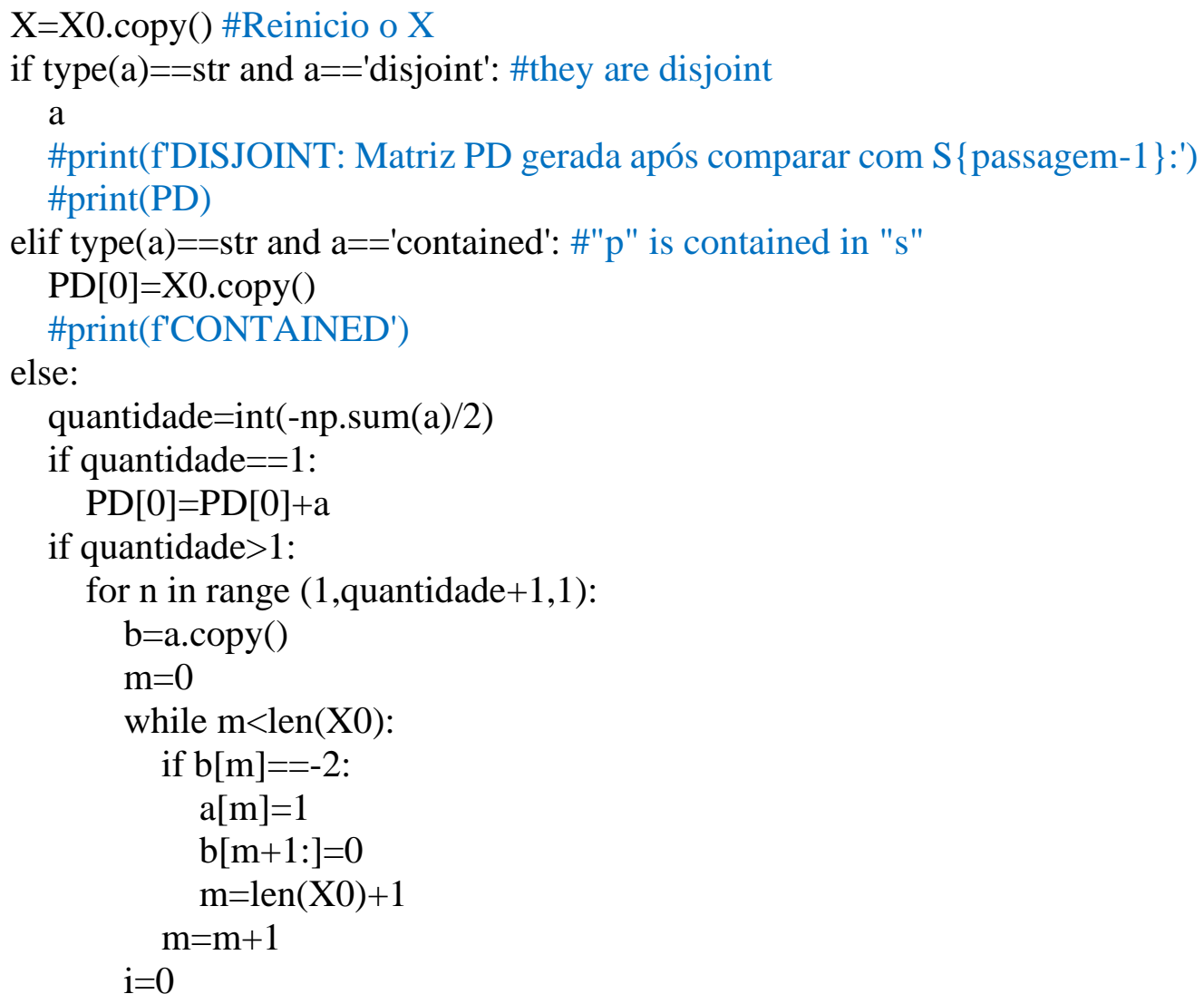

while i<linhas*len(X0): \#Coloco o novo termo no primeiro que é igual

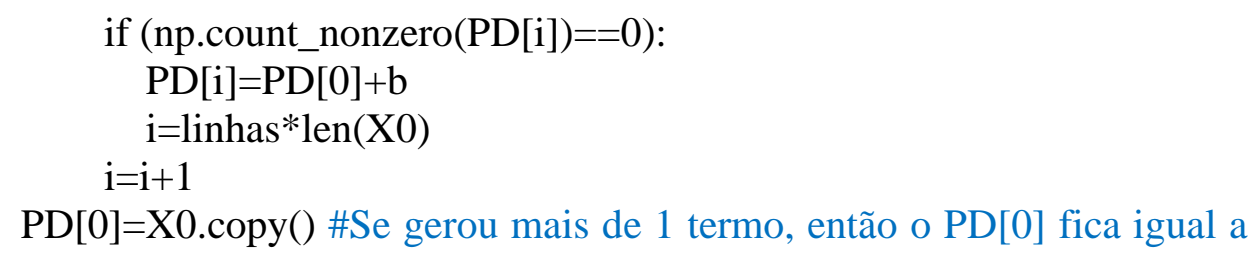

\#print(f'Matriz PD gerada após comparar com S\{passagem-1\}:')

\#print(PD)

termos $=$ termos -1

\#A cada SET cuja comparação acabou, complementa-se o conjunto "D" (disjoint)

$\mathrm{D}=\mathrm{np} . \mathrm{vstack}((\mathrm{D}, \mathrm{PD}))$

$\mathrm{i}=0$

while $\mathrm{i}<\mathrm{len}(\mathrm{D})$ :

if (np.count_nonzero(D[i])==0):

$\mathrm{D}=$ np.delete $(\mathrm{D}, \mathrm{i}, 0)$

$\mathrm{i}=\mathrm{i}-1$

$\mathrm{i}=\mathrm{i}+1$

\#Por fim, temos a matriz D representando todos os path-sets disjuntos!

print(f'A matriz D tem $\{$ len(D) $\}$ linhas.')

$\operatorname{print}(\mathrm{D})$

stop=timeit.default_timer()

print(f'Tempo de processamento: $\{($ stop-start):.2f $\}$ segundos.') 
\#2 $2^{\circ}$ ) CALCULAR A CONFIABILIDADE DO SISTEMA POÇO E COMPARAR OS DIVERSOS CASOS

\#OBJETIVO: Parte principal da dissertação de mestrado

import numpy as np \#arrays e matrizes

import pandas as pd

import math

import timeit

import matplotlib.pyplot as plt

from itertools import product

from datetime import date

from datetime import datetime

def weibull(alpha,beta):

"1"'

-> Calcula a confiabilidade no tempo de um componente do sistema sem considerar testes.

:param alpha: fator de escala (dias/falha $->$ inverso da taxa de falha se beta $=1$ )

:param beta: fator de forma (se beta $=1->$ exponencial)

:return eCSB_R: confiabilidade do componente sem considerar testes nem inspeções "" "

eCSB_R = np.exp(-np.power(t/alpha, beta) $)$

return eCSB_R

def weibull_testes(alpha,beta,eCSB,Caso):

"" "

-> Calcula a confiabilidade no tempo de um componente do sistema.

:param alpha: fator de escala (dias/falha $->$ inverso da taxa de falha se beta=1)

:param beta: fator de forma (se beta $=1->$ exponencial)

:param eCSB: indexador que indica o componente

:param Caso: Aba do excel ("CasoBase" ou "CasoReal") com as informações dos testes :return eCSB_R_testes: confiabilidade do componente considerando os testes e inspeções realizados

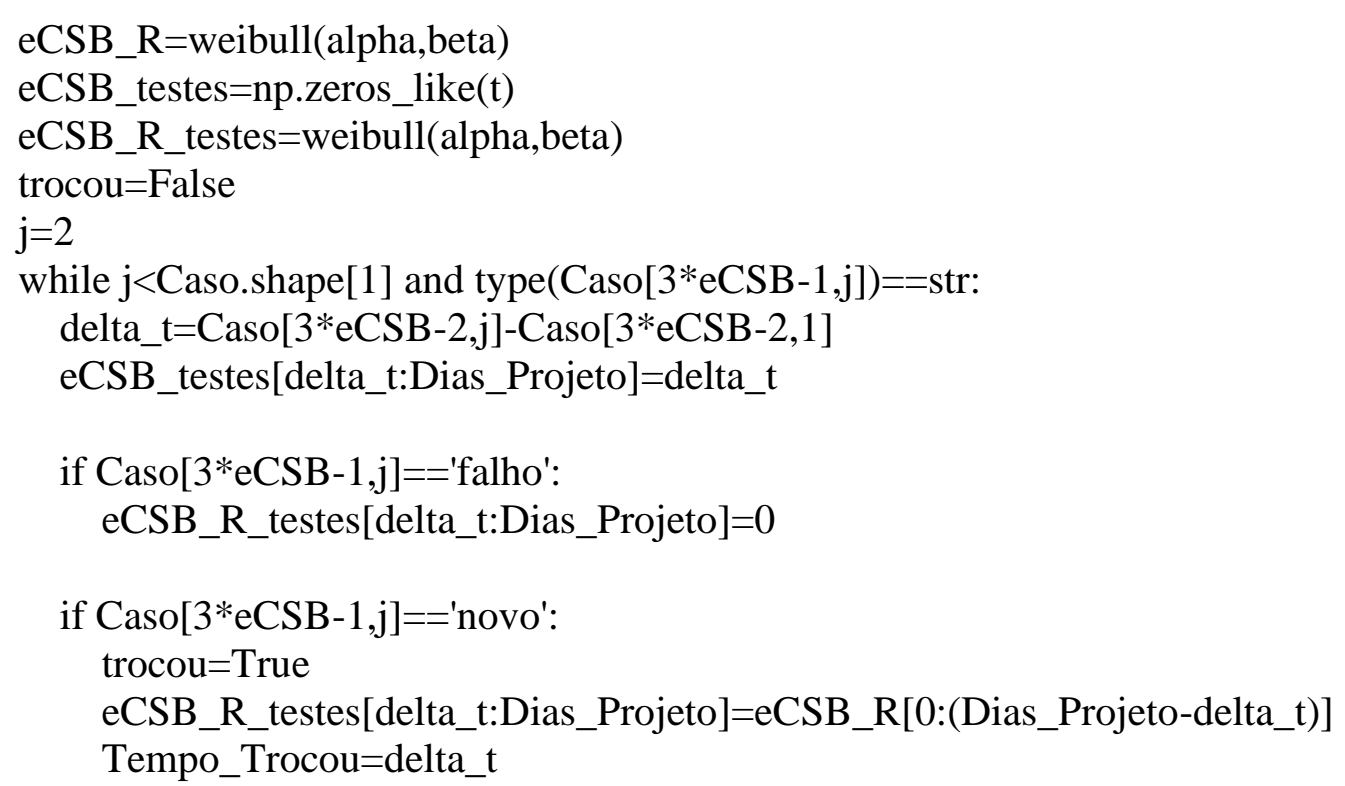


if $\mathrm{Caso}[3 * \mathrm{eCSB}-1, \mathrm{j}]==$ 'sucesso':

if trocou:

eCSB_testes[delta_t:Dias_Projeto]=delta_t-Tempo_Trocou

eCSB_R_testes[delta_t:Dias_Projeto]=eCSB_R[(delta_t-

Tempo_Trocou):(Dias_Projeto-Tempo_Trocou)]/np.exp(-np.power((TC[eCSB-

1]*eCSB_testes[delta_t:Dias_Projeto])/alpha, beta))

else:

eCSB_R=weibull(alpha,beta)

eCSB_R_testes[delta_t:Dias_Projeto]=eCSB_R[delta_t:Dias_Projeto]/np.exp(-

np.power((TC[eCSB-1]*eCSB_testes[delta_t:Dias_Projeto])/alpha, beta))

alpha $=$ alpha/ 1.00

$\mathrm{j}=\mathrm{j}+1$

return eCSB_R_testes

def plotar(R,titulo,legenda):

-> Plota o gráfico da confiabilidade em função do tempo.

:param R: Curva de confiabilidade de um componente do sistema

:param titulo: Título do Gráfico

:param legenda: Legenda do Gráfico

""'"

plt.figure(titulo)

plt.plot(t/365, R, label=legenda)

plt.title(titulo)

plt.xlabel('Time in Operational Phase [years]')

plt.ylabel(titulo)

plt.autoscale(tight $=$ True)

plt.grid(True)

plt.legend()

plt.show()

\#PROGRAMA PRINCIPAL:

start=timeit.default_timer()

\#Abrindo o arquivo em excel "Confiabilidade.xlsx e suas abas "Parametros", "Caso Base"

e Caso Real"

print('IMPORTANTE: A planilha "Confiabilidade.xlsx" deve estar dentro da mesma pasta deste programa. $\left.\mid n^{\prime}\right)$

xlsx $=$ pd.ExcelFile("Confiabilidade.xlsx")

Parametros $=$ pd.read_excel $($ xlsx,'Parametros',header=None $)$

Parametros $=$ Parametros.to_numpy()

CasoBase $=$ pd.read_excel $($ xlsx, 'CasoBase')

CasoBase $=$ CasoBase.to_numpy ()

CasoReal $=$ pd.read_excel $\left(x l s x,{ }^{\prime}\right.$ CasoReal' $)$

CasoReal $=$ CasoReal.to_numpy ()

\#Todos os dados do poço exemplo estão no arquivo em excel "Confiabilidade.xlsx. \#A parte abaixo do código pega esses dados de dentro do arquivo. 
Poço $=$ Parametros $[1,1]$

Início_Produção = Parametros[2,1]

Fim_Projeto $=$ Parametros[3,1]

Data_ALARP $=$ Parametros[4,1]

Data_Cálculo $=$ Parametros[5,1]

Data_ProxTeste $=$ Parametros $[6,1]$

Dias_Projeto $=($ Fim_Projeto-Início_Produção $)$.days \#print $($ type $($ Dias_Projeto $))->$ int

Dias_ALARP $=($ Data_ALARP-Início_Produção).days

Dias_Operados $=($ Data_Cálculo-Início_Produção).days

Dias_ProxTeste $=($ Data_ProxTeste-Início_Produção).days

num_elementos $=$ Parametros $[1,3]$

if Dias_Projeto<=0:

print('A data do Fim do Projeto do poço deve ser superior a data da conclusão da Completação do Poço. In')

else:

$\operatorname{print}\left(\mathrm{f}^{\prime}\right.$ Poço: $\left.\{\text { Poço }\}^{\prime}\right)$

print(f'Fim da Completação: \{Início_Produção\}')

print(f'Fim do Projeto: $\{$ Fim_Projeto $\}$ ')

print(f'Anos de Projeto: $\{($ Dias_Projeto/365):.1f $\}$ ')

print(f'Data do Cálculo: \{Data_Cálculo\}')

print(f'Dias já Operados: \{Dias_Operados\}')

print(f'Dias do Próximo Teste: \{Dias_ProxTeste $\}$ ')

\#Transformando as datas das planilhas do excel em ".toordinal" para facilitar as contas do Weibull

dimensão $=$ CasoBase.shape

for $i$ in range (1,dimensão[0],3):

for $\mathrm{j}$ in range (1,dimensão[1],1):

if type(CasoBase $[\mathrm{i}, \mathrm{j}]) !=$ float:

CasoBase $[\mathrm{i}, \mathrm{j}]=$ date $\cdot$ toordinal $($ CasoBase $[\mathrm{i}, \mathrm{j}])$

dimensão = CasoReal.shape

for $i$ in range (1,dimensão[0],3):

for $\mathrm{j}$ in range (1,dimensão[1],1):

if type(CasoReal[i,j])!=float:

CasoReal $[\mathrm{i}, \mathrm{j}]=$ date.toordinal $($ CasoReal $[\mathrm{i}, \mathrm{j}])$

t=np.arange( 0 , Dias_Projeto, 1) \#print(type (t)) -> numpy.ndarray

elemento_R=np.arange(num_elementos*Dias_Projeto,dtype=float).reshape(num_eleme ntos,Dias_Projeto)

elemento_R_CasoBase=np.arange(num_elementos*Dias_Projeto,dtype=float).reshape( num_elementos,Dias_Projeto)

elemento_R_CasoReal=np.arange(num_elementos*Dias_Projeto,dtype=float).reshape(n um_elementos,Dias_Projeto)

elemento_alpha0 $=$ np.ones(num_elementos)

elemento_alpha=np.ones(num_elementos)

elemento_beta=np.ones(num_elementos,dtype=float)

for $\mathrm{i}$ in range $(0$, num_elementos, 1$)$ :

elemento_beta[i] $=$ Parametros $[8+\mathrm{i}, 3]$ 
elemento_alpha0[i]=Parametros[8+i,2]

\#Test Coverage (TC) is the fraction of failures detected during proof testing \#O vetor TC todo igual a 1 indica que não está sendo considerado o Test Coverage $\mathrm{TC}=\mathrm{np} . \operatorname{array}([1,1,1,1,1,1,1,1,1,1,1,1,1,1,1,1,1,1,1,1,1,1,1,1,1,1,1,1,1,1,1])$ \#O vetor TC abaixo foi utilizado para o exemplo em que o Test Coverage foi considerado \#TC=np. $\operatorname{array}([0.95,0.95,0.95,0.95,0.95,0.95,0.8,0.8,0.8,0.8,0.8,0.8,0.8,0.8,0.95,0.95,0$. $95,0.95,0.8,0.95,0.95,0.8,0.95,0.95,0.95,0.95,0.95,0.95,0.8,0.8,1])$

\#Abaixo é apenas uma opção deixada no código para variar as taxas de falha constantes dos componentes por algum fator.

\#O objetivo é ter alguma sensibilidade da alteração da taxa de falha de alguns componentes no resultado final de confiabilidade do sistema.

\#Escolha do fator para sensibilidade das taxas de falha CONSTANTES: fator=?

fator=1 \#como o fator escolhido é 1, não há alterações nos valores de taxa de falha fatores=np.array $($ list (product(np.array $([1$, fator, $1 /$ fator $])$, repeat=5))

aTub=np.ones(len(fatores))

aTAC $=$ np.column_stack $($ fatores $[:, 0])$

aFTC $=$ np.column_stack(fatores $[:, 1])$

aLCP=np.column_stack(fatores $[:, 2])$

aCas=np.column_stack(fatores[:,3])

aXMT=np.column_stack(fatores[:,4])

fatores $=$ np.insert(fatores, $1, \mathrm{aTub}[:]$, axis $=1$ )

fatores $=$ np.insert(fatores, 2, aTAC $[:]$, axis $=1$ )

fatores $=$ np.insert(fatores, $5, \mathrm{aTub}[:]$, axis $=1$ )

fatores $=$ np.insert (fatores, $7, \mathrm{aCas}[:]$, axis $=1$ )

fatores $=$ np.insert (fatores, $8, \mathrm{aCas}[:]$, axis $=1$ )

fatores=np.insert(fatores, 10,aXMT[:],axis=1)

fatores $=$ np.insert(fatores, $11, \mathrm{aXMT}[:]$, axis $=1$ )

fatores $=$ np.insert(fatores, 12, aXMT[:],axis=1)

fatores $=$ np.insert(fatores, $13, \mathrm{aXMT}[:]$, axis $=1$ )

fatores=np.insert(fatores, 14,aFTC[:],axis=1)

fatores $=$ np.insert(fatores, 15, aLCP [:],axis $=1$ )

fatores $=$ np.insert(fatores, $16, \mathrm{aFTC}[:]$, axis $=1$ )

fatores $=$ np.insert(fatores, $17, \mathrm{aLCP}[$ :],axis $=1$ )

fatores=np.insert(fatores, 18,aXMT[:],axis=1)

fatores $=$ np.insert(fatores, $19, \mathrm{aFTC}[$ :], axis $=1$ )

fatores=np.insert(fatores, $20, \mathrm{aLCP}[$ :],axis $=1$ )

fatores $=$ np.insert(fatores, 21,aXMT[:],axis $=1$ )

fatores $=$ np.insert(fatores, $22, \mathrm{aFTC}[:], \mathrm{axis}=1$ )

fatores $=$ np.insert(fatores, 23, aLCP[:],axis $=1$ )

fatores=np.insert(fatores, 24,aFTC[:],axis=1)

fatores $=$ np.insert(fatores, 25, aLCP[:],axis $=1$ )

fatores $=$ np.insert(fatores, 26,aFTC[:],axis $=1$ )

fatores $=$ np.insert(fatores, 27,aLCP[:],axis=1)

fatores=np.insert(fatores, 28,aXMT[:],axis=1)

fatores=np.insert(fatores, 29, aXMT[:],axis=1)

fatores $=$ np.insert(fatores, $30, \mathrm{aTub}[:], \mathrm{axis}=1$ )

for repete in range $(0$, len(fatores), 1$)$ : 
for $\mathrm{i}$ in range (0,num_elementos, 1$)$ :

elemento_alpha[i]=elemento_alpha0[i]/fatores[repete,i]

elemento_R[i]=weibull(elemento_alpha[i],elemento_beta[i])

elemento_R_CasoBase[i]=weibull_testes(elemento_alpha[i],elemento_beta[i],i+1,Caso Base)

elemento_R_CasoReal[i]=weibull_testes(elemento_alpha[i],elemento_beta[i],i+1,Caso Real)

\#CONFIABILIDADE DO CASO BASE DO SISTEMA (Só CSBs): Caso Base com os CSBs e testes definidos pelo projeto

R_sistema_CasoBase_CSBs=1-(1-

elemento_R_CasoBase[0]*elemento_R_CasoBase[1]*elemento_R_CasoBase[2]*eleme nto_R_CasoBase[3]*elemento_R_CasoBase[4])*(1-

elemento_R_CasoBase[6]*elemento_R_CasoBase[7]*elemento_R_CasoBase[8]*eleme nto_R_CasoBase[9]*elemento_R_CasoBase[13]*elemento_R_CasoBase[14]*elemento _R_CasoBase[15]*elemento_R_CasoBase[18]*elemento_R_CasoBase[19]*elemento_

R_CasoBase[20]*elemento_R_CasoBase[21]*elemento_R_CasoBase[30])

\#print (f'\nR_sistema_CasoBase_CSBs: $\ln \{$ R_sistema_CasoBase_CSBs $\} \backslash n '$ ')

\#CONFIABILIDADE DO SISTEMA: Como a matriz D é de PATH-SETs disjuntos, basta somar probabilidades

R_sistema $=0$

R_sistema_CasoBase $=0$

R_sistema_CasoReal $=0$

for $i$ in range $(0$, len $(D), 1)$ :

$\mathrm{P}=1$

P_CasoBase $=1$

P_CasoReal $=1$

for $\mathrm{j}$ in range $(0$, num_elementos, 1$)$ :

if $\mathrm{D}[\mathrm{i}][\mathrm{j}]==1$ :

$\mathrm{P}=\mathrm{P}^{*}$ elemento_R[j]

P_CasoBase $=$ P_CasoBase*elemento_R_CasoBase $[\mathrm{j}]$

P_CasoReal=P_CasoReal*elemento_R_CasoReal[j]

elif $\mathrm{D}[\mathrm{i}][\mathrm{j}]==-2$ :

$\mathrm{P}=\mathrm{P} *(1-$-elemento_R[j])

P_CasoBase=P_CasoBase*(1-elemento_R_CasoBase[j])

P_CasoReal=P_CasoReal*(1-elemento_R_CasoReal[j])

R_sistema $=R \_$sistema $+P$

R_sistema_CasoBase $=\mathrm{R} \_$sistema_CasoBase $+\mathrm{P} \_$CasoBase

R_sistema_CasoReal=R_sistema_CasoReal+P_CasoReal

\#PRAZO PARA INTERVENÇÃO

Min_R_sistema_CasoBase $=1$

Min_R_sistema_CasoBase_CSBs $=1$

for $\mathrm{k}$ in range (0, Dias_Projeto, 1$)$ :

if(R_sistema_CasoBase[k]<Min_R_sistema_CasoBase):

Min_R_sistema_CasoBase $=\mathrm{R} \_$sistema_CasoBase $[\mathrm{k}]$

if(R_sistema_CasoBase_CSBs[k]<Min_R_sistema_CasoBase_CSBs): 
Min_R_sistema_CasoBase_CSBs=R_sistema_CasoBase_CSBs[k]

DataMax_Rel_CasoBase $=0$

DataMax_Rel_CasoBase_CSBs $=0$

for $\mathrm{k}$ in range (Dias_Operados, Dias_Projeto, 1):

if R_sistema_CasoReal[k] >=Min_R_sistema_CasoBase:

DataMax_Rel_CasoBase $=\mathrm{k}$

if R_sistema_CasoReal[k]>=Min_R_sistema_CasoBase_CSBs:

DataMax_Rel_CasoBase_CSBs=k

\#PRAZO PARA PRÓXIMOS TESTES/VERIFICAÇÕES

DataMaxTeste_Rel_CasoBase $=0$

DataMaxTeste_Rel_CasoBase_CSBs $=0$

for $\mathrm{k}$ in range (Dias_Operados, Dias_ProxTeste, 1):

if R_sistema_CasoReal[k]>=R_sistema_CasoBase[Dias_ProxTeste-1]:

DataMaxTeste_Rel_CasoBase $=\mathrm{k}$

if R_sistema_CasoReal[k]>=R_sistema_CasoBase_CSBs[Dias_ProxTeste-1]:

DataMaxTeste_Rel_CasoBase_CSBs=k

if $($ repete $==0)$ or $($ DataMax_Rel_CasoBase $<$ DataIntervencao) or $($ DataIntervencao $==0$ and DataMax_Rel_CasoBase_CSBs $<=$ DataIntervencao_CSBs):

print (R_sistema)

print (R_sistema_CasoBase)

print (R_sistema_CasoBase_CSBs)

print (R_sistema_CasoReal)

plt.figure('1 - Confiabilidade do Sistema')

\#plt.plot(t/365, 1-R_sistema, 'k--', color='black', label='Projeto (sem testes ou reparos)')

plt.plot(t/365, 1-R_sistema_CasoBase, color='black', label='Caso Base (todos os testes positivos)')

\#plt.plot(t/365, 1-R_sistema_CasoBase_CSBs, color='black', label='Base Case

CSBs (all CSB tests positive)')

plt.plot(t/365, 1-R_sistema_CasoReal, 'k:', color='black', label='Caso Real')

plt.xlabel('Tempo na Etapa de Produção [anos]')

plt.ylabel('Probabilidade de Perda de Contenção')

plt.title('F(t) - Poço Exemplo')

plt.autoscale(tight=True)

plt.grid(True)

plt.legend()

\#plt.axis $([0,27,0,0.022])$ \#zoom no gráfico

plt.show()

$\operatorname{print}\left(f^{\prime} R \_P r o j e t o(\right.$ no fim do projeto $\left.)=\{\text { R_sistema[Dias_Projeto-1]:.5f }\}^{\prime}\right)$

$\operatorname{print}\left(\mathrm{f}^{\prime} \mathrm{R} \_\right.$Atual $=\left\{\mathrm{R} \_\right.$sistema_CasoReal[Dias_Operados $\left.]: .5 \mathrm{f}\right\}$ ' $)$

$\left.\operatorname{print}\left(f^{\prime} R \_A t u a l \text { menos } 1 \text { dia }=\left\{R \_s i s t e m a \_C a s o R e a l\left[D i a s \_O p e r a d o s-1\right]: .5 f\right\}\right\}^{\prime}\right)$

$\operatorname{print}\left(\mathrm{f}^{\prime} \mathrm{R} \_\right.$CasoBase $($valor mínimo $\left.)=\{\text {Min_R_sistema_CasoBase:.5f }\}^{\prime}\right)$

print(f'R_CasoBase_CSBs (valor mínimo)

$\{$ Min_R_sistema_CasoBase_CSBs:.5f $\}$ ')

if DataMax_Rel_CasoBase $==0$ :

print(f'O risco atual é maior que o risco máximo previsto no projeto.') 
DataIntervencao=DataMax_Rel_CasoBase

else:

print(f'A intervenção deve ocorrer em até \{(DataMax_Rel_CasoBaseDias_Operados)/(365/12):.1f\} meses a partir da data do cálculo.')

print(f'A intervenção deve ocorrer em até \{(DataMax_Rel_CasoBaseDias_ALARP)/(365/12):.1f\} meses a partir da data da perda da condição de 2 CSBs Independentes.')

DataIntervencao=DataMax_Rel_CasoBase

if (DataMaxTeste_Rel_CasoBase>Dias_Operados):

print(f'Os próximos testes podem ocorrer em até

$\{($ DataMaxTeste_Rel_CasoBase-Dias_Operados $) /(365 / 12): .1 f\}$ meses a partir da data do cálculo para manter o mesmo nível de risco atual.')

else:

print('Até a intervenção, prever testes nas demais barreiras que possam contribuir para aumentar a confiabilidade do poço.')

if DataMax_Rel_CasoBase_CSBs==0:

print(f'O risco atual é maior que o risco máximo previsto nos CSBs de projeto.')

DataIntervencao_CSBs=DataMax_Rel_CasoBase_CSBs else:

print $\left(f^{\prime} \backslash\right.$ CSBs: A intervenção deve ocorrer em até \{(DataMax_Rel_CasoBase_CSBs-Dias_Operados)/(365/12):.1f $\}$ meses a partir da data do cálculo.')

print(f'CSBs: A intervenção deve ocorrer em até $\{($ DataMax_Rel_CasoBase_CSBs-Dias_ALARP)/(365/12):.1f $\}$ meses a partir da data da perda da condição de 2 CSBs Independentes.')

DataIntervencao_CSBs=DataMax_Rel_CasoBase_CSBs

if (DataMaxTeste_Rel_CasoBase_CSBs $>$ Dias_Operados):

print(f'Os próximos testes podem ocorrer em até

$\{($ DataMaxTeste_Rel_CasoBase_CSBs-Dias_Operados $) /(365 / 12): .1 \mathrm{f}\}$ meses a partir da data do cálculo para manter o mesmo nível de risco atual.')

else:

print('Até a intervenção, prever testes nas demais barreiras que possam contribuir para aumentar a confiabilidade do poço')

if (fator==1):

break

stop=timeit.default_timer()

$\operatorname{print}\left(f^{\prime} P a s s a g e m ~\{r e p e t e+1\}\right.$ de $\{$ len(fatores) $\}$ : o tempo de processamento está em $\left\{(\right.$ stop-start):.2f $\}$ segundos. $\left.\mid n^{\prime}\right)$ 